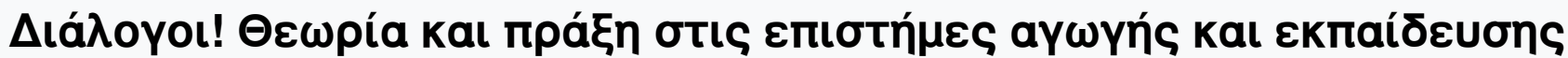

Tó 5 (2019)

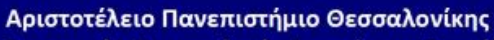

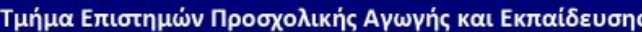

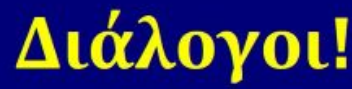

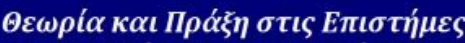

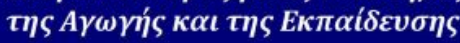

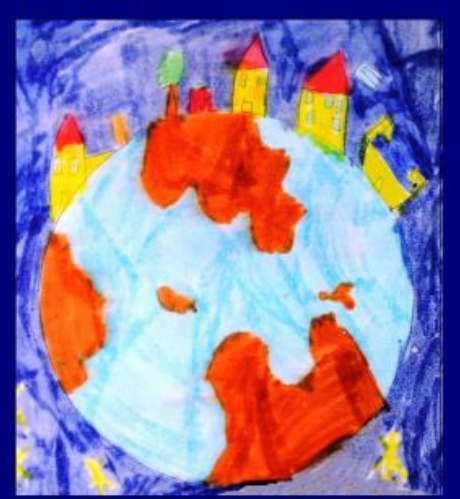

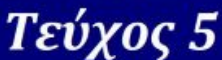
2019

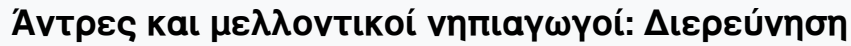

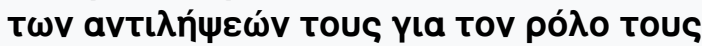

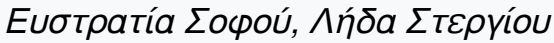

doi: $10.12681 /$ dial.20804

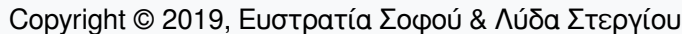

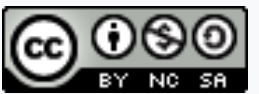

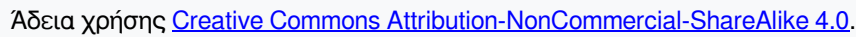

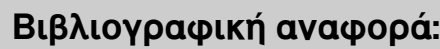

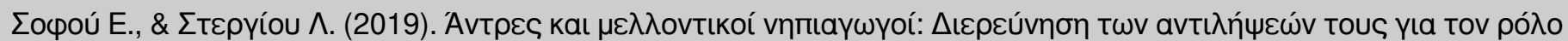

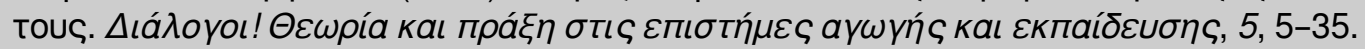

https://doi.org/10.12681/dial.20804 


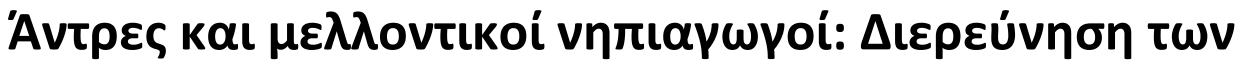

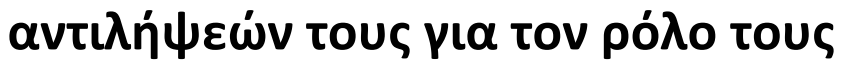

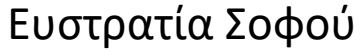

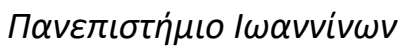

$\Lambda \eta ́ \delta \alpha \Sigma \tau \varepsilon \rho ү i ́ o u$

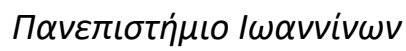

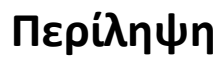

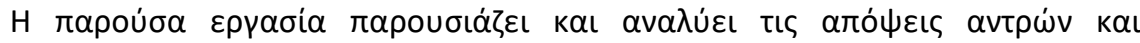

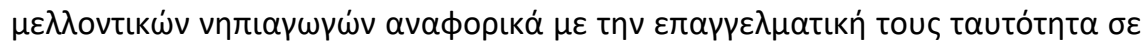

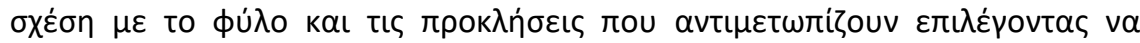

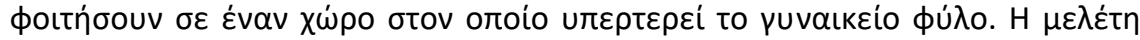

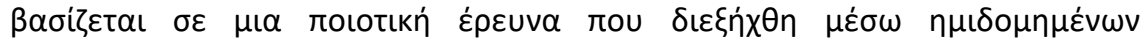

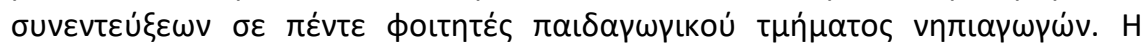

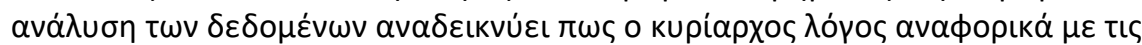

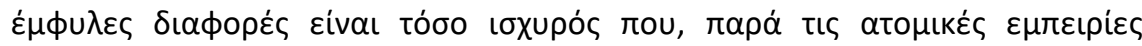

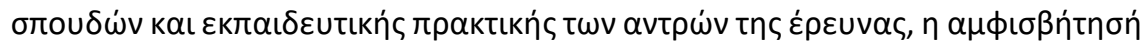

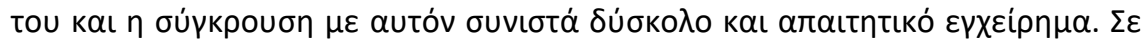

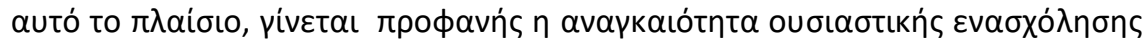

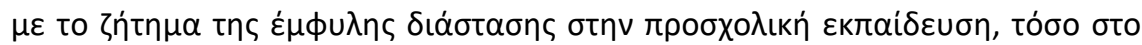

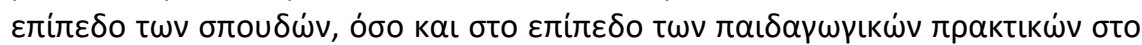

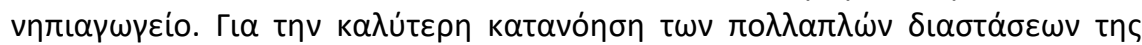

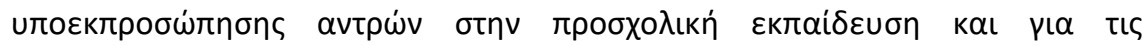

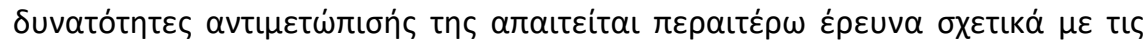

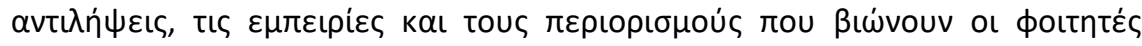

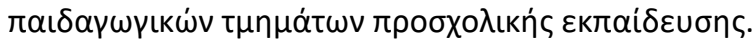

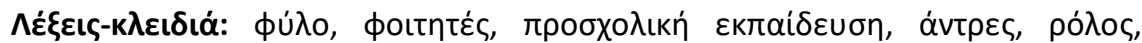

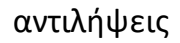

\begin{abstract}
The paper presents and analyzes the views of men and future preschool educators on their gender identity and the challenges they face by choosing to study in a context where female gender prevails. The study is based on a qualitative survey conducted through semi-structured interviews with five men who study preschool teaching. The analysis of the data shows that the traditional gender discourse is so strong that it is difficult to challenge or disrupt stereotypical constructions of gender despite their involvement in early childhood teacher education programme. In this context, the article highlights the need for providing opportunities in pre-service and in-service programmes to explore gender issues. In order to better understand the multiple dimensions of under-representation of men in pre-preschool education and the possibilities for dealing with it, further research is needed on the perceptions, experiences and limitations experienced by men who study preschool teaching.
\end{abstract}

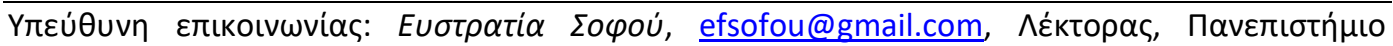
I 
Keywords: male student teachers, preschool education, role, perceptions.

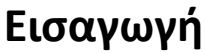

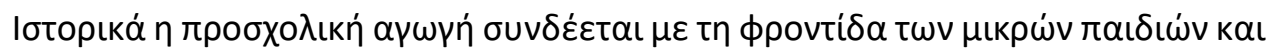

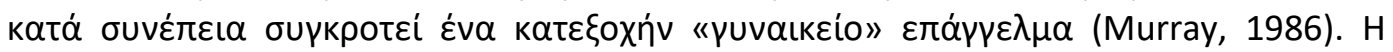

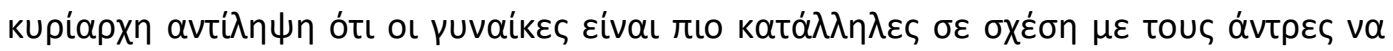

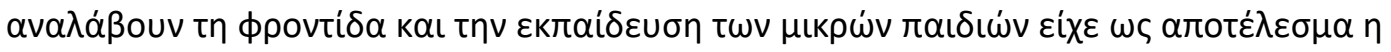

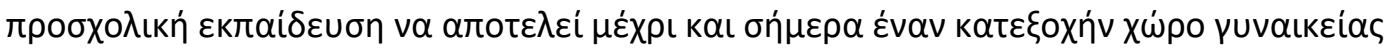

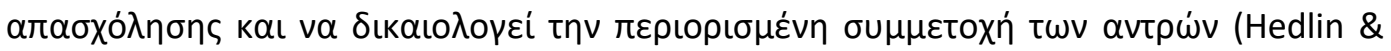

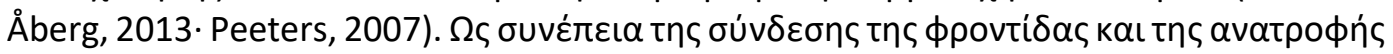

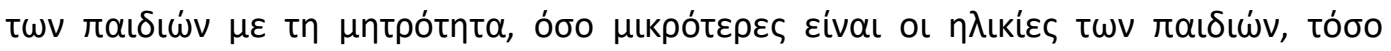

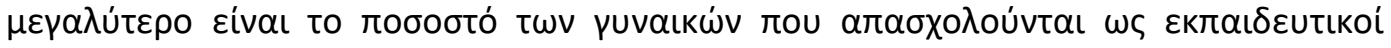

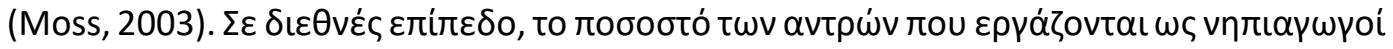

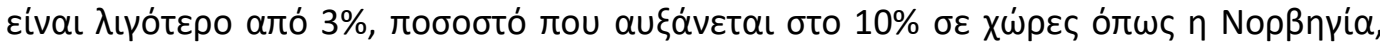

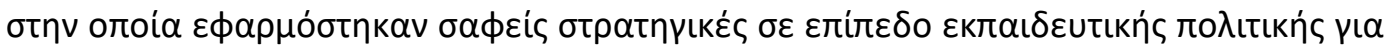

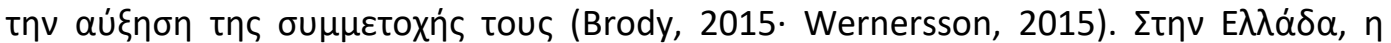

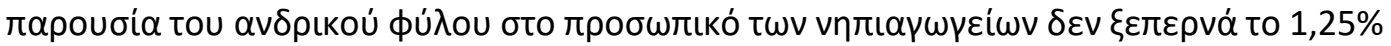

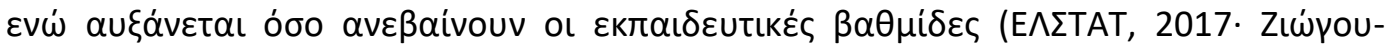

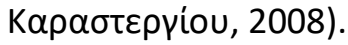

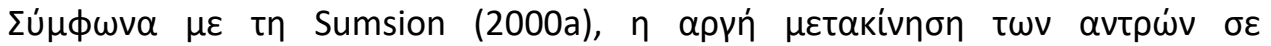

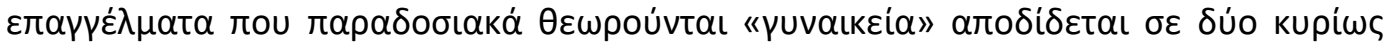

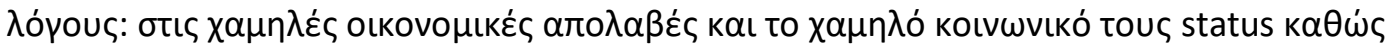

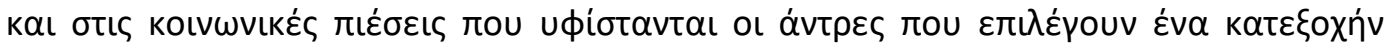

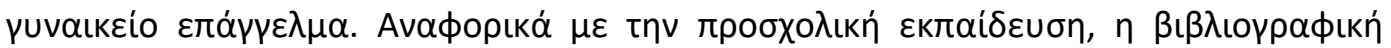

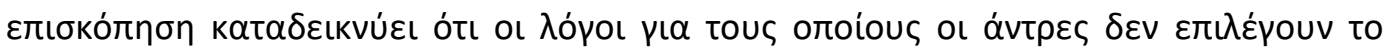

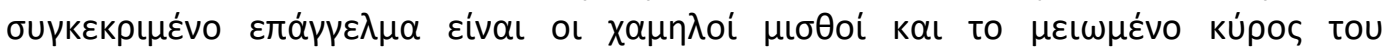

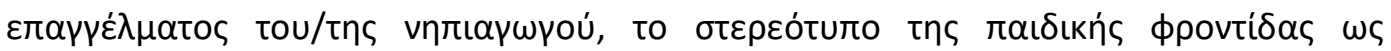

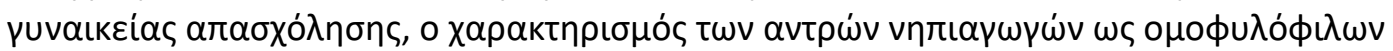

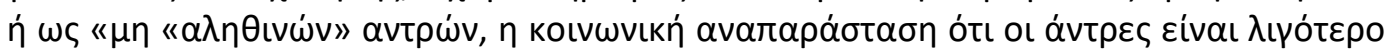

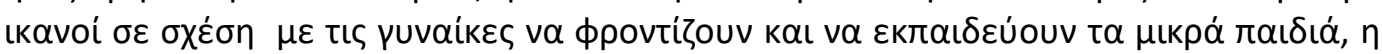

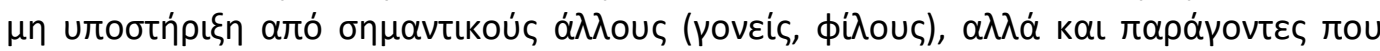

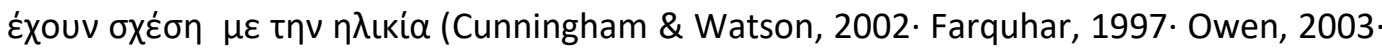

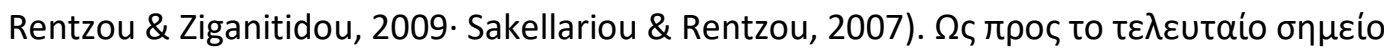

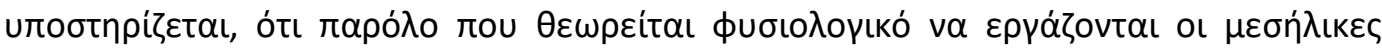

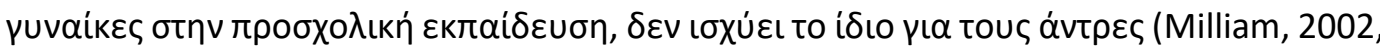
о́r. avaф. бтo Rentzou, 2013, б. 272).

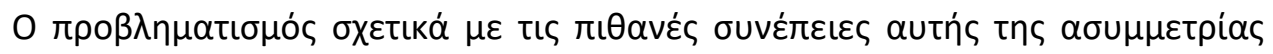

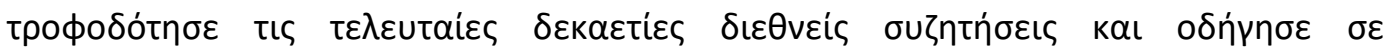
$\pi \rho \omega \tau$ то

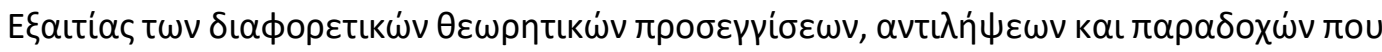

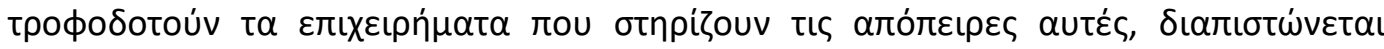

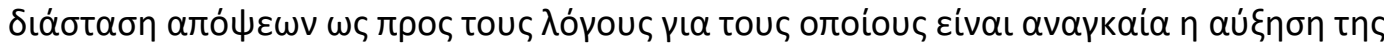

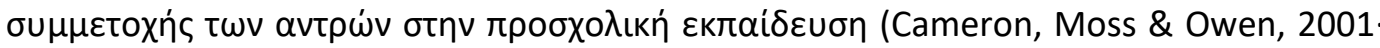
MacNaughton \& Newman, 2001. Sumsion, 2005. Wernersson, 2015). П $\alpha \rho \alpha \dot{\lambda} \lambda \lambda \eta \lambda \alpha$,

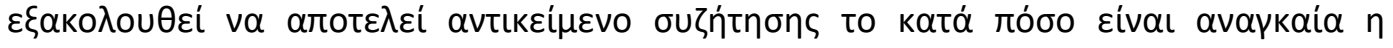




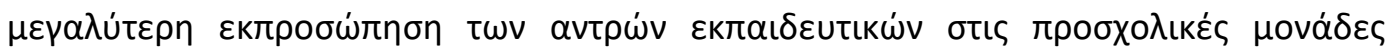
(Brownhill, Warin \& Wernersson, 2015. MacNaughton \& Newman, 2001).

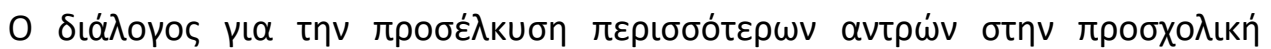

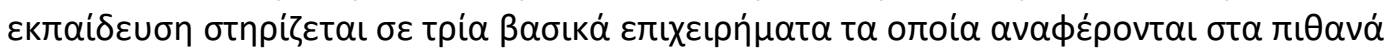

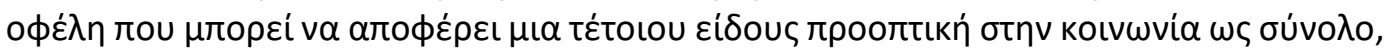

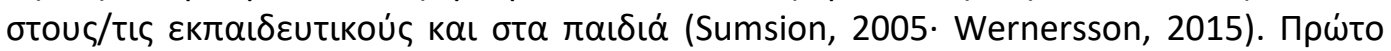

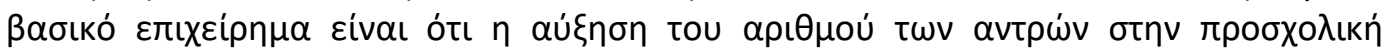

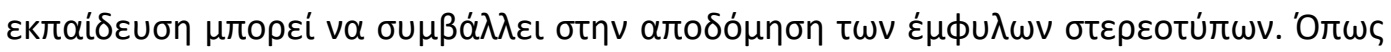

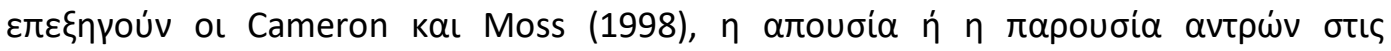

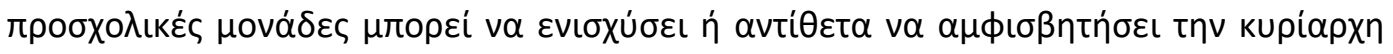

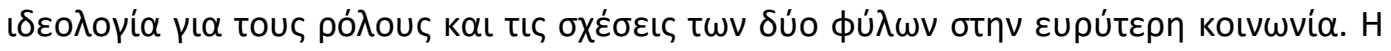

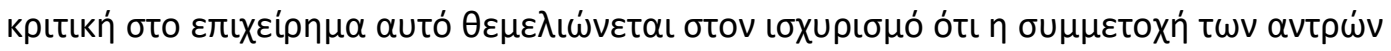

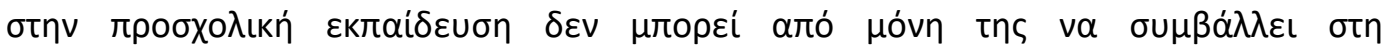

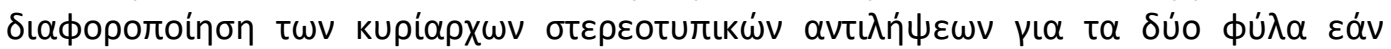

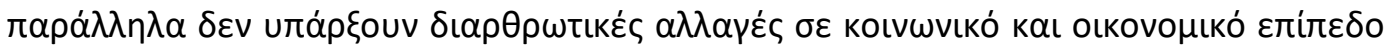

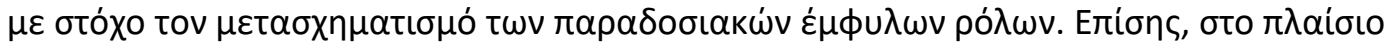

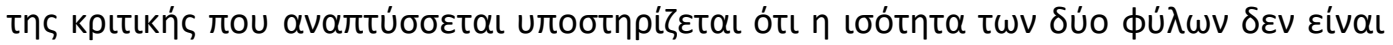

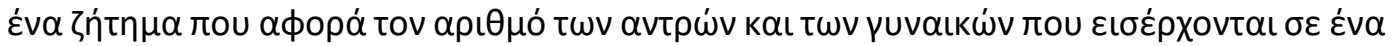

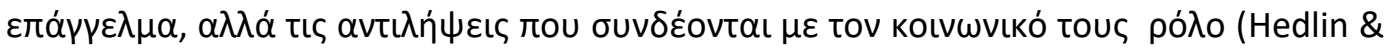
Åberg, 2013).

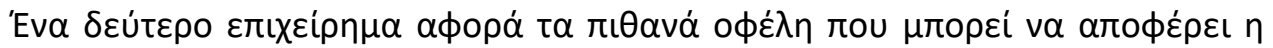

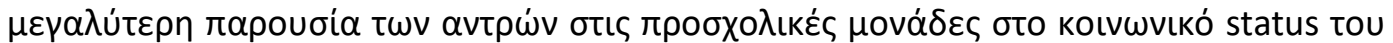

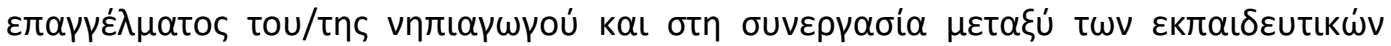

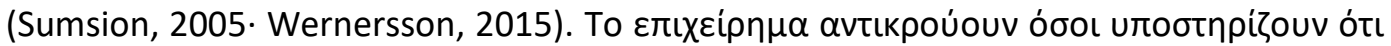

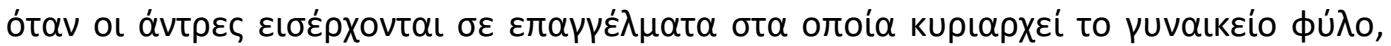

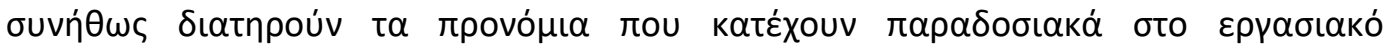

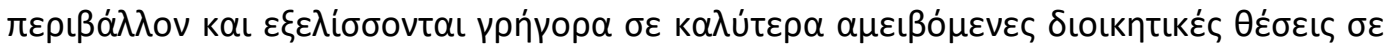

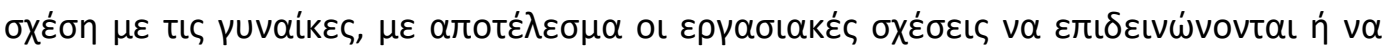

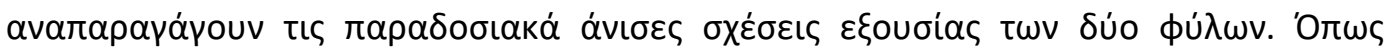

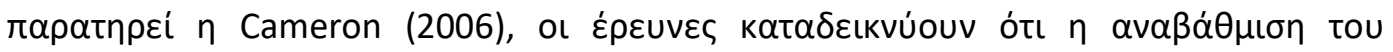

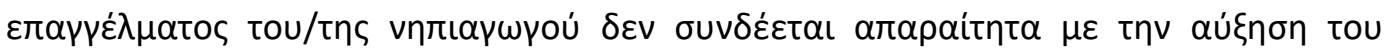

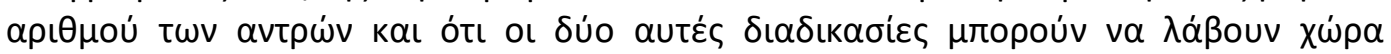

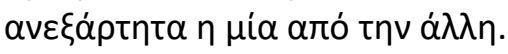

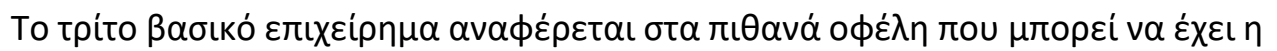

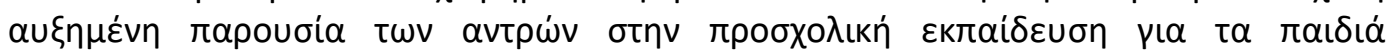

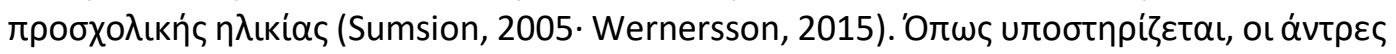

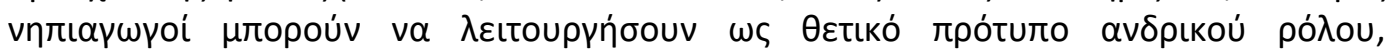

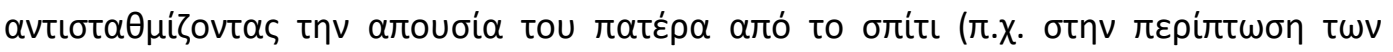

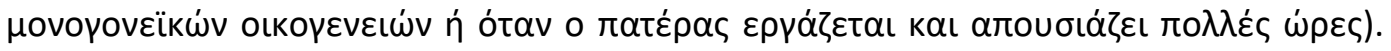

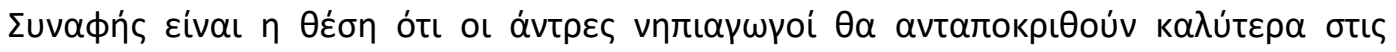

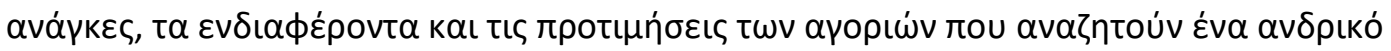

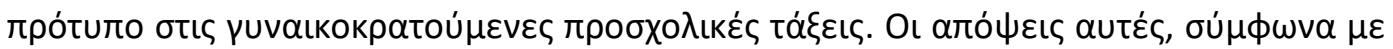

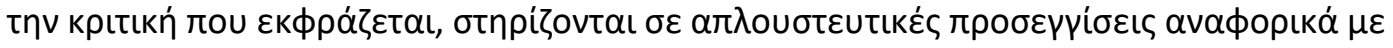

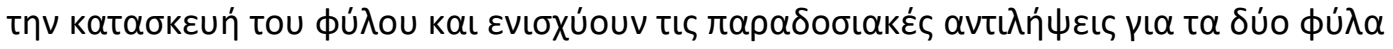

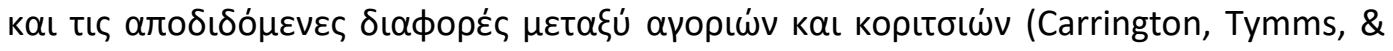
Merrell, 2008. Warin, 2014). 


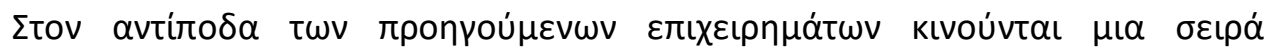

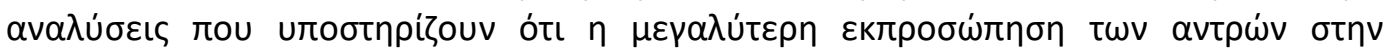

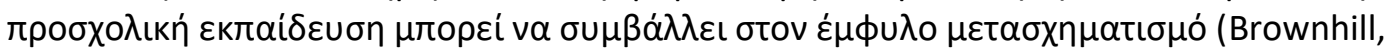

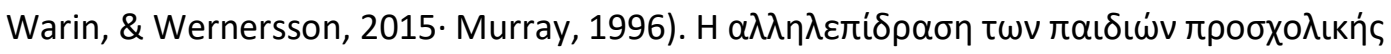

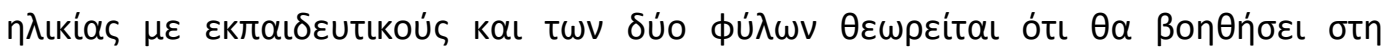

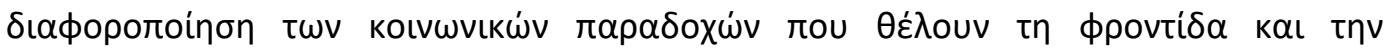

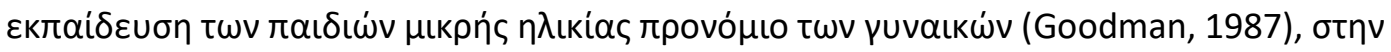

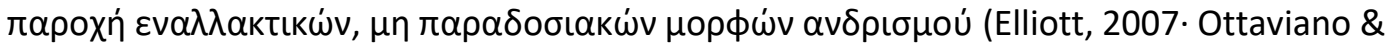

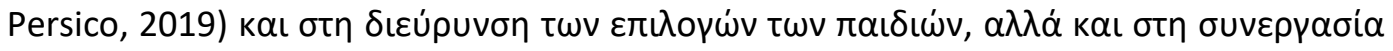

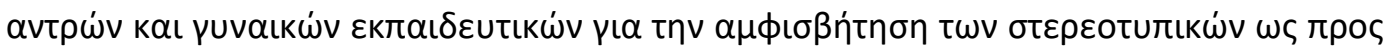

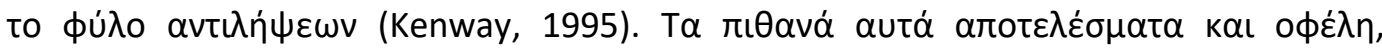

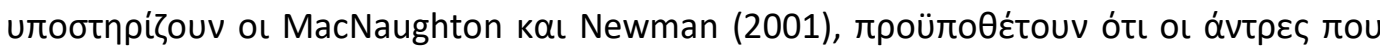

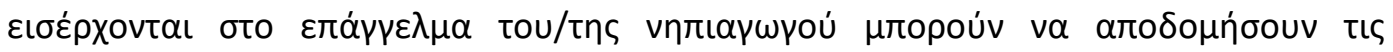

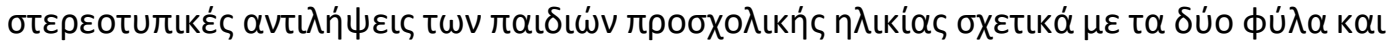

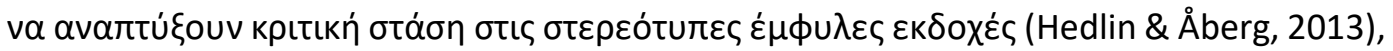

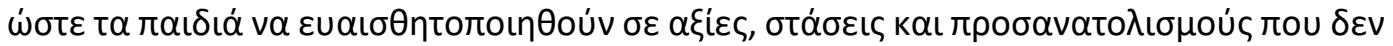

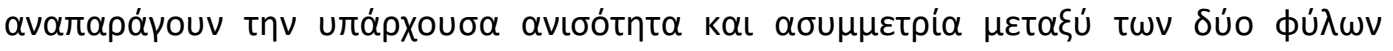
(Коүкі́ठоu, 2016).

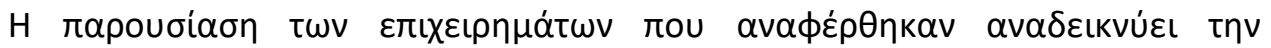

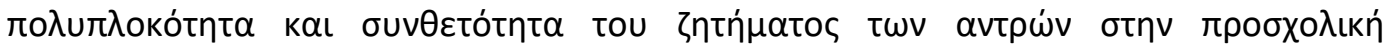

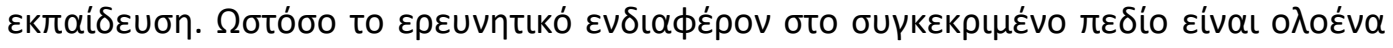

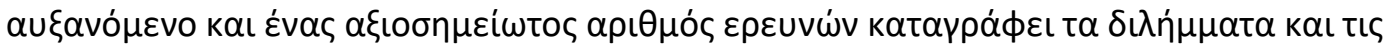

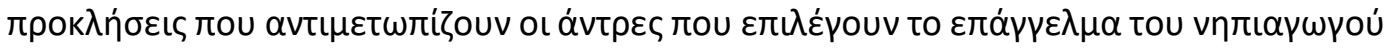
(Cooney \& Bitter, 2001. Peeters, 2007. Rentzou, 2011. Rentzou, 2013. Rentzou \& Ziganitidou, 2014. Sakellariou \& Rentzou, 2010. Stroud, Smith, Ealy, \& Hurst, 2000.

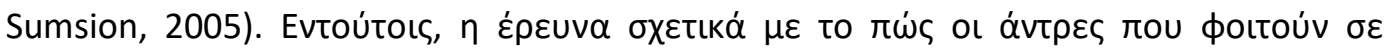

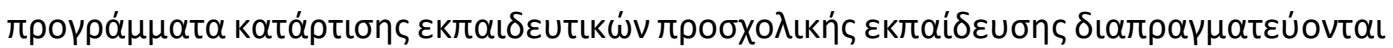

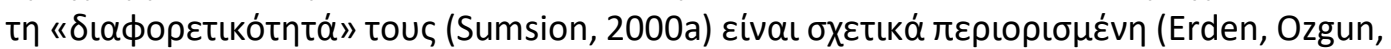
\& Ciftci, 2011· Hedlin \& Åberg, 2013. Heikkilä \& Hellman, 2017· Jones, 2007· Sakellariou \& Rentzou, 2007· Stroud, Smith, \& Hurst, 2000· Sumsion, 2000a).

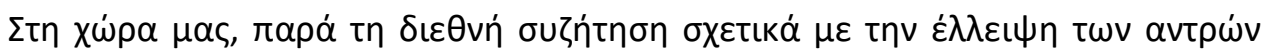

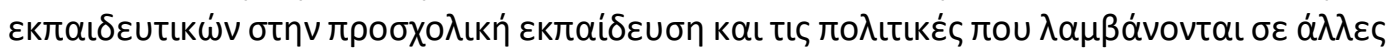

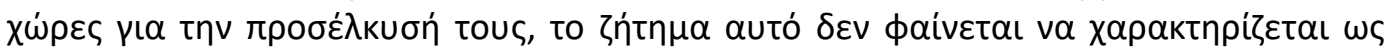

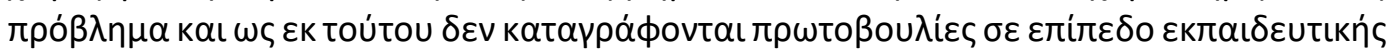

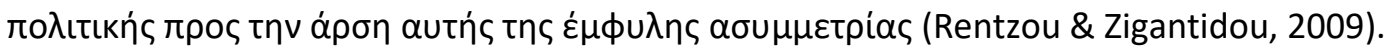

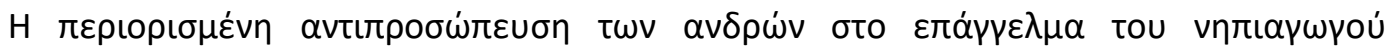

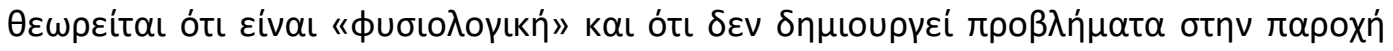

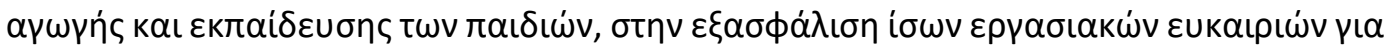

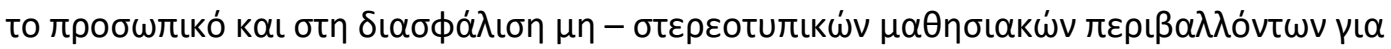

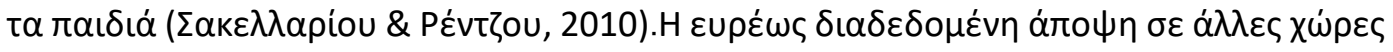

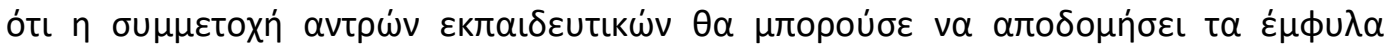

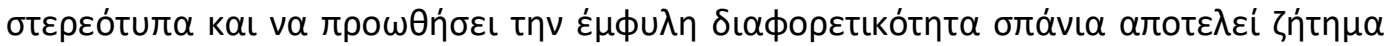

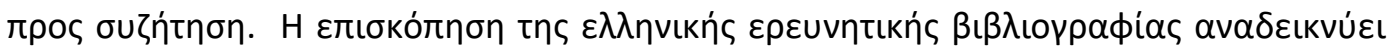

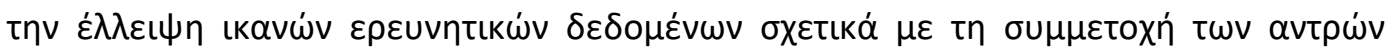

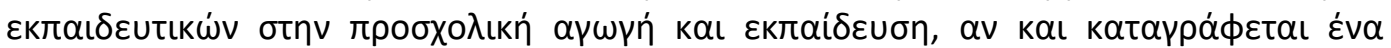

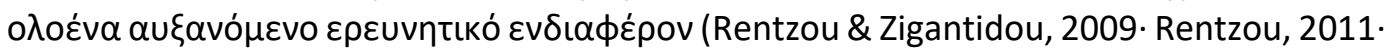




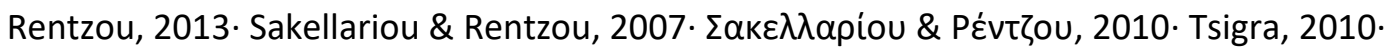

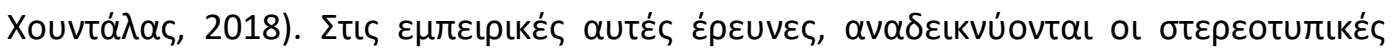

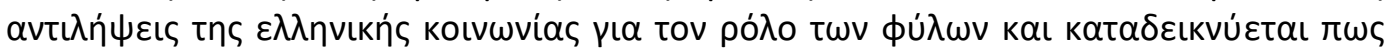

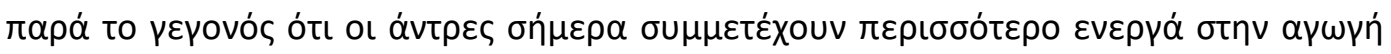

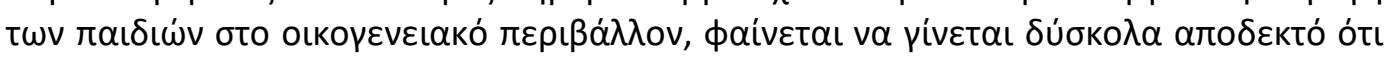

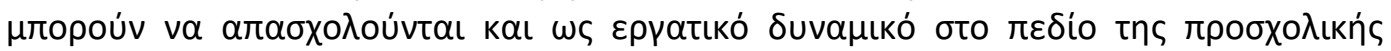

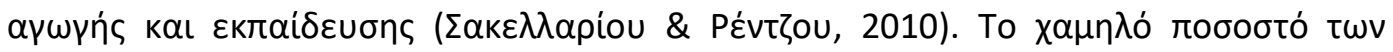

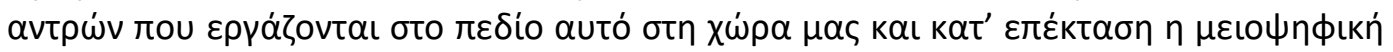

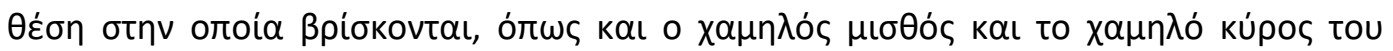

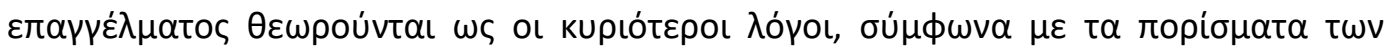

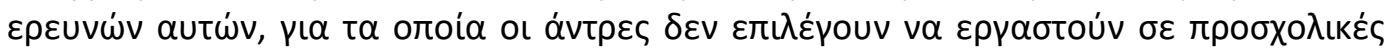

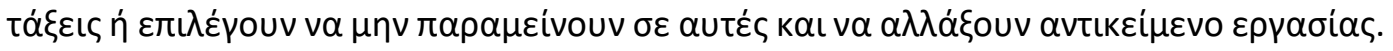

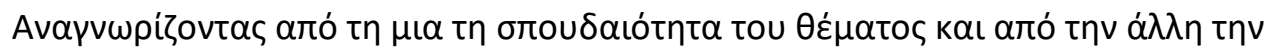

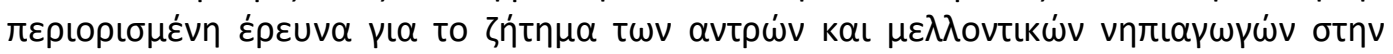

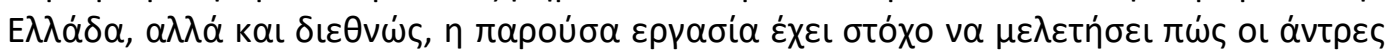

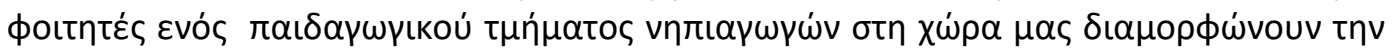

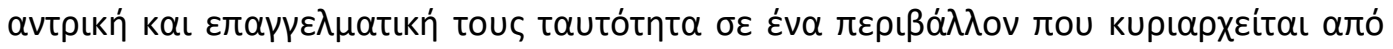

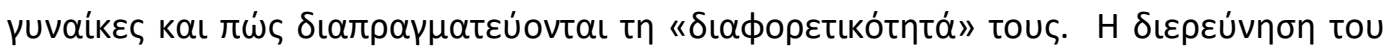

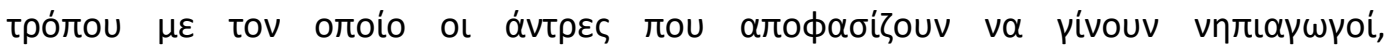

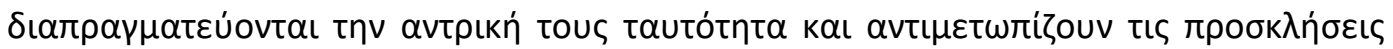

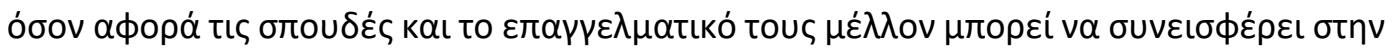

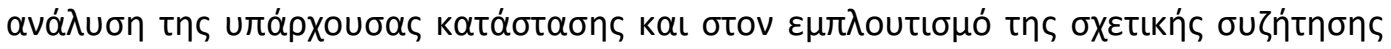

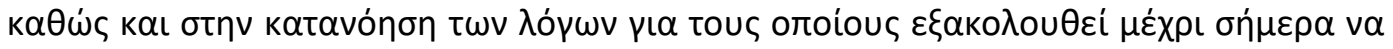

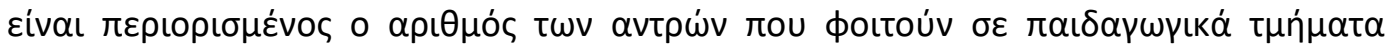

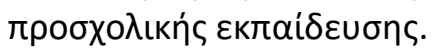

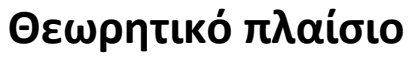

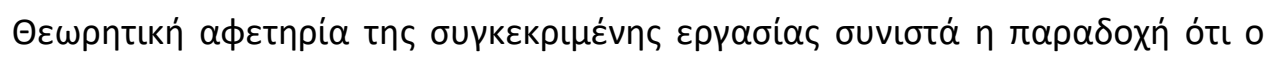

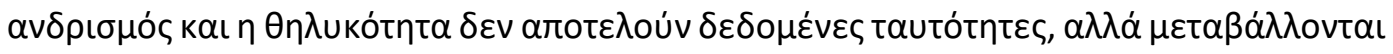

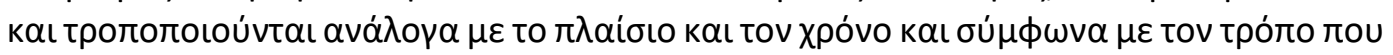

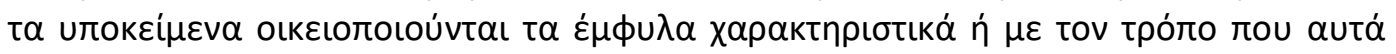

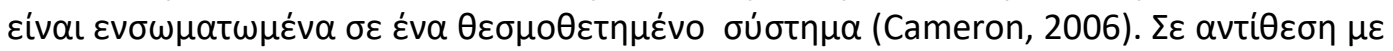

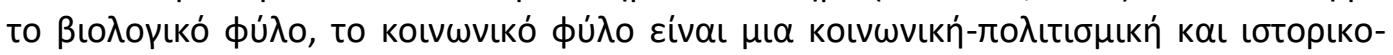

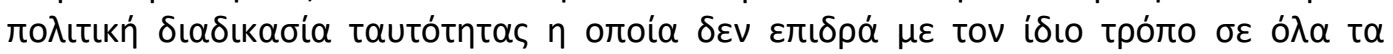

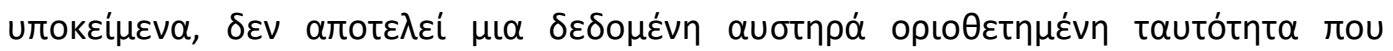

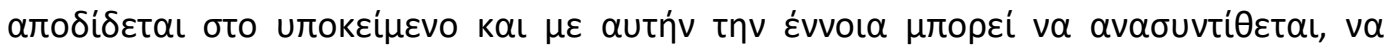

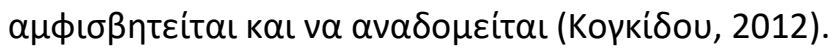

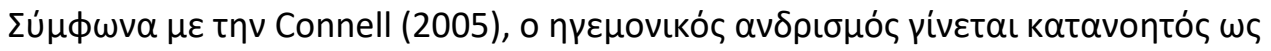

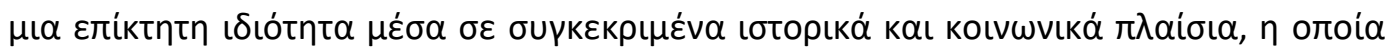

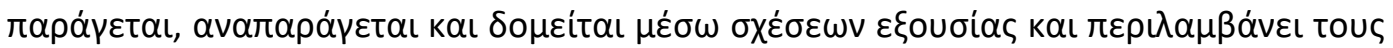

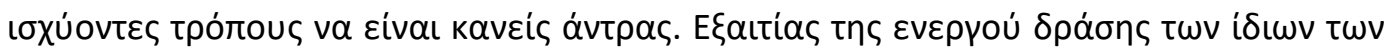

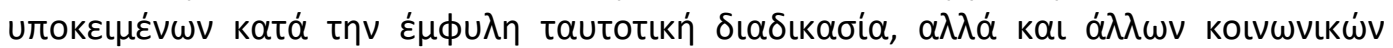

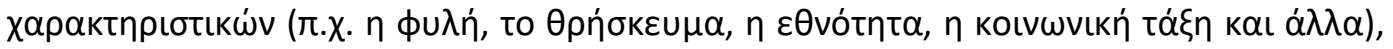

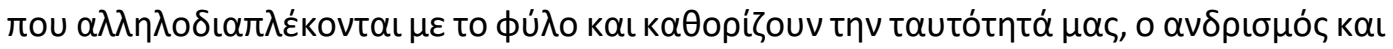

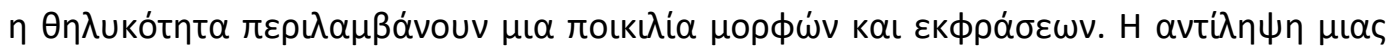

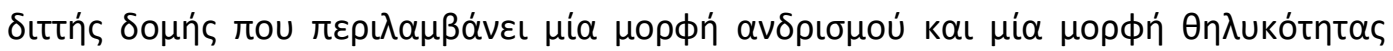




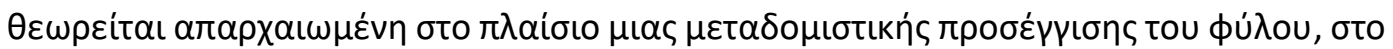

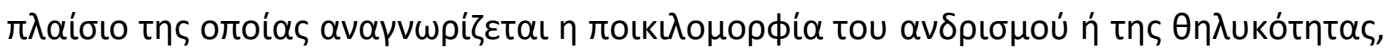

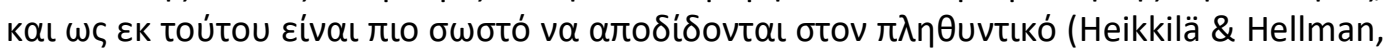

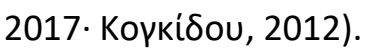

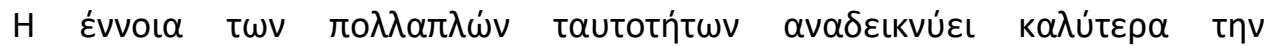

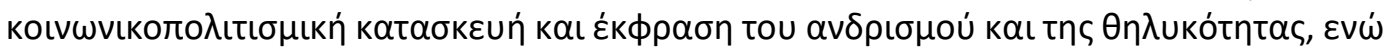

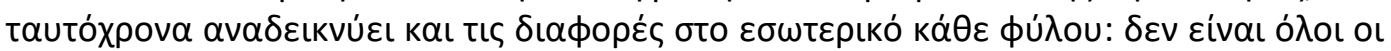

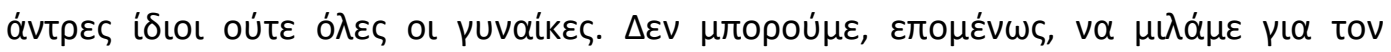

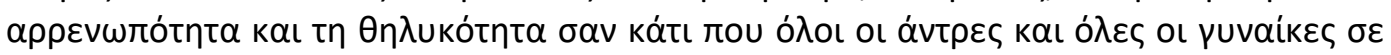

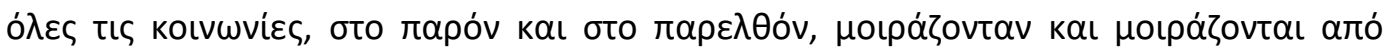

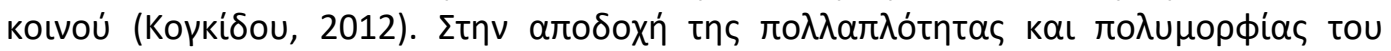

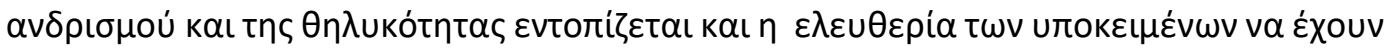

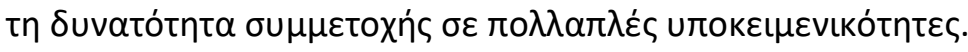

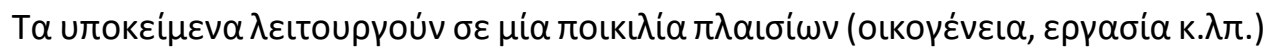

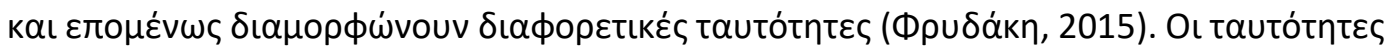

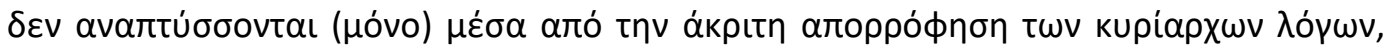

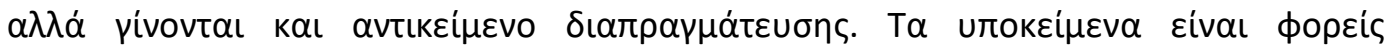

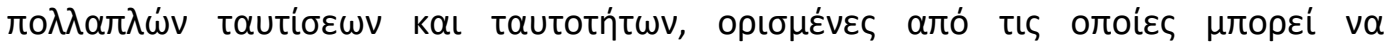

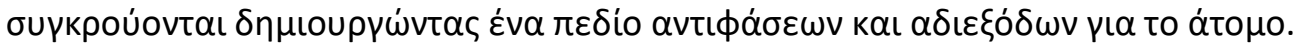

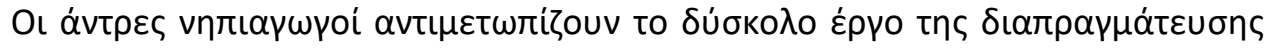

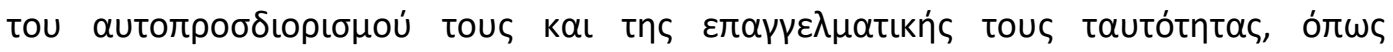

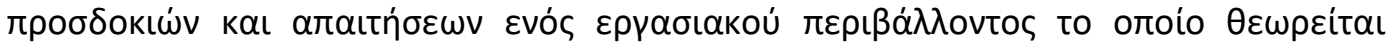

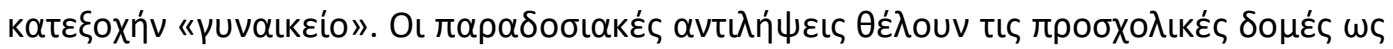

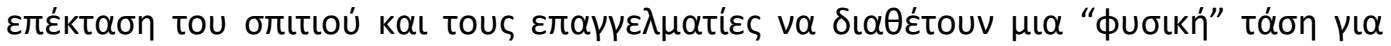

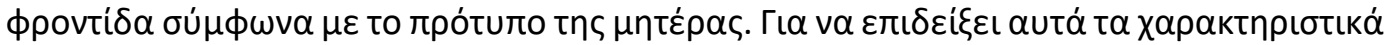

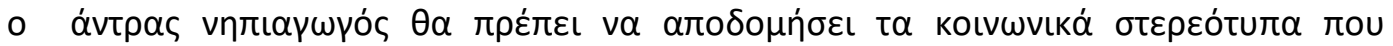

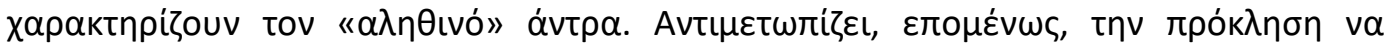

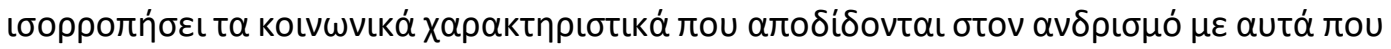

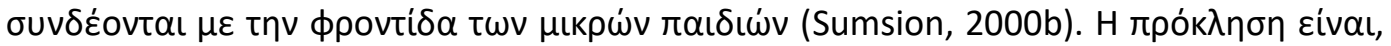

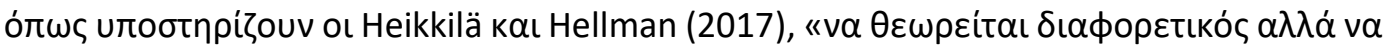

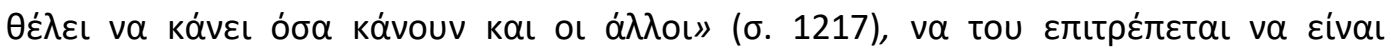

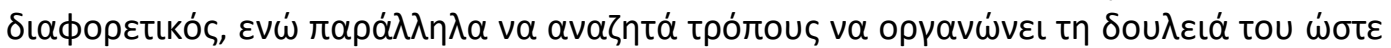

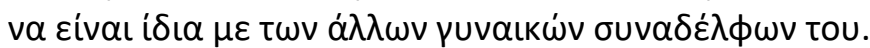

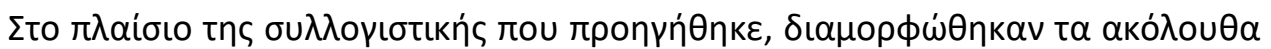

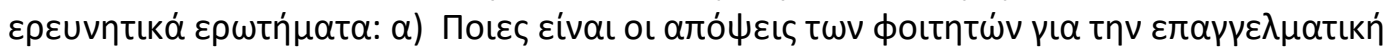

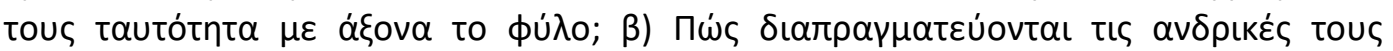

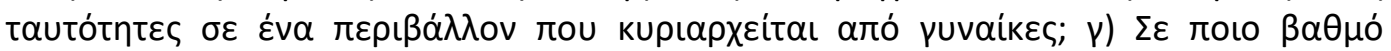

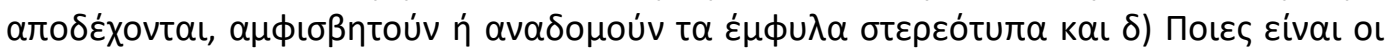

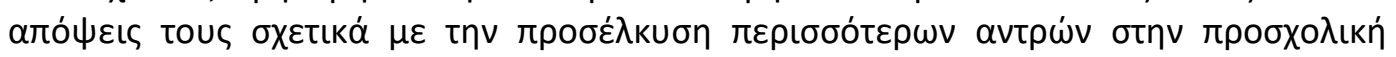
$\varepsilon \kappa \pi \alpha i ́ \delta \varepsilon \cup \sigma \eta ;$

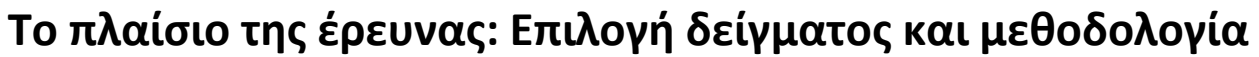

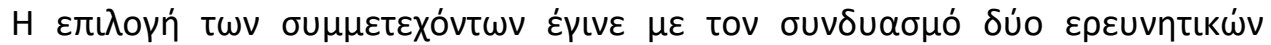

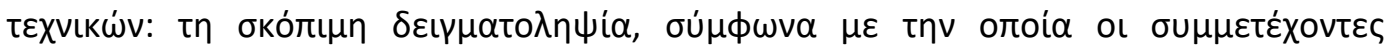

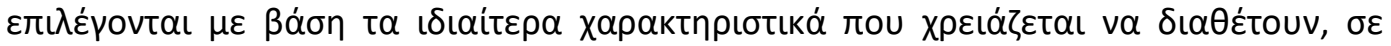




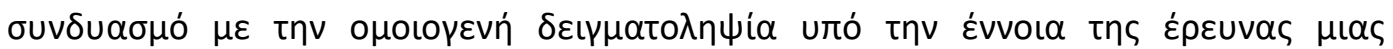

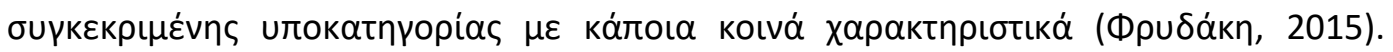

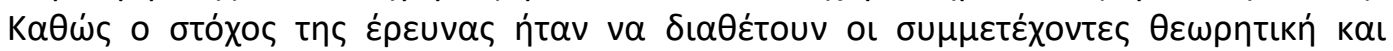

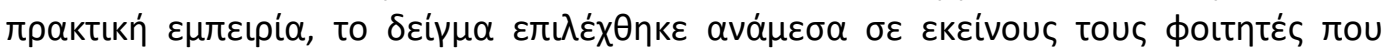

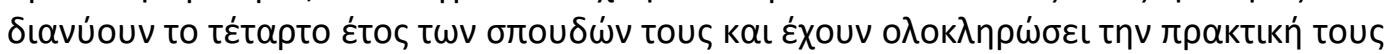

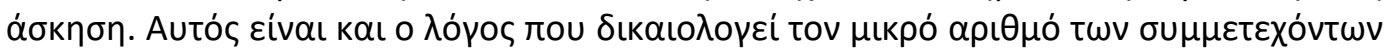

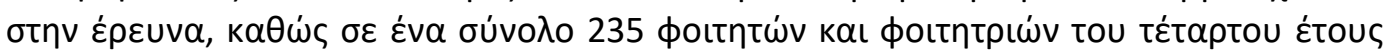

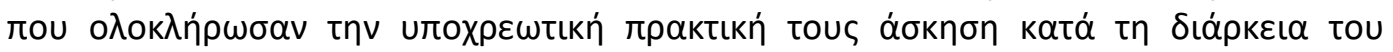

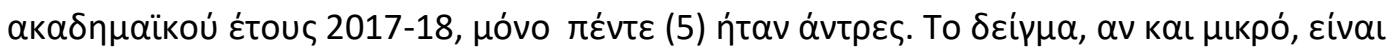

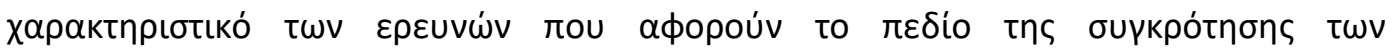

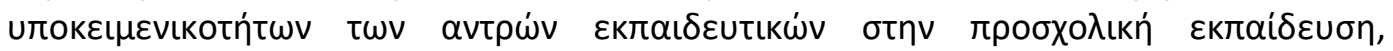

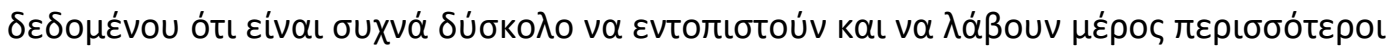

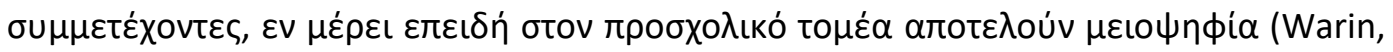
2015).

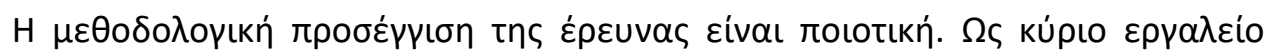

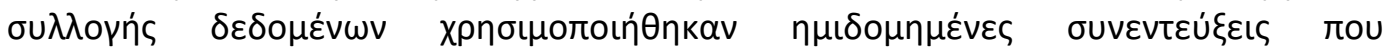

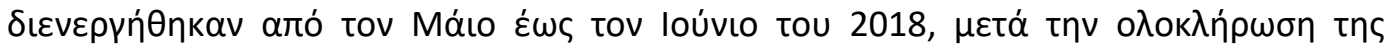

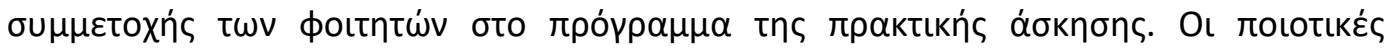

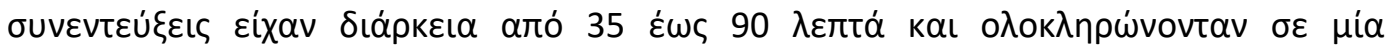

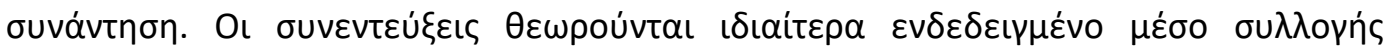

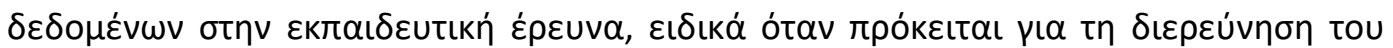

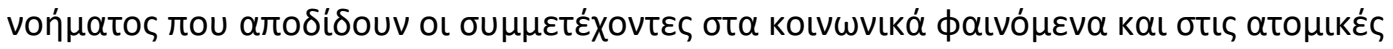

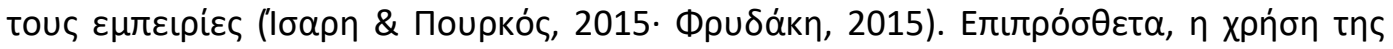

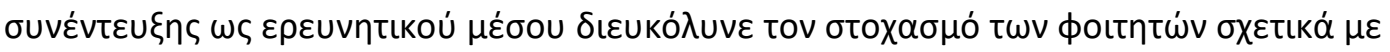

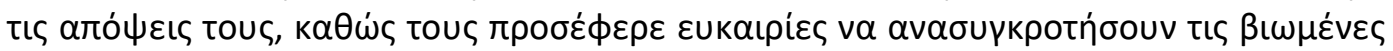

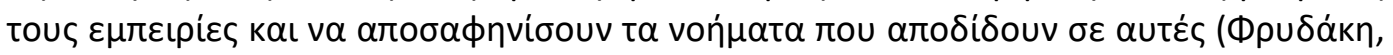
2015).

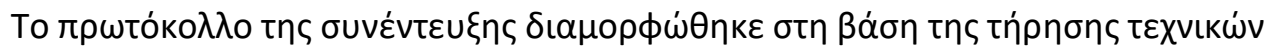

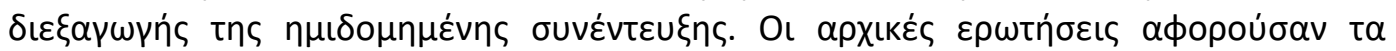

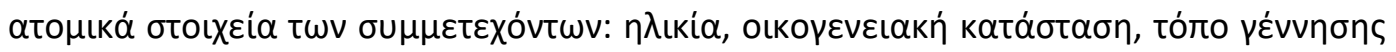

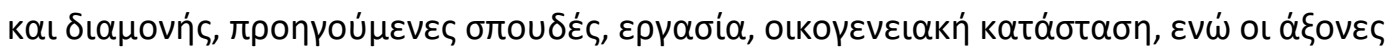

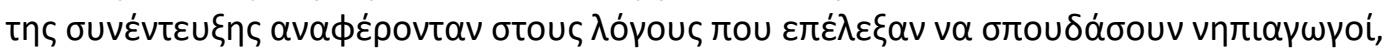

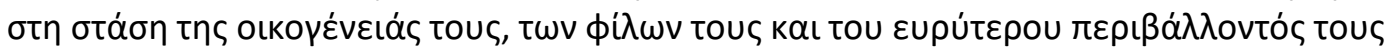

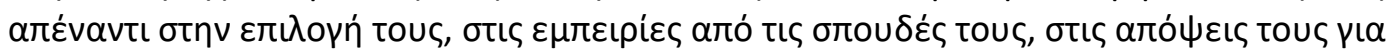

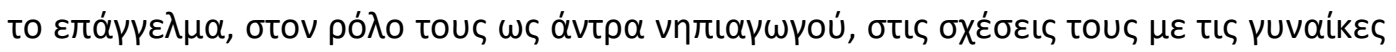

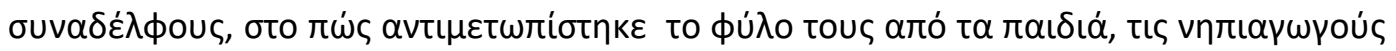

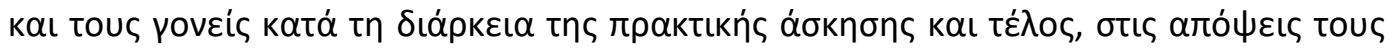

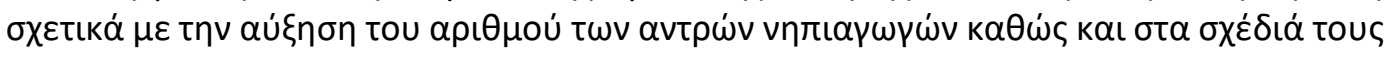

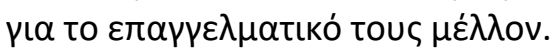

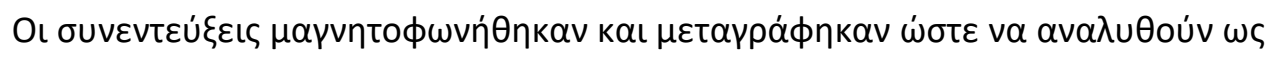

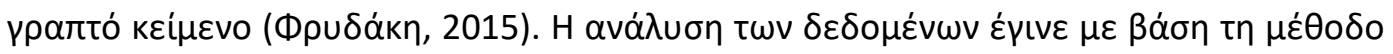

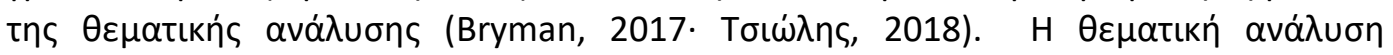

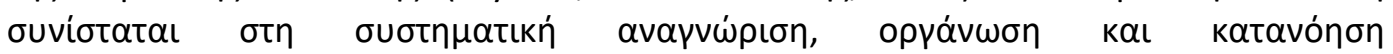

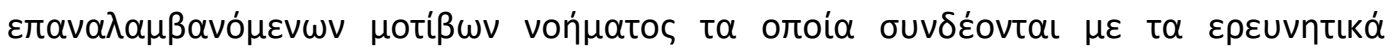

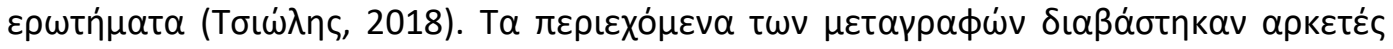

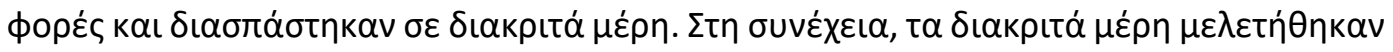




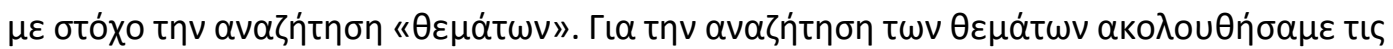

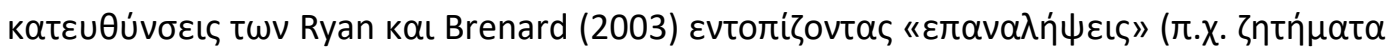

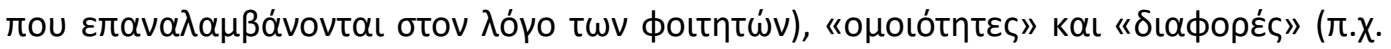

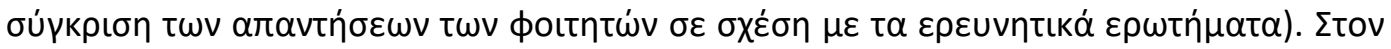

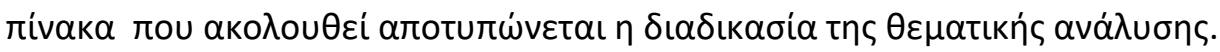

\begin{tabular}{|c|c|c|}
\hline 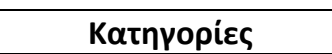 & Үлокатпүорієц & 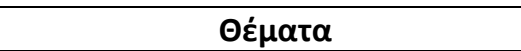 \\
\hline \multirow[t]{2}{*}{ 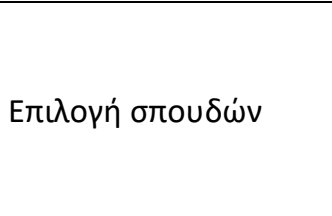 } & $\Sigma u v \varepsilon เ \delta \eta \tau n ́$ & 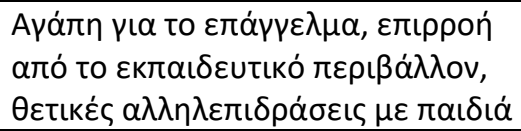 \\
\hline & Tuxaía & 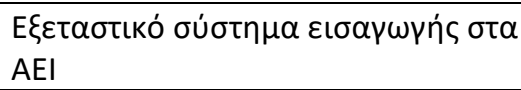 \\
\hline \multirow{4}{*}{ 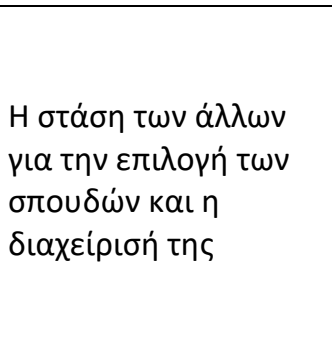 } & 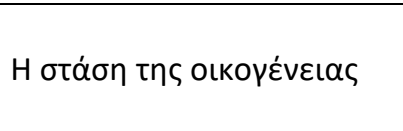 & 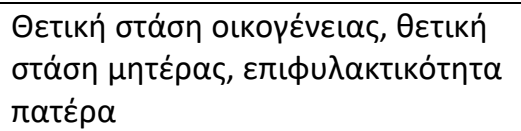 \\
\hline & 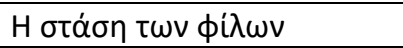 & 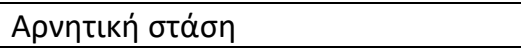 \\
\hline & 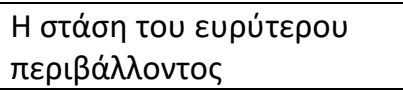 & 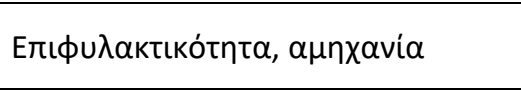 \\
\hline & 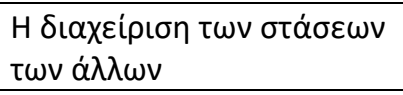 & 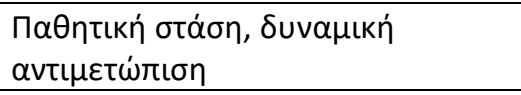 \\
\hline \multirow{3}{*}{ 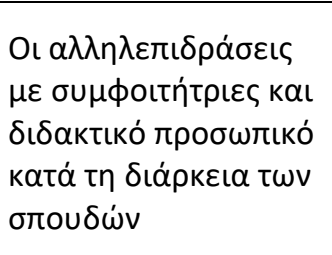 } & 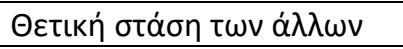 & 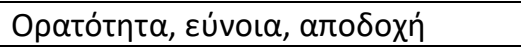 \\
\hline & 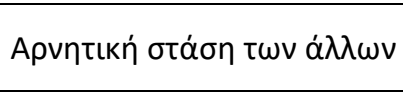 & 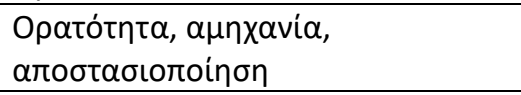 \\
\hline & 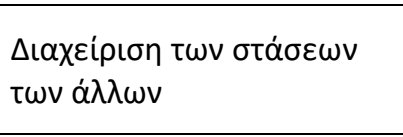 & 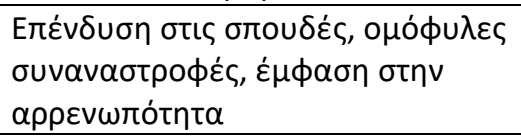 \\
\hline \multirow{3}{*}{ 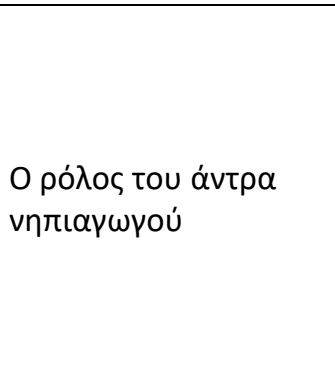 } & 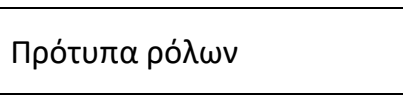 & 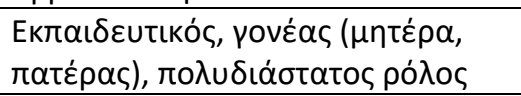 \\
\hline & 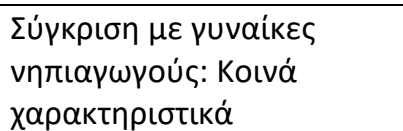 & 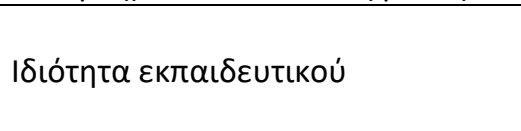 \\
\hline & 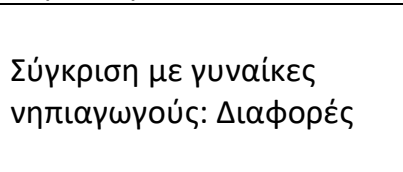 & 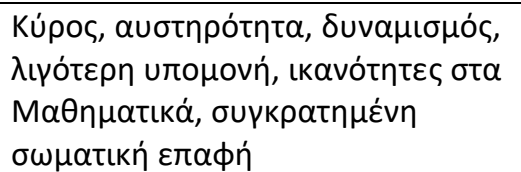 \\
\hline \multirow{2}{*}{$\begin{array}{l}\text { Oı } \alpha \lambda \lambda \eta \lambda \varepsilon \pi \iota \delta \rho \alpha ́ \sigma \varepsilon เ \varsigma \\
\mu \varepsilon \tau \alpha \pi \alpha \iota \delta \iota \alpha\end{array}$} & $\sum \tau \alpha \dot{\sigma} \sigma \eta \tau \omega v \pi \alpha \iota \delta \iota \omega \dot{~}$ & 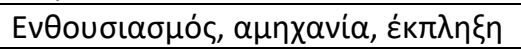 \\
\hline & 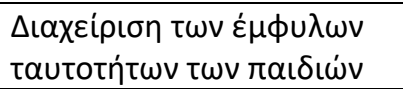 & 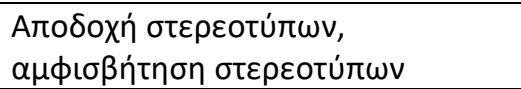 \\
\hline \multirow{2}{*}{ 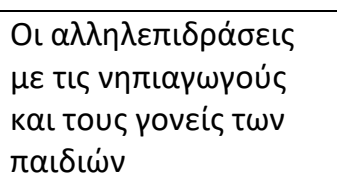 } & 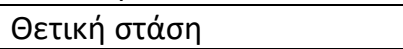 & \\
\hline & 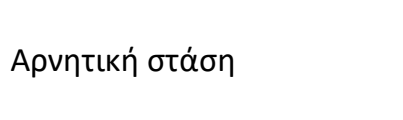 & 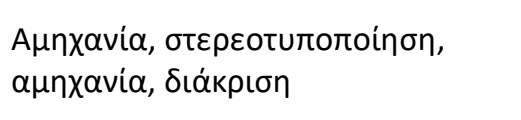 \\
\hline \multirow[t]{2}{*}{ 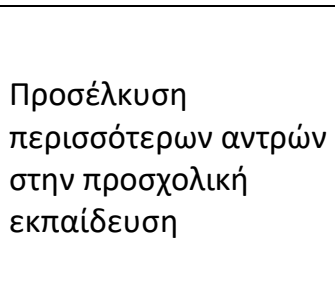 } & 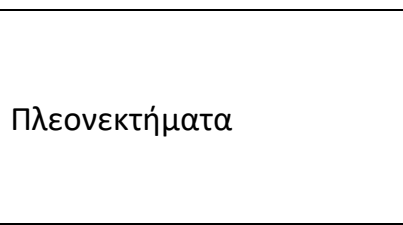 & 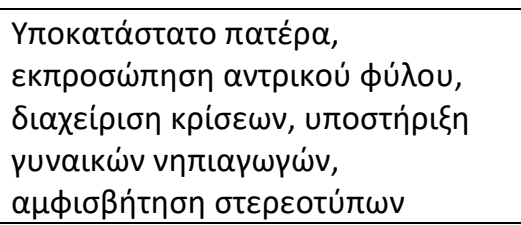 \\
\hline & 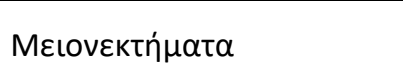 & 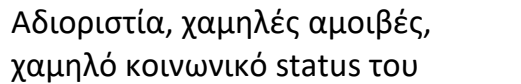 \\
\hline
\end{tabular}




\begin{tabular}{|c|c|c|}
\hline & & 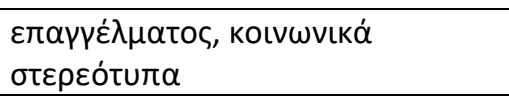 \\
\hline \multirow{2}{*}{ 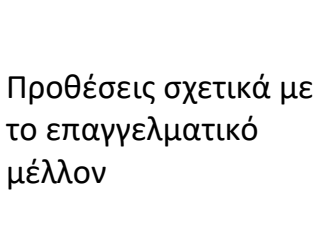 } & 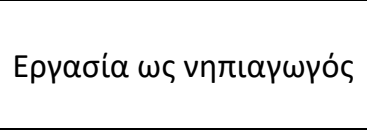 & 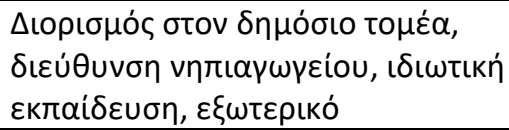 \\
\hline & 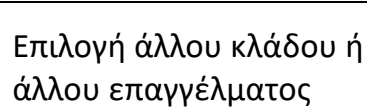 & 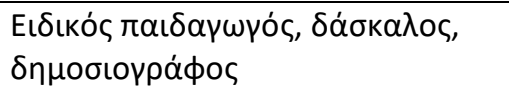 \\
\hline
\end{tabular}

\section{Пívaкаৎ 1}

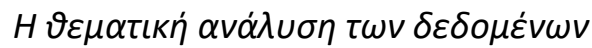

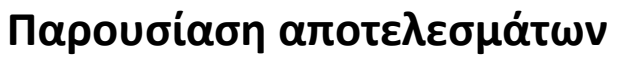

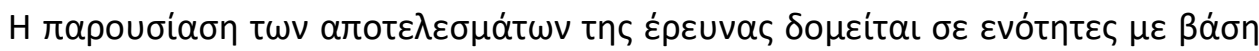

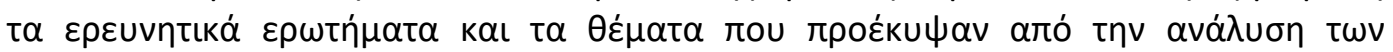

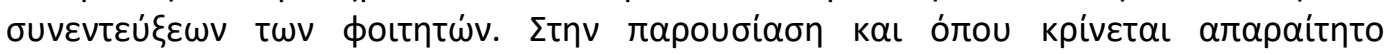

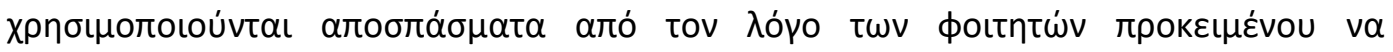

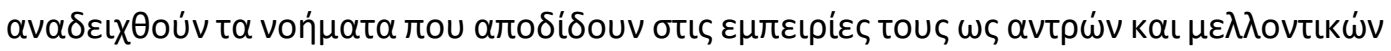

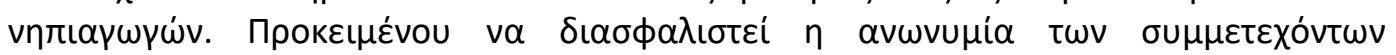

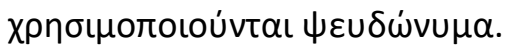

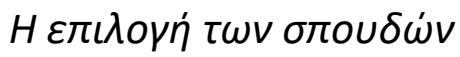

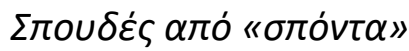

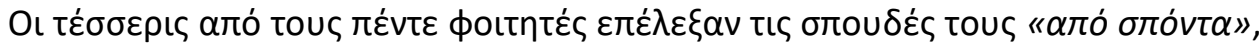

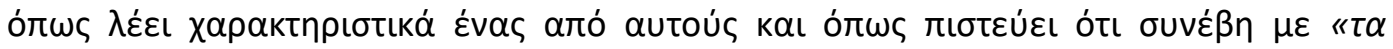

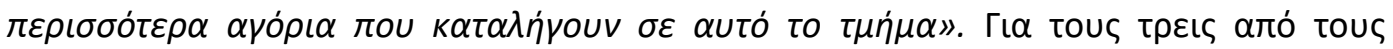

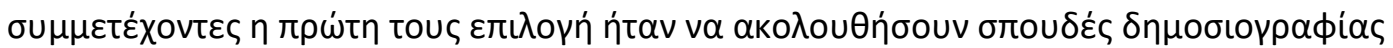

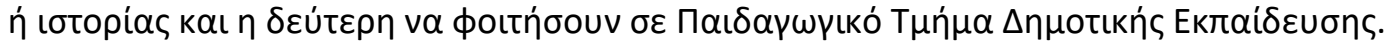

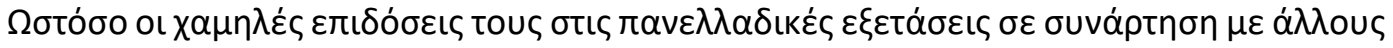

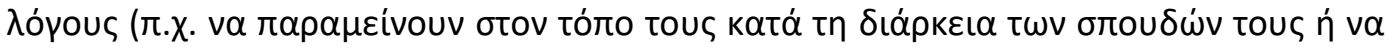

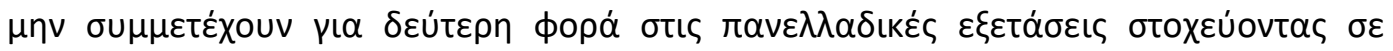

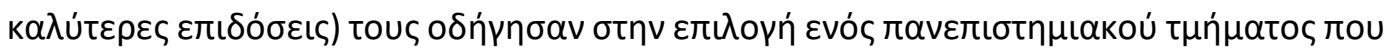

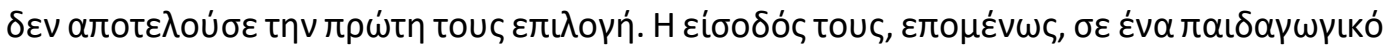

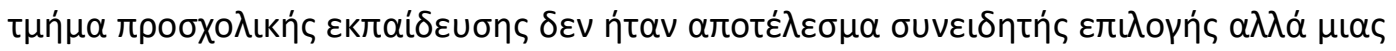

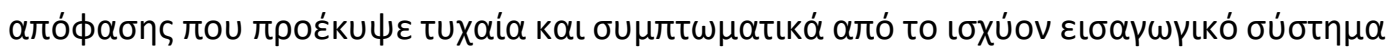

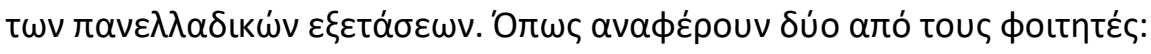

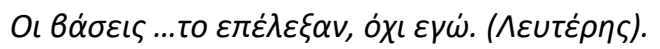

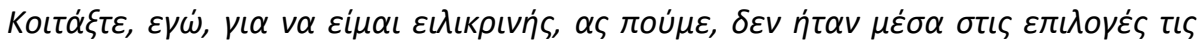

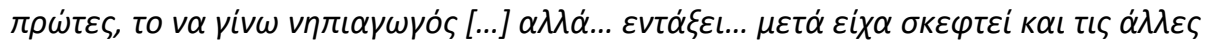

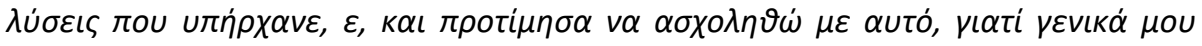

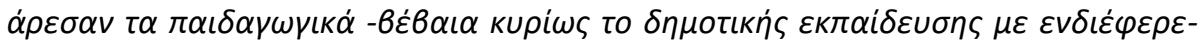

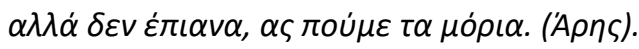

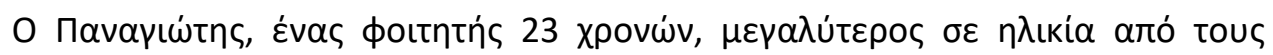

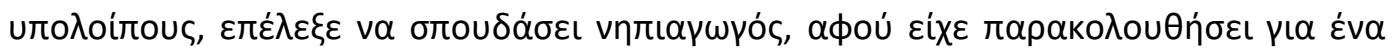

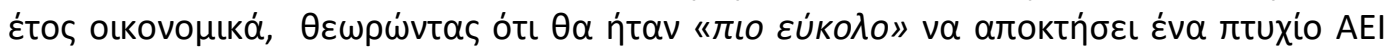




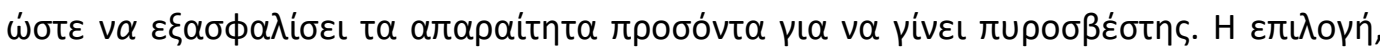

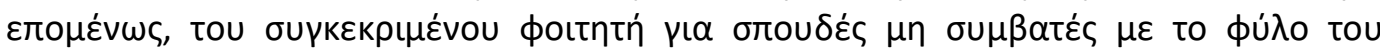

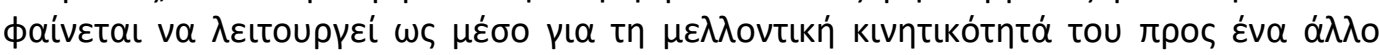

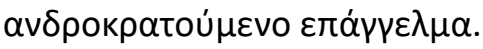

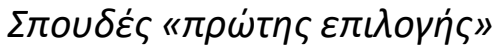

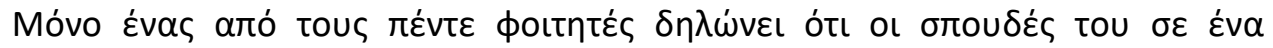

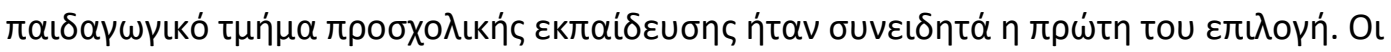

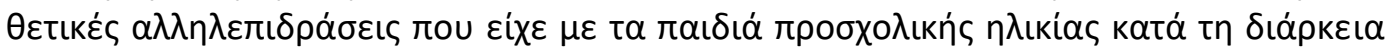

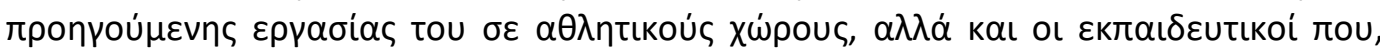

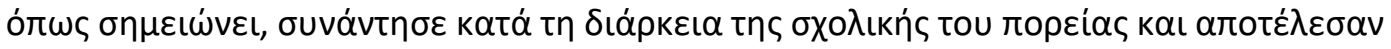

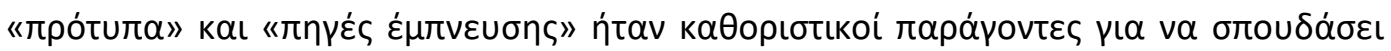

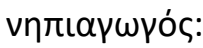

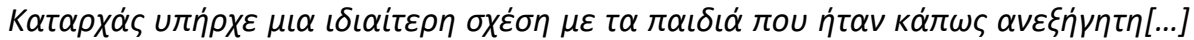

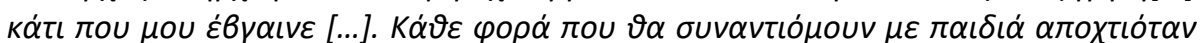

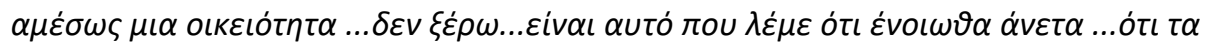

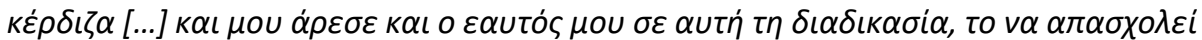

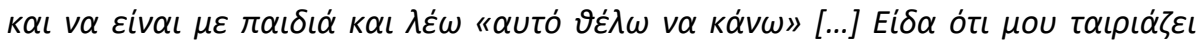

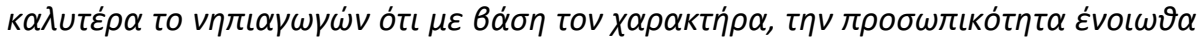

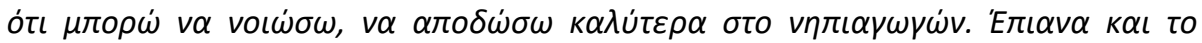

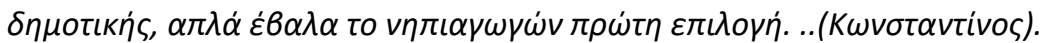

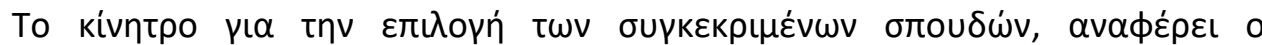

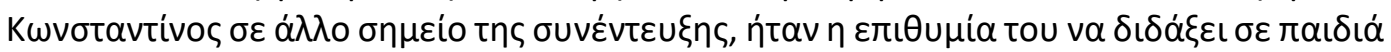

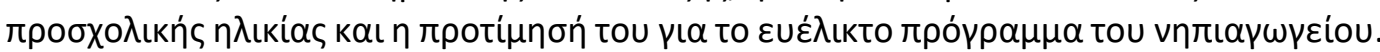

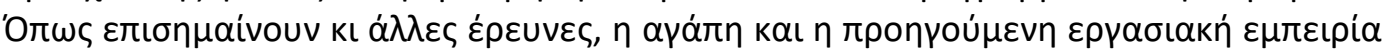

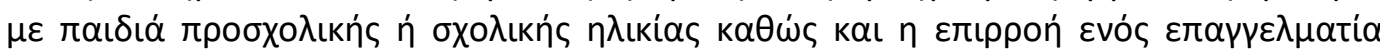

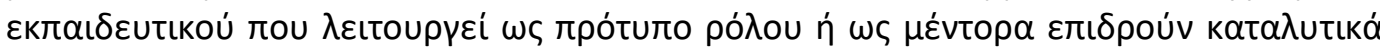

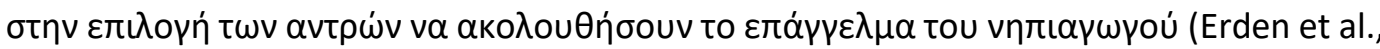
2011. Peeters, 2007. Pirard, Schoenmaeckers, \& Camus, 2015. Rentzou \& Zigantidou, 2009. Stroud et al., 2000).

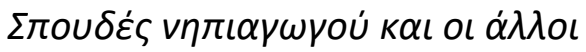

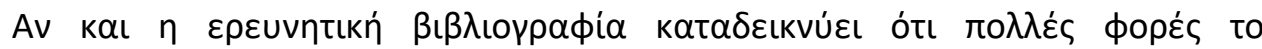

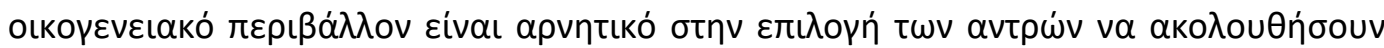

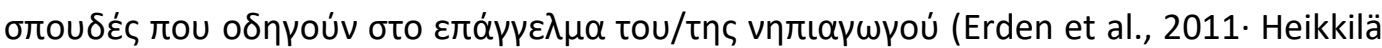

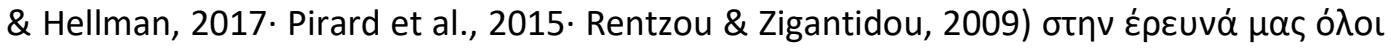

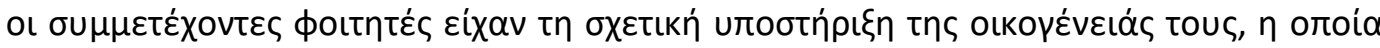

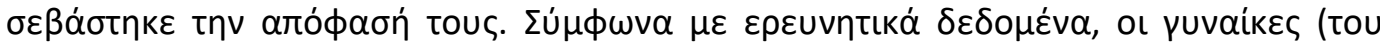

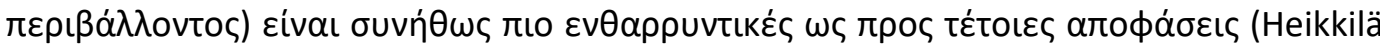

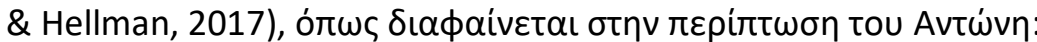

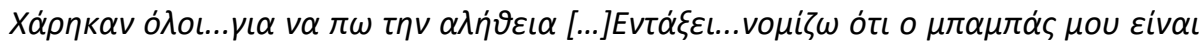

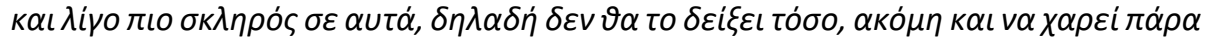

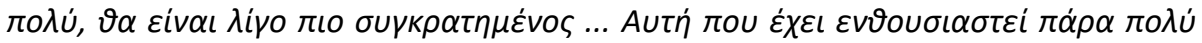

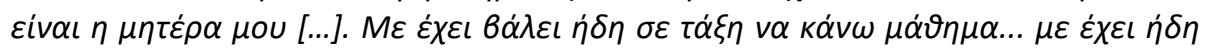

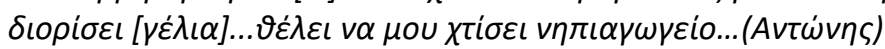




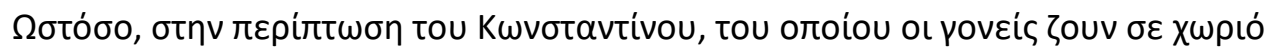

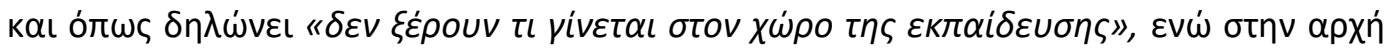

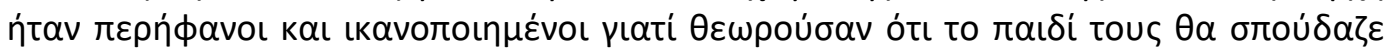

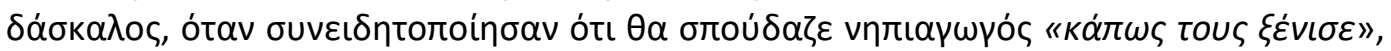

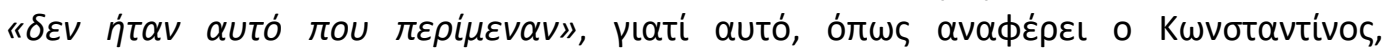

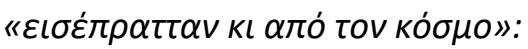

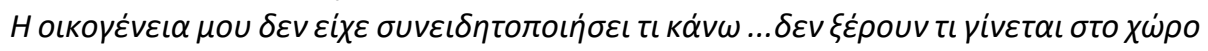

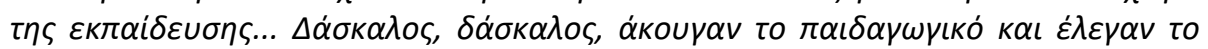

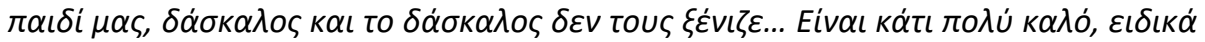

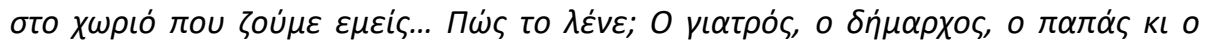

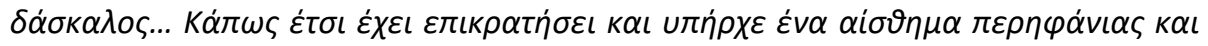

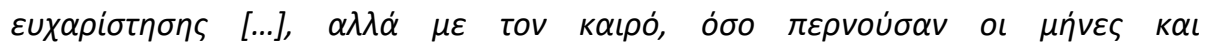

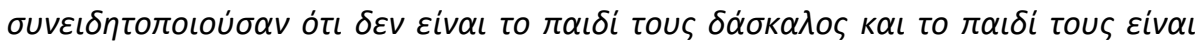

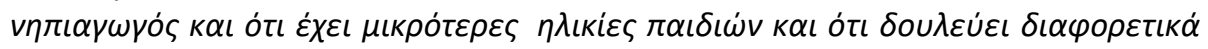

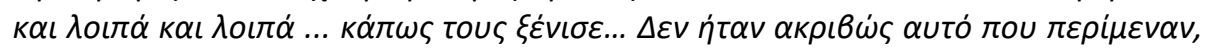

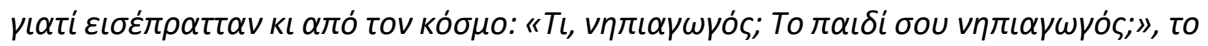

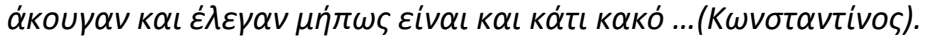

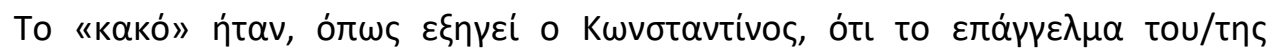

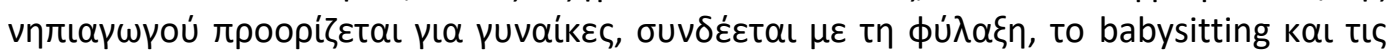

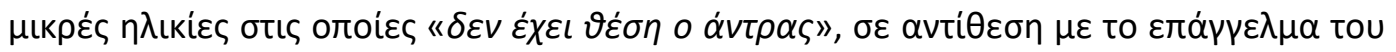

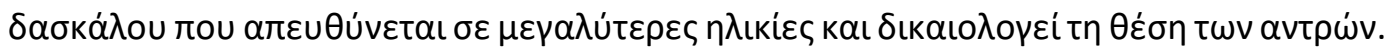

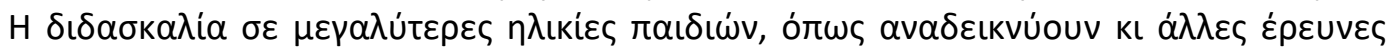

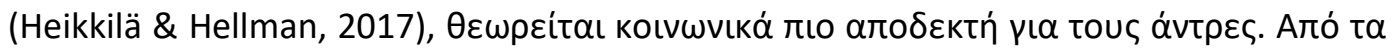

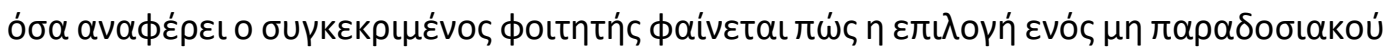

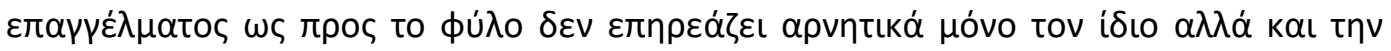

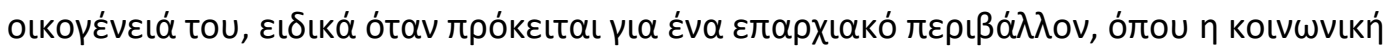

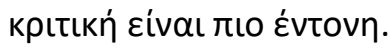

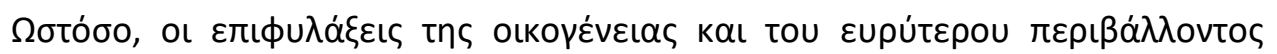

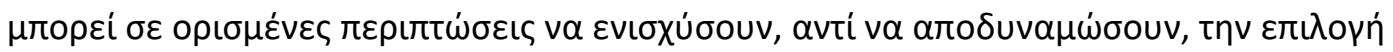

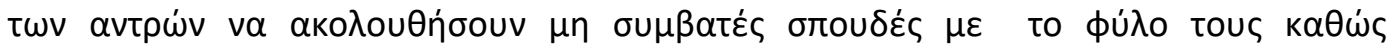

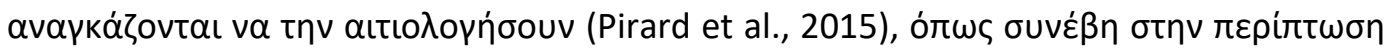
tou Kwvotavtívou:

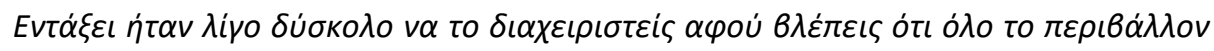

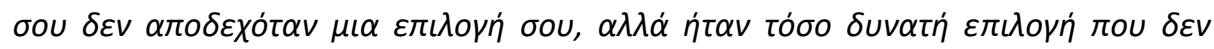

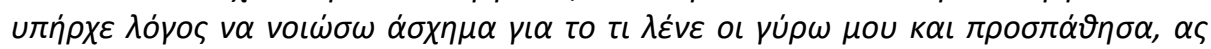

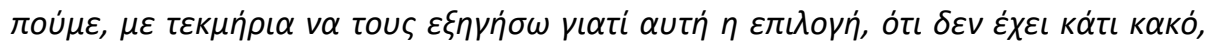

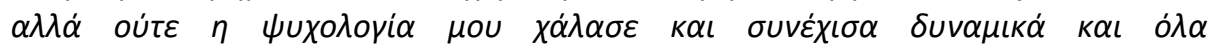

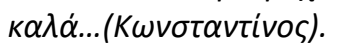

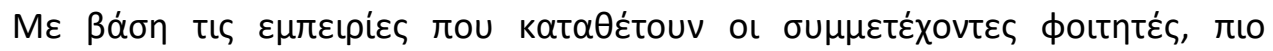

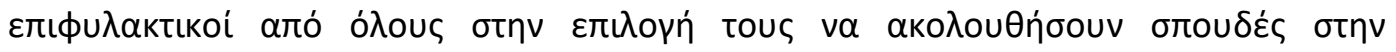

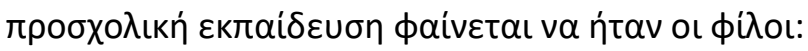

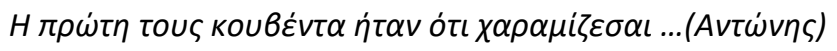

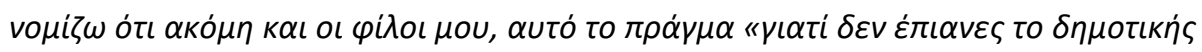

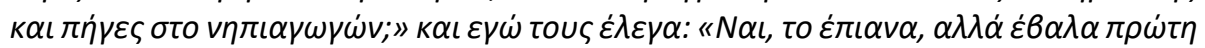

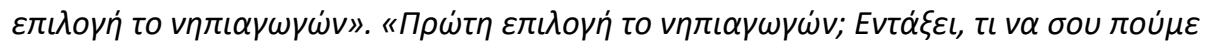

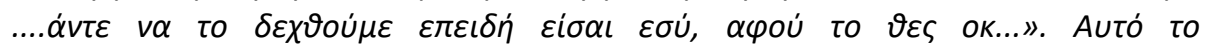
кó $\mu \pi \iota \alpha \sigma \mu \alpha . . .(\kappa \omega v \sigma \tau \alpha v \tau i ́ v o \varsigma)$. 


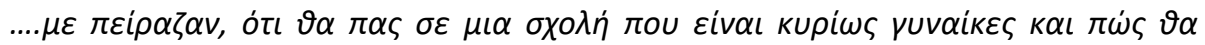

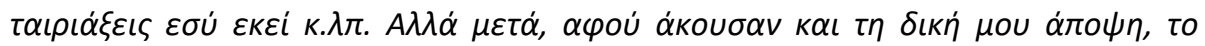
$\delta \varepsilon ́ \chi \tau \eta \kappa \alpha v . . .(' A \rho \eta \varsigma)$.

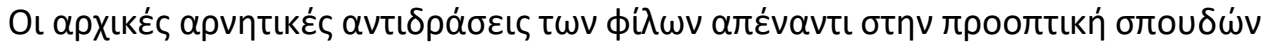

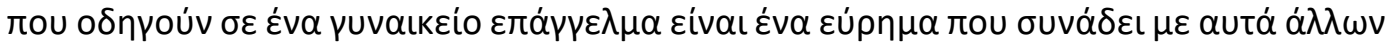

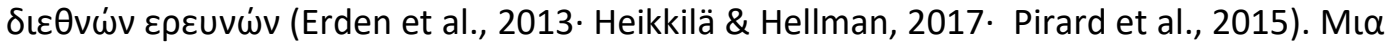
$\pi$

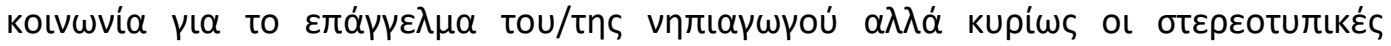

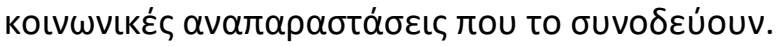

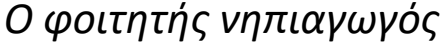

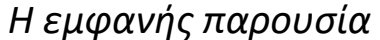

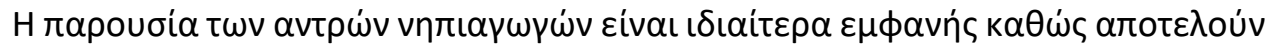

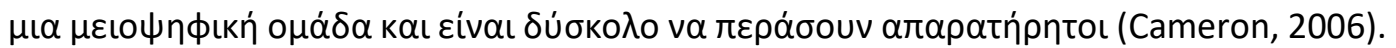

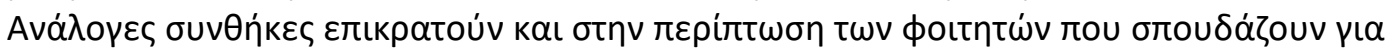

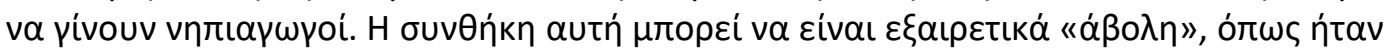

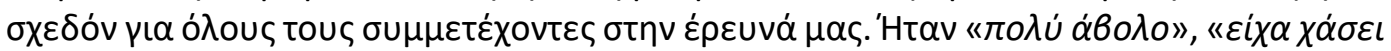

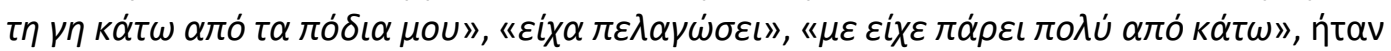

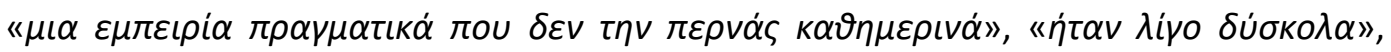

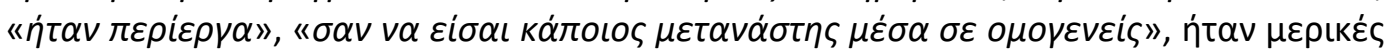

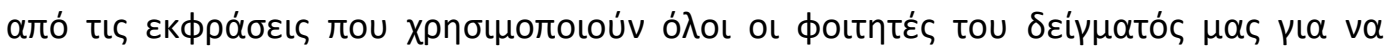

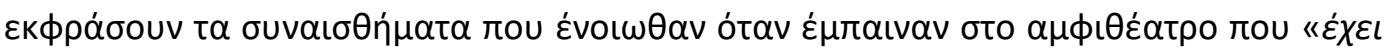

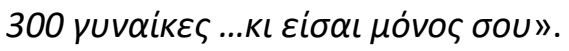

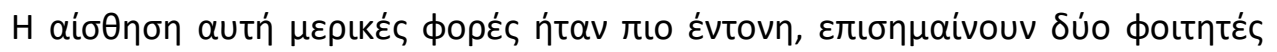

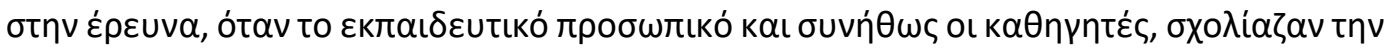

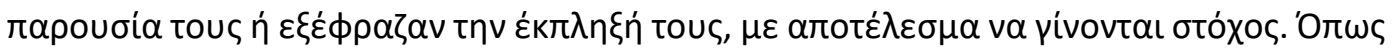

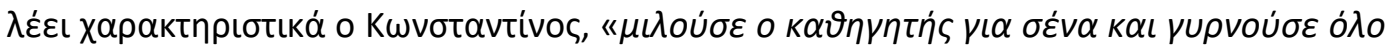

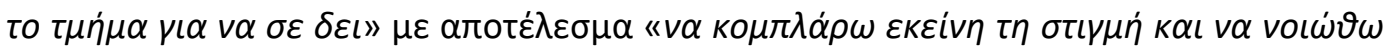

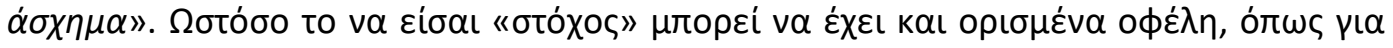

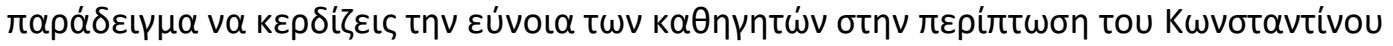

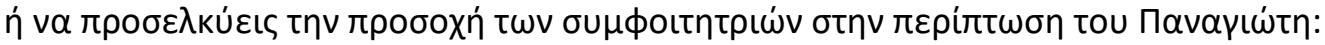

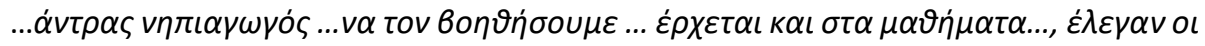

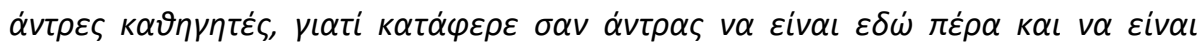

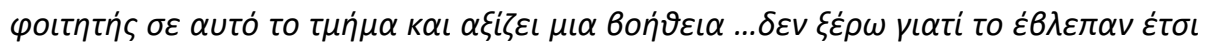

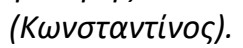

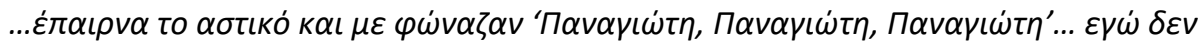

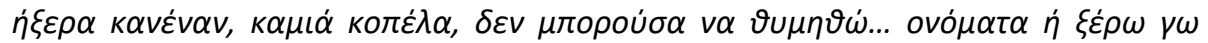
$\delta \iota \dot{\alpha} \varphi о \rho \alpha . . .(\Pi \alpha v \alpha \nu \iota \omega \dot{\tau} \eta \varsigma)$.

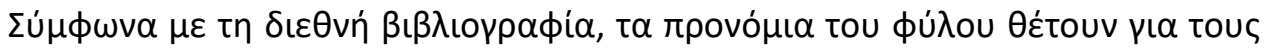

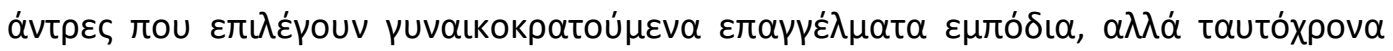

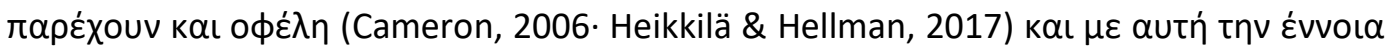

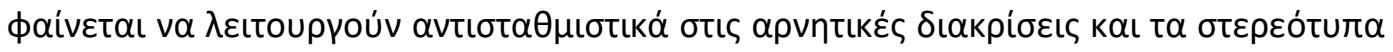

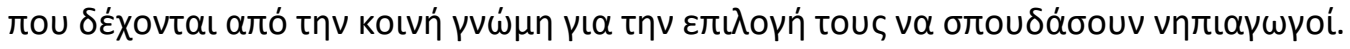




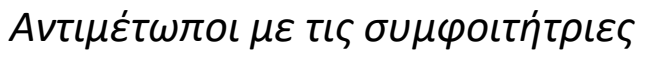

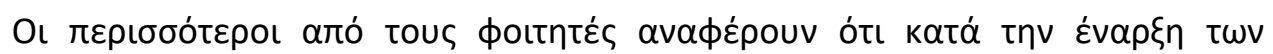

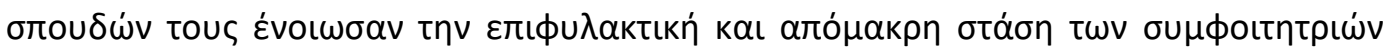

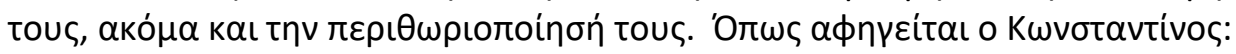

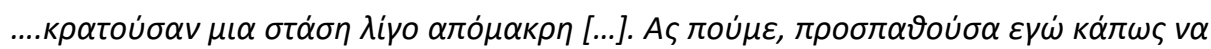

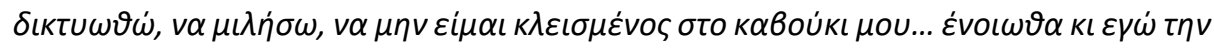

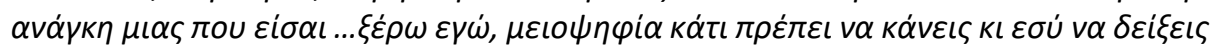

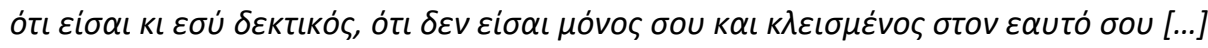

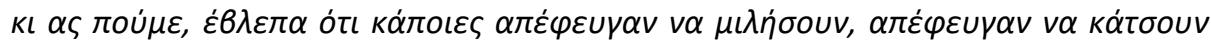

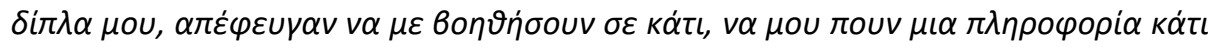

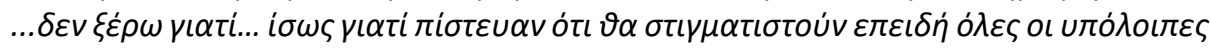

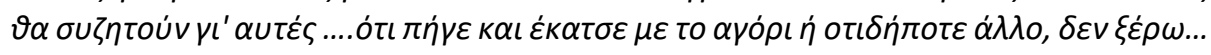

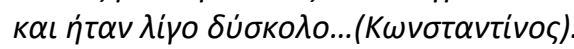

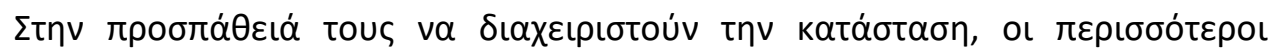

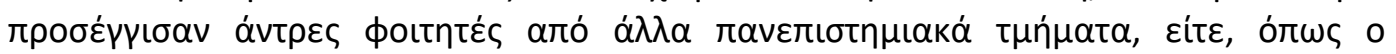

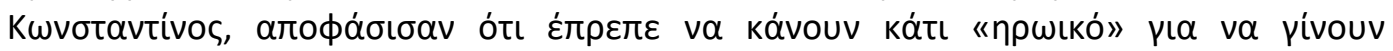

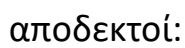

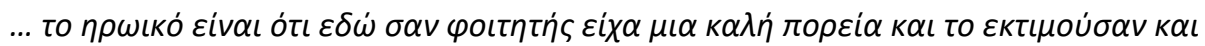

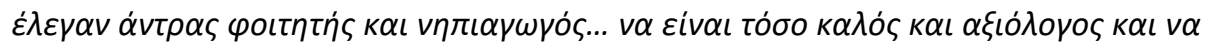

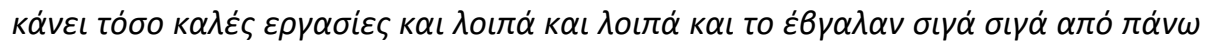

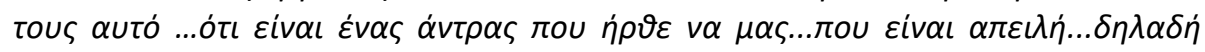

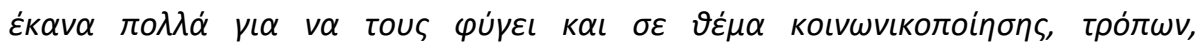

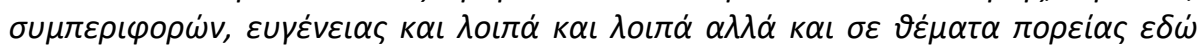

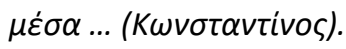

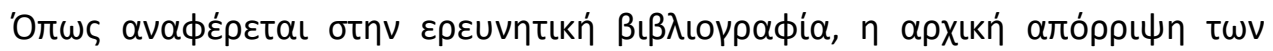

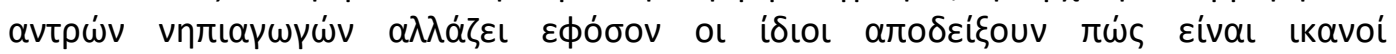

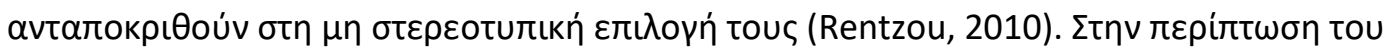

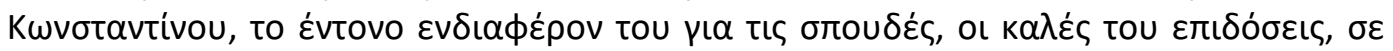

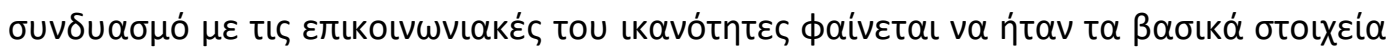

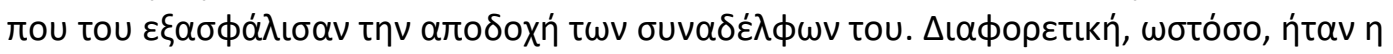

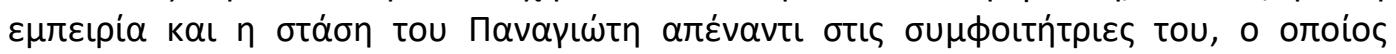

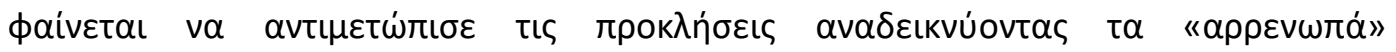

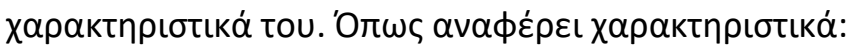

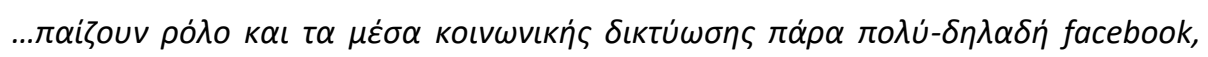

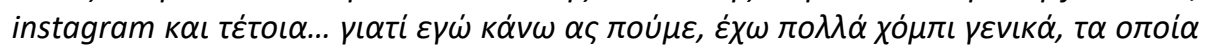

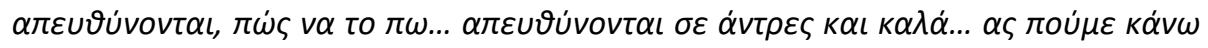

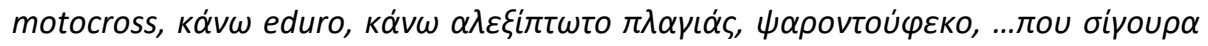

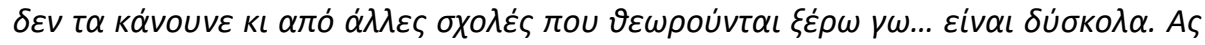

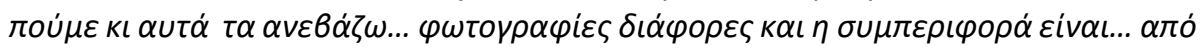

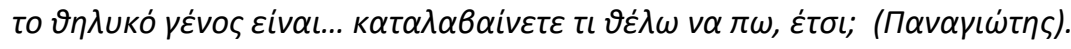

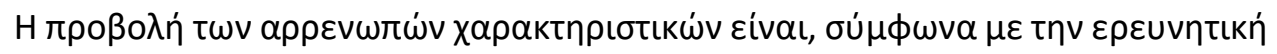

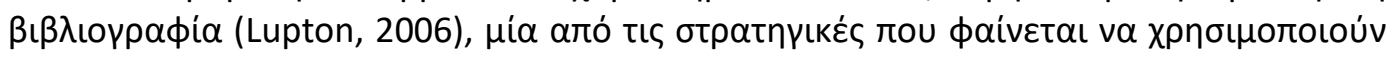

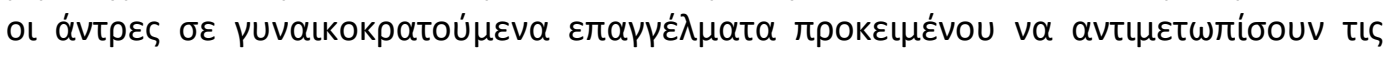

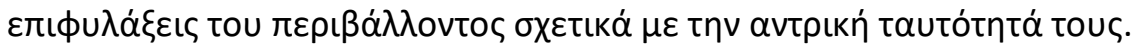




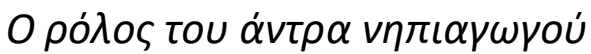

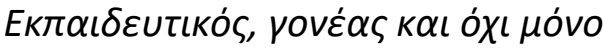

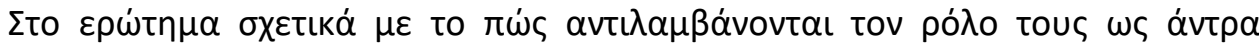

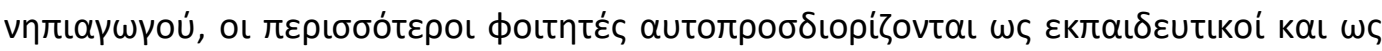

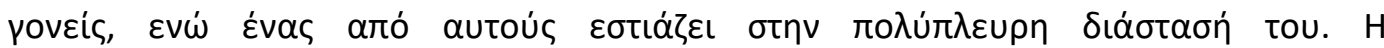

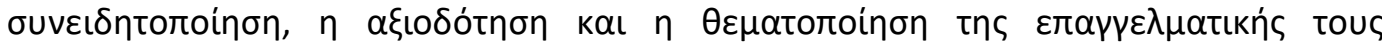

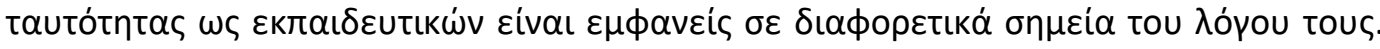

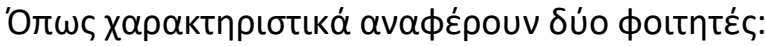

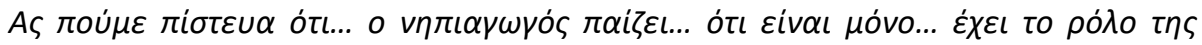

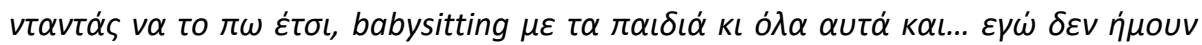

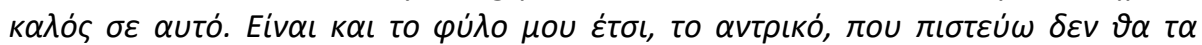

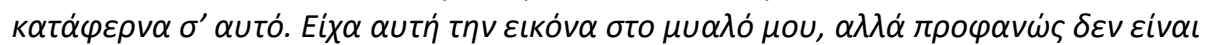

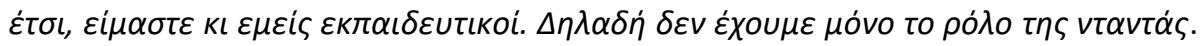

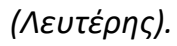

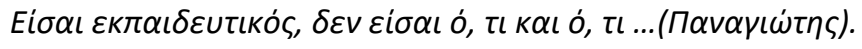

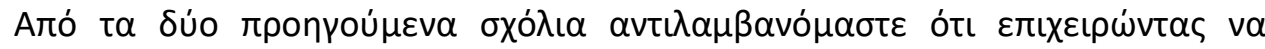

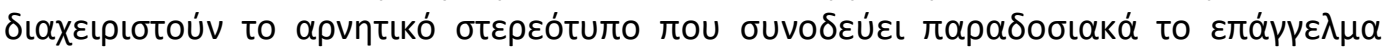

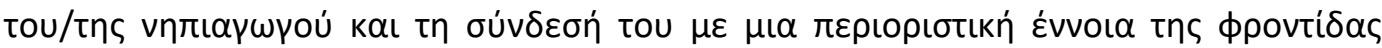

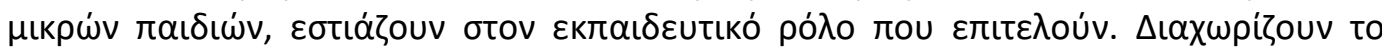

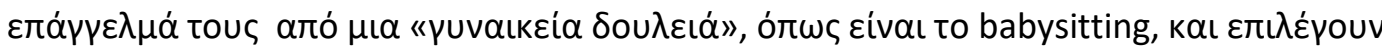

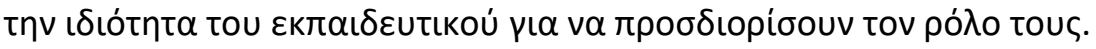

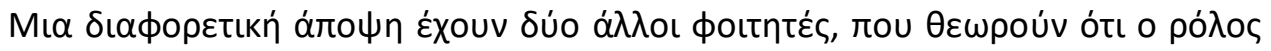

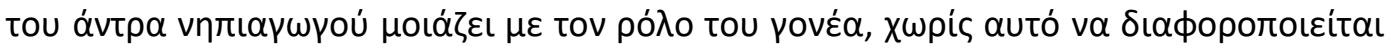

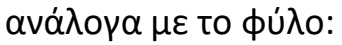

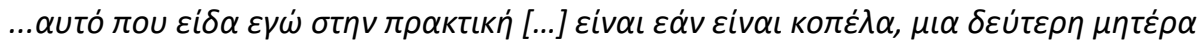

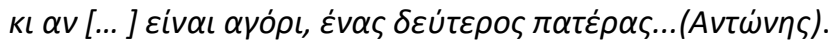

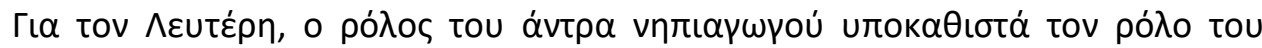

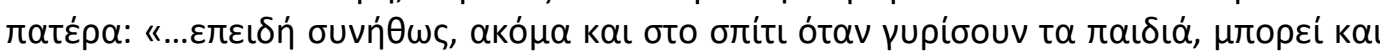

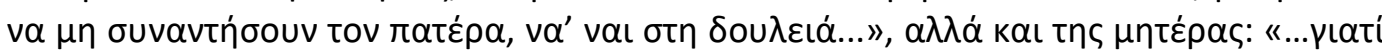

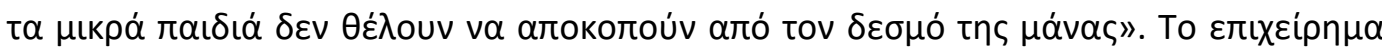

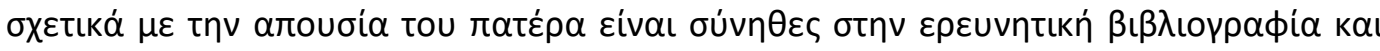

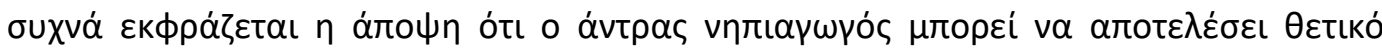

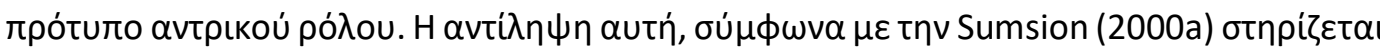

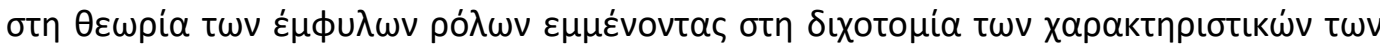

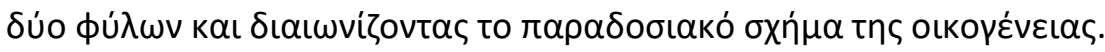

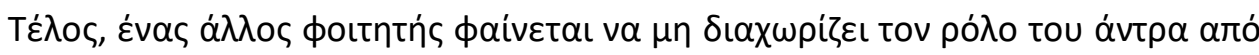

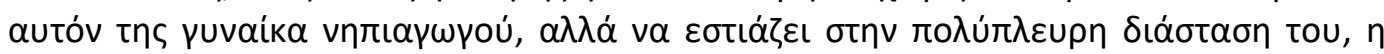

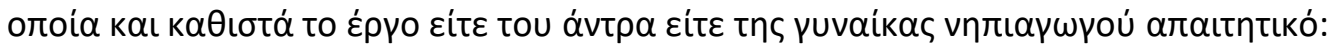

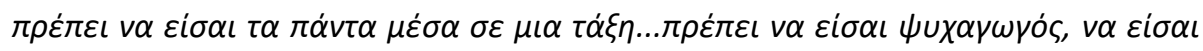

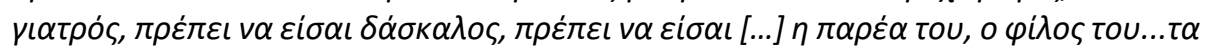

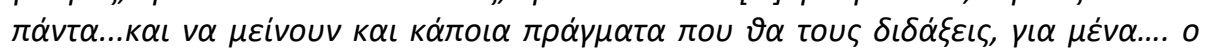

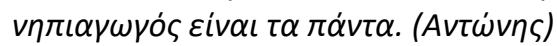




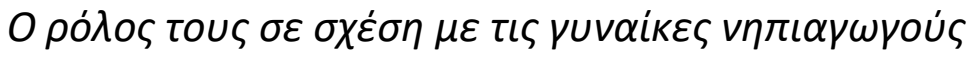

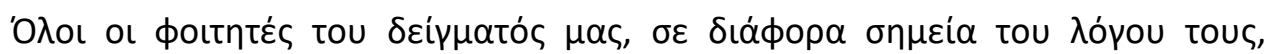

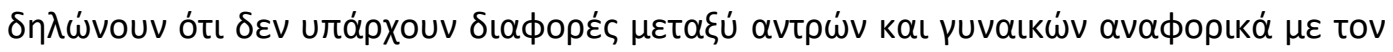

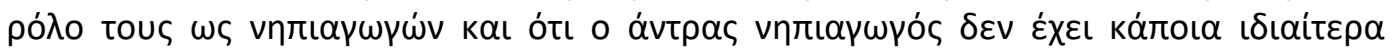

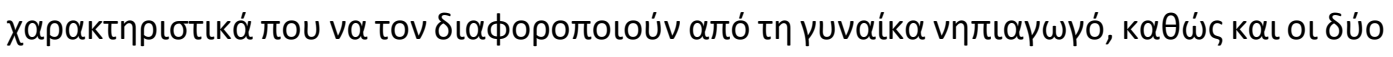

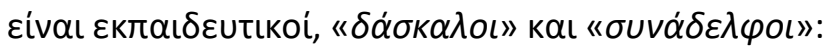

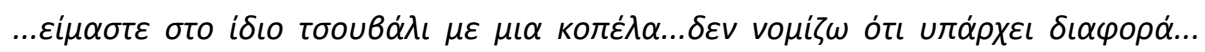

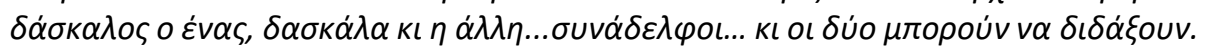

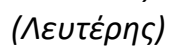

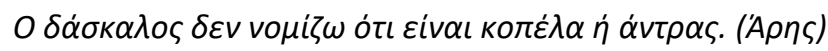

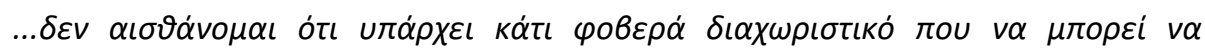

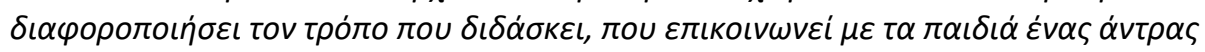

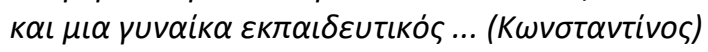

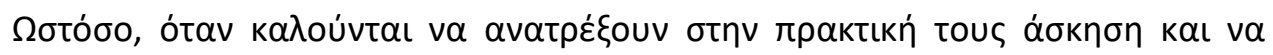

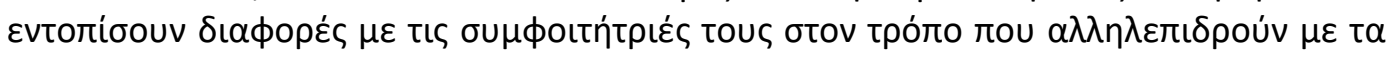

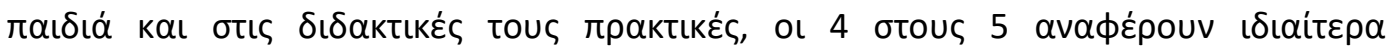

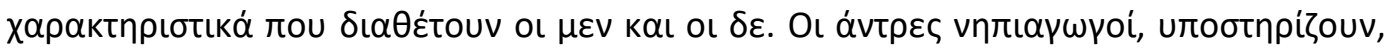

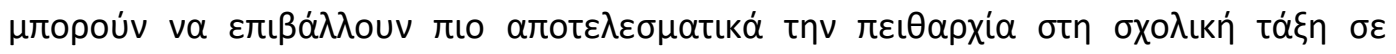

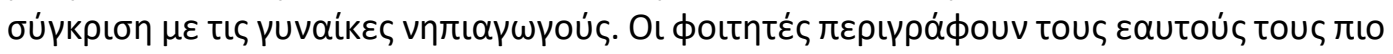

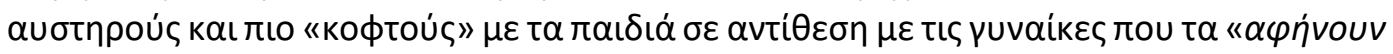

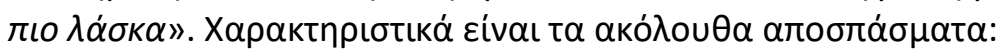

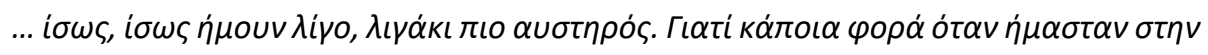

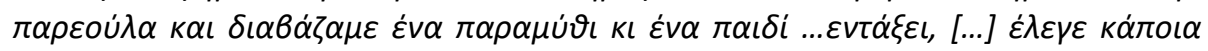

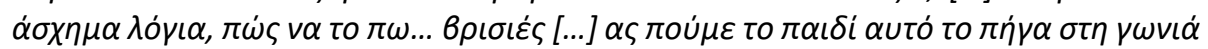

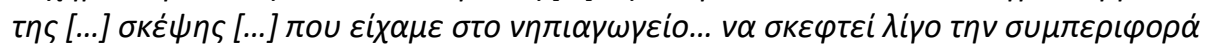
tou. ('Apпs)

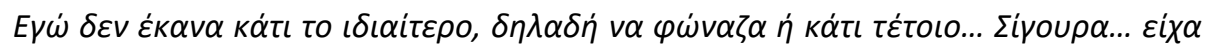

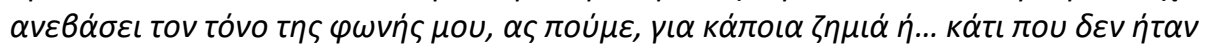

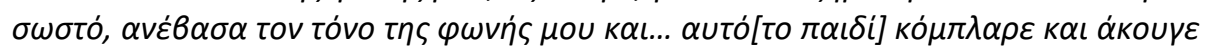

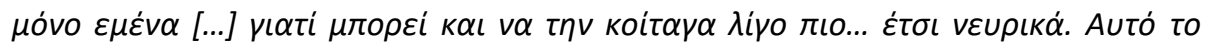

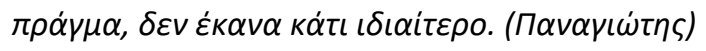

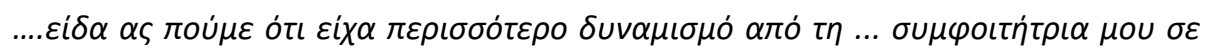

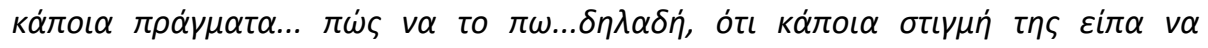

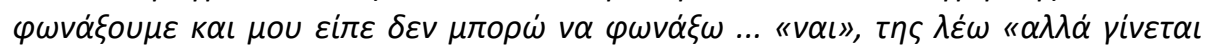

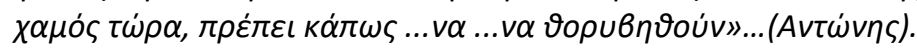

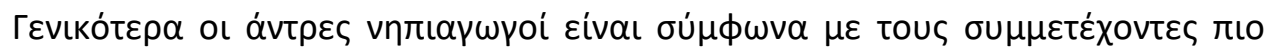

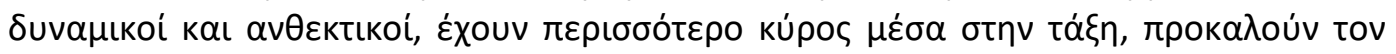

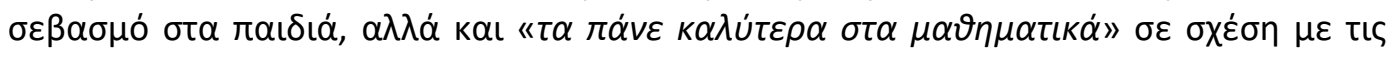

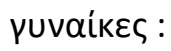

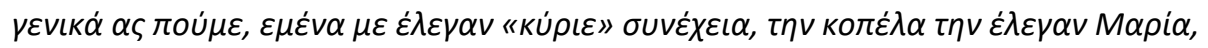

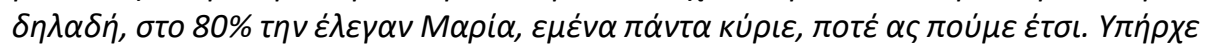

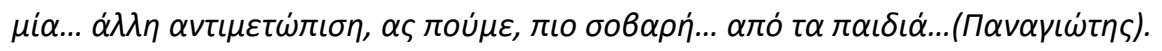

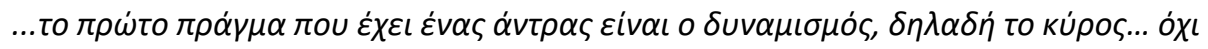

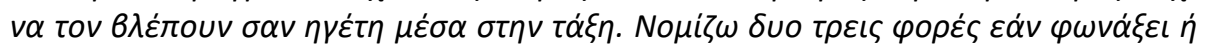




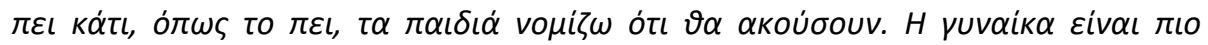

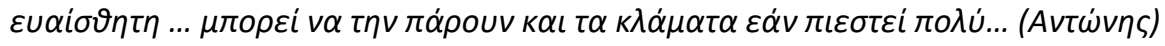

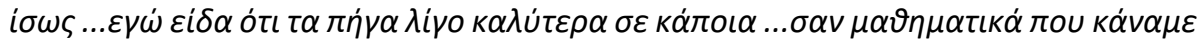

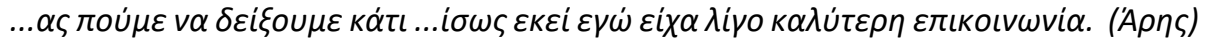

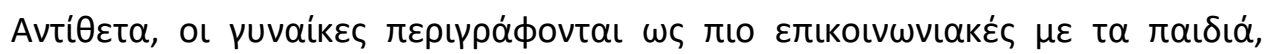

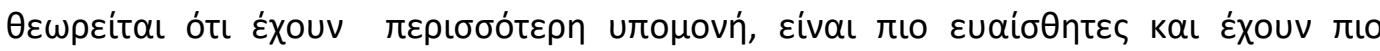

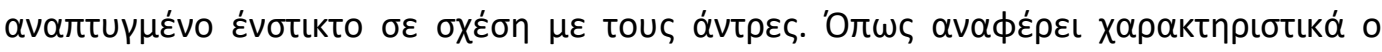
Avtúvnc:

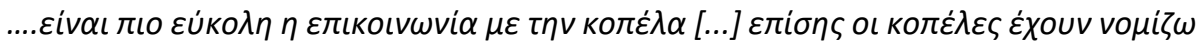

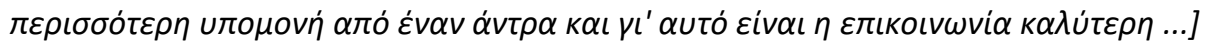

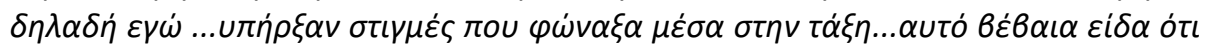

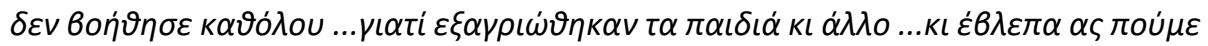

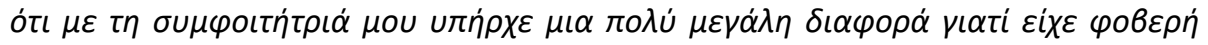

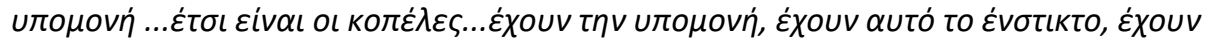

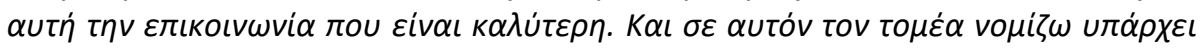

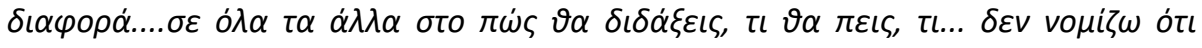

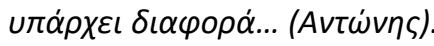

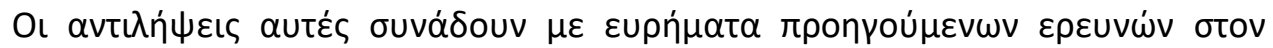

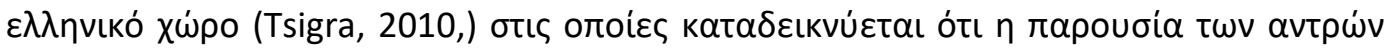

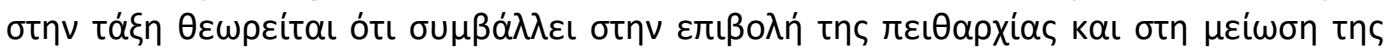

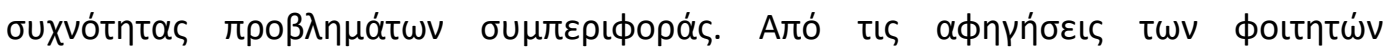

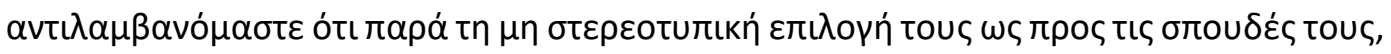

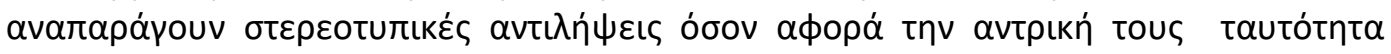

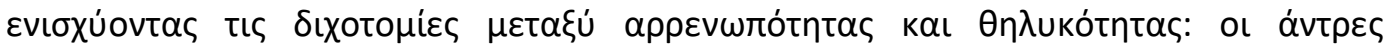

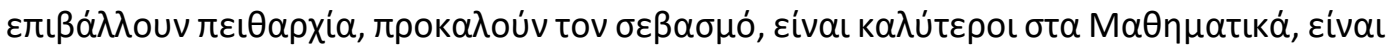

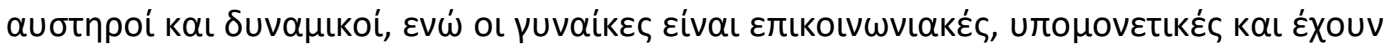

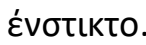

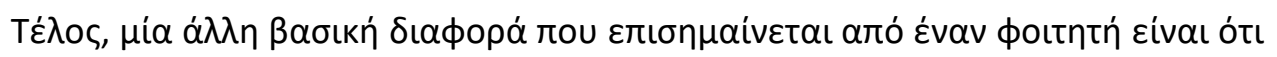

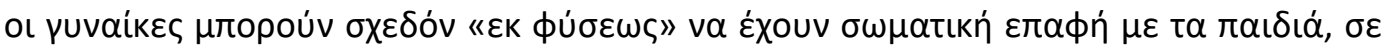

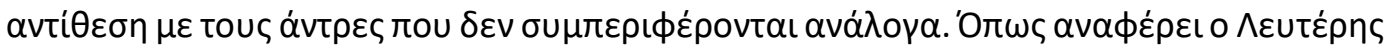

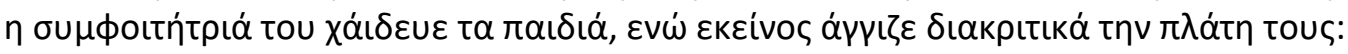

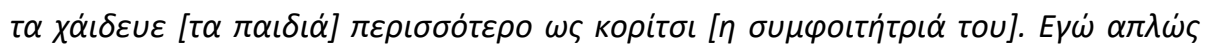

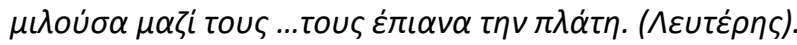

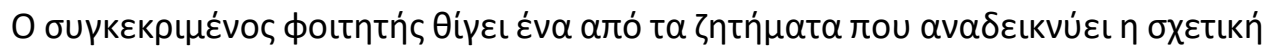

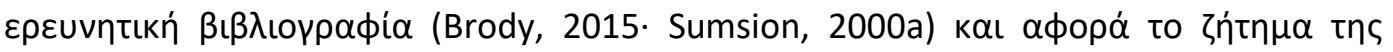

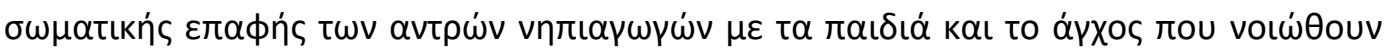

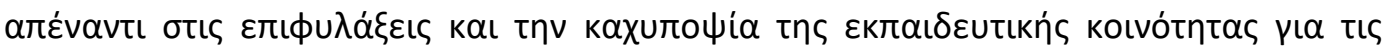

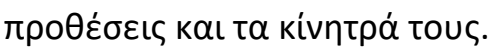

\section{$H \alpha \lambda \lambda \eta \lambda \varepsilon \pi i \delta \rho \alpha \sigma \eta \mu \varepsilon \tau \alpha \pi \alpha \iota \delta ı \dot{\alpha}$}

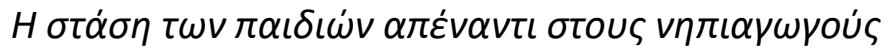

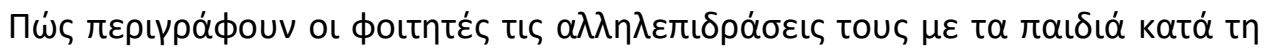

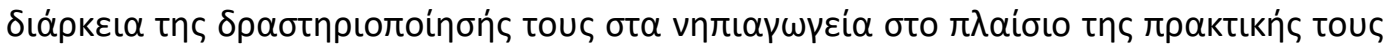

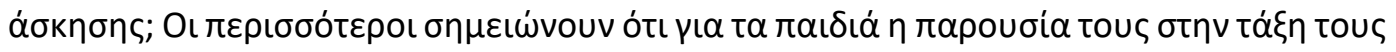




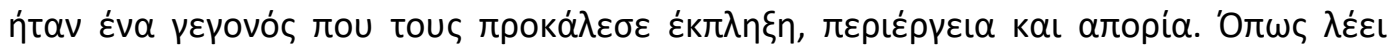

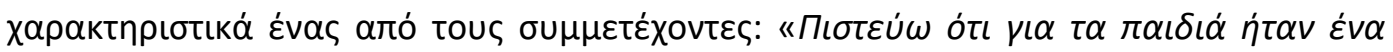

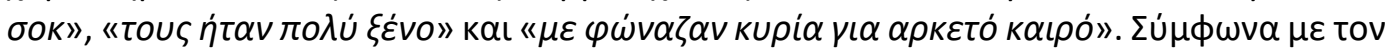

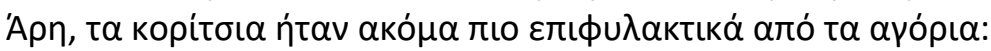

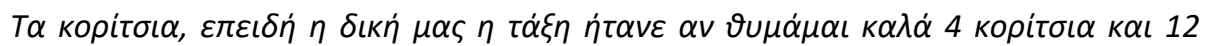

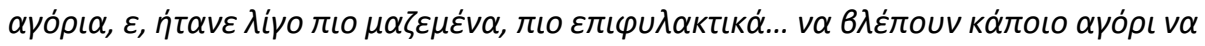

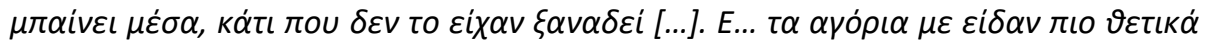

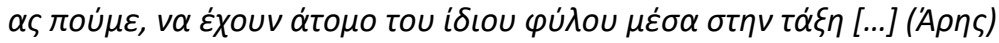

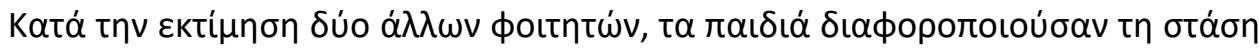

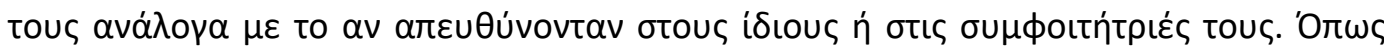

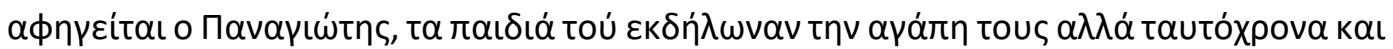

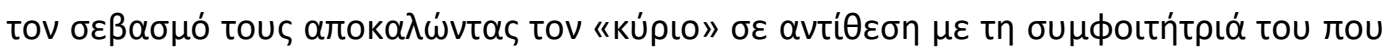

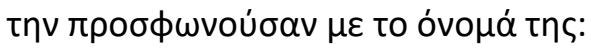

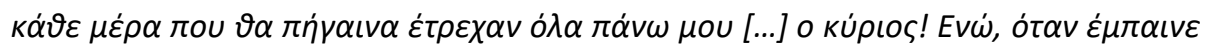

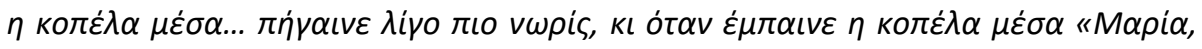

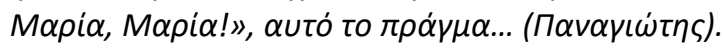

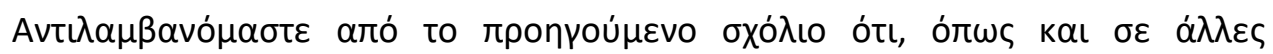

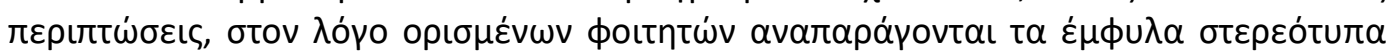

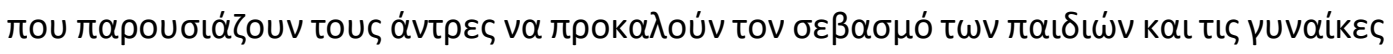

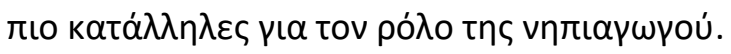

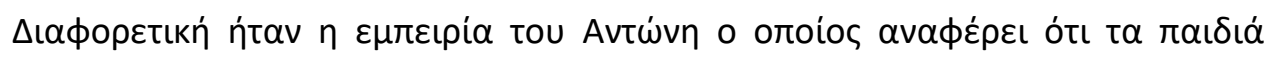

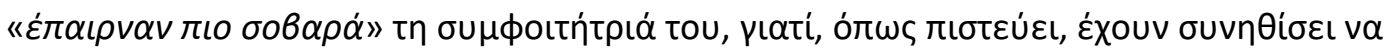

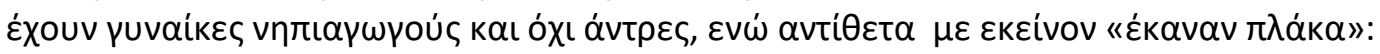

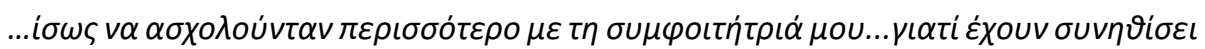

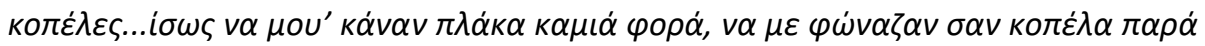

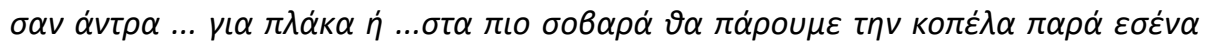

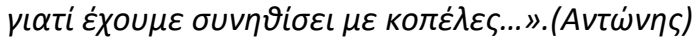

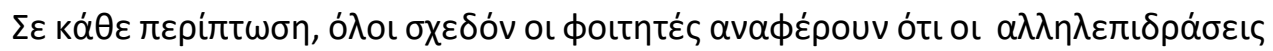

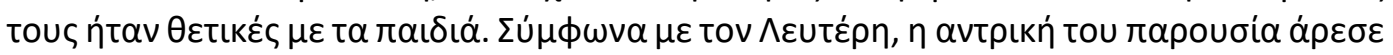

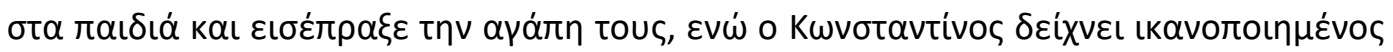

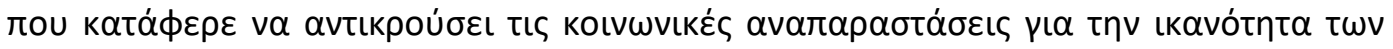

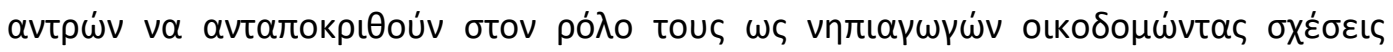

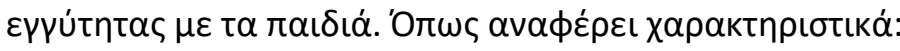

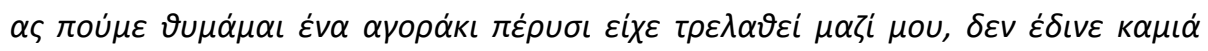

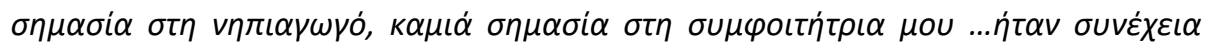

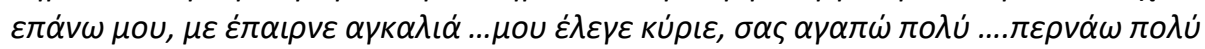

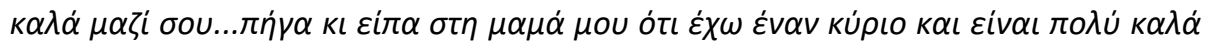

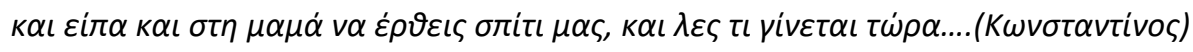

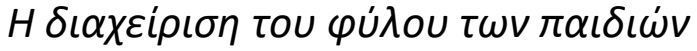

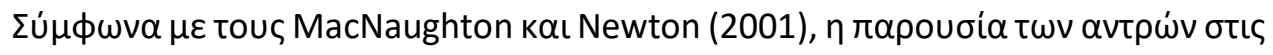

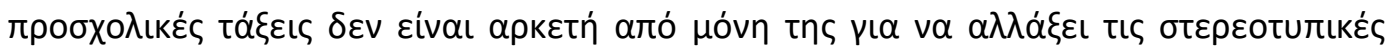

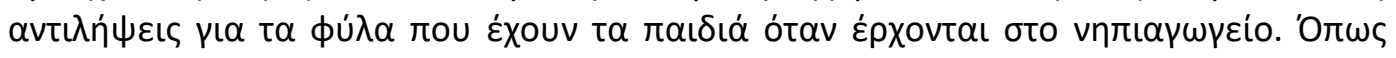

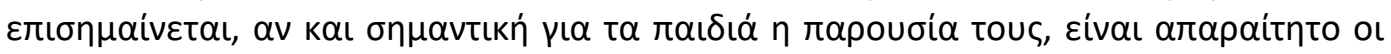

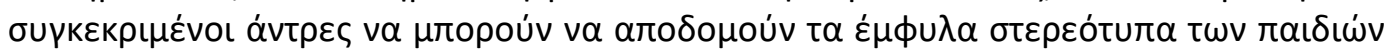




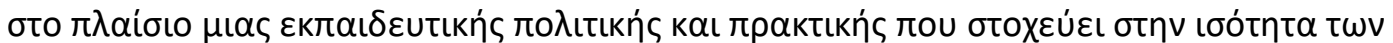

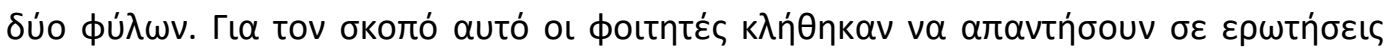

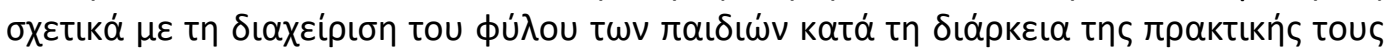

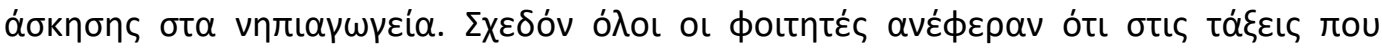

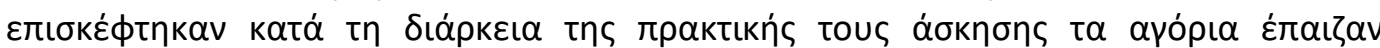

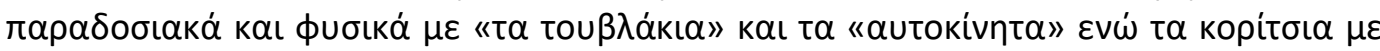

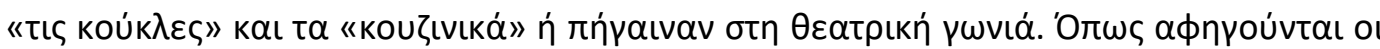

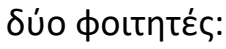

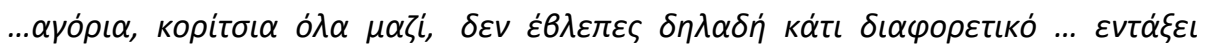

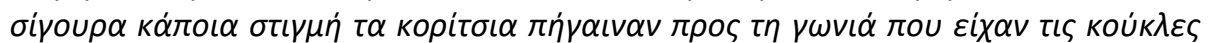

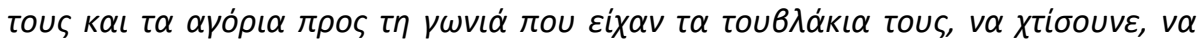

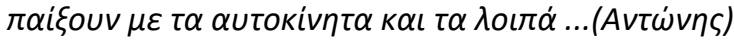

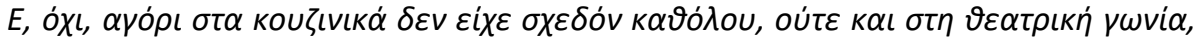

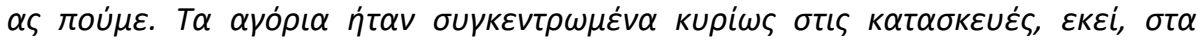

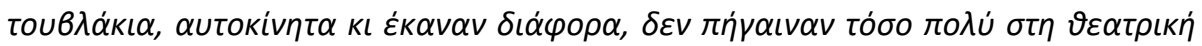

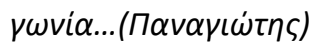

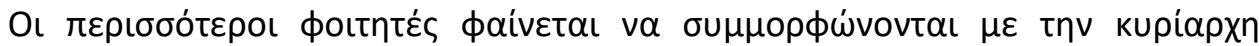

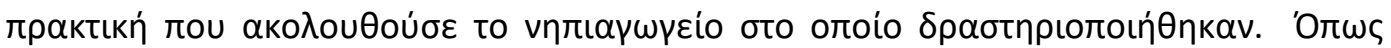

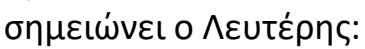

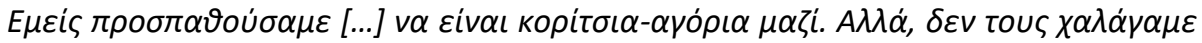

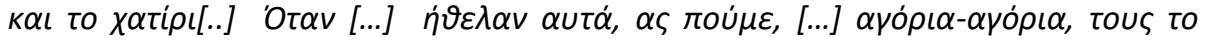

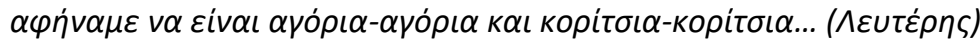

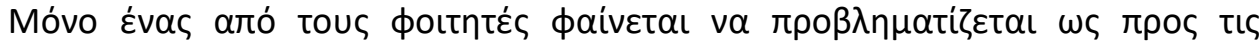

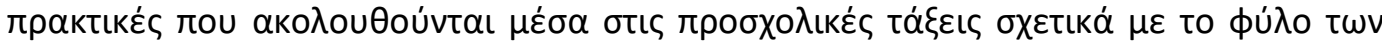

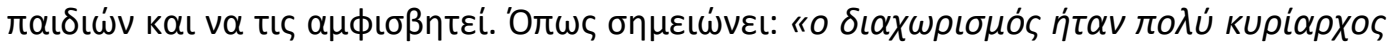

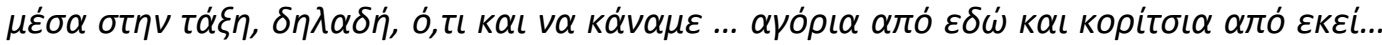

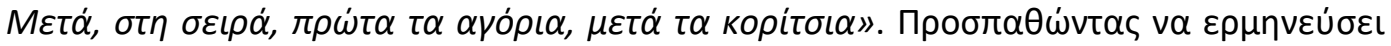

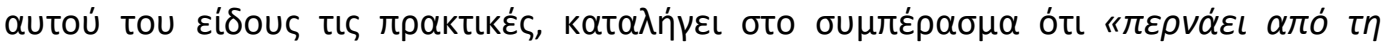

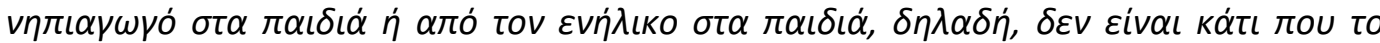

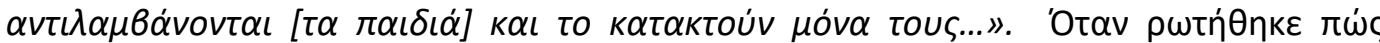

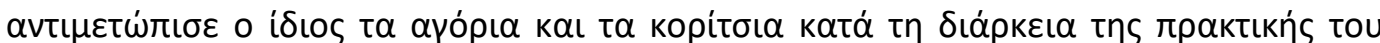

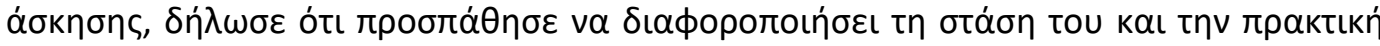

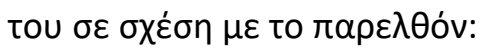

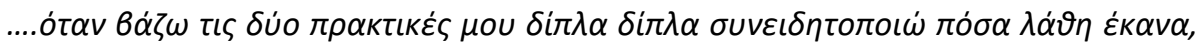

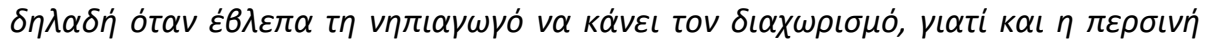

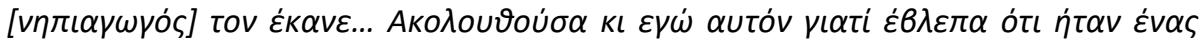

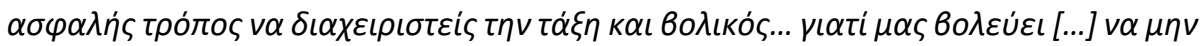

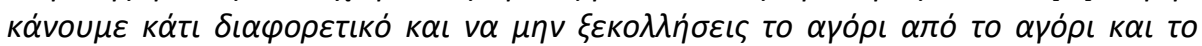

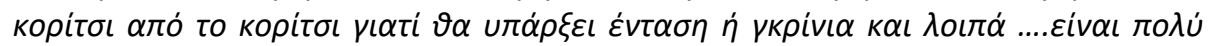

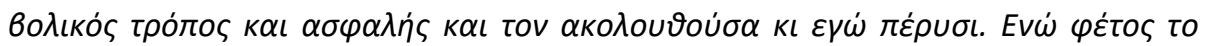

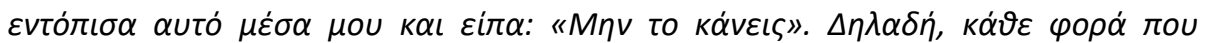

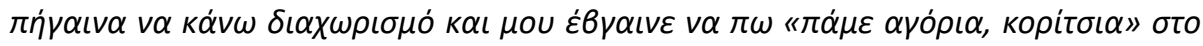

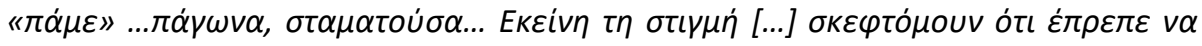

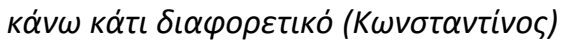

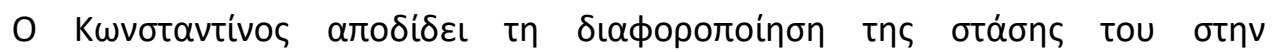

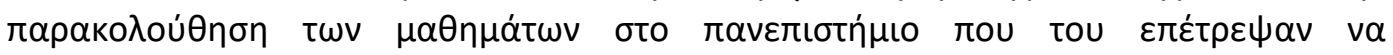




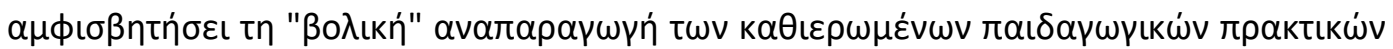

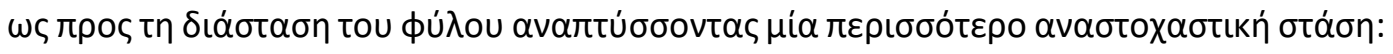

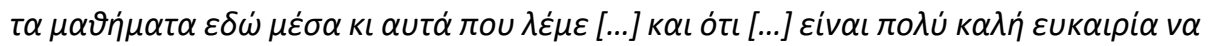

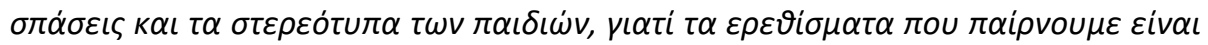

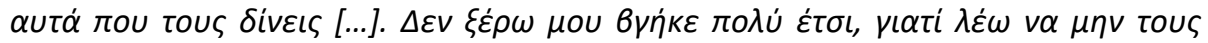

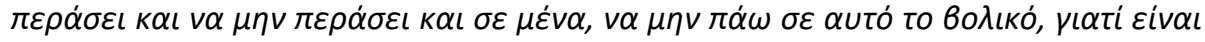

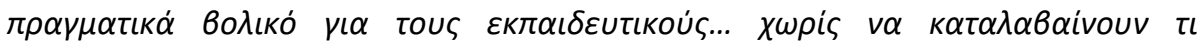

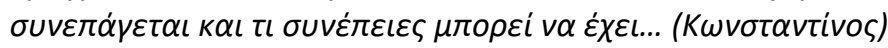

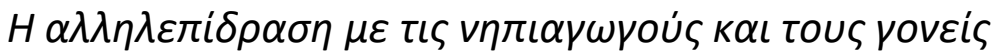

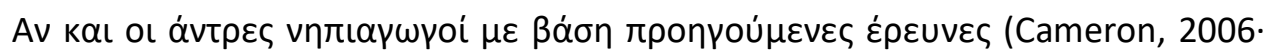
Farquhar, 1997· Rentzou, 2011· Rentzou \& Zigantidou, 2009· Sumsion, 2000a) cívaı үevıkó

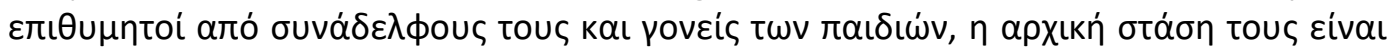

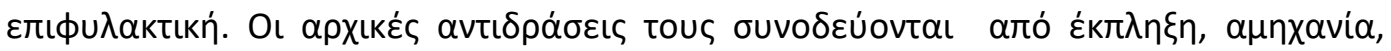

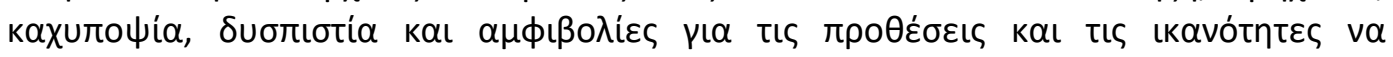

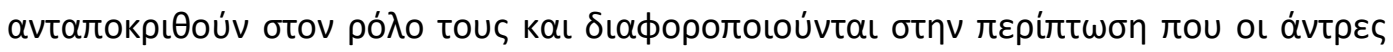

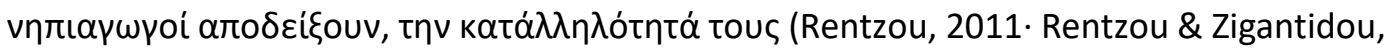

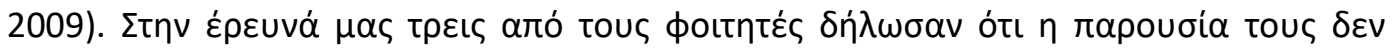

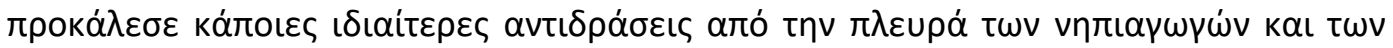

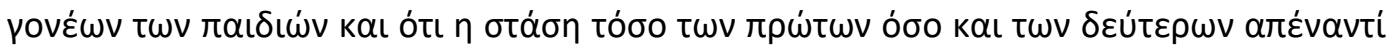

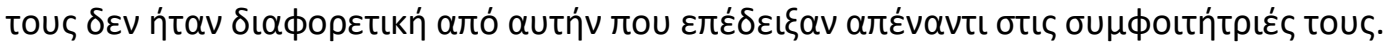

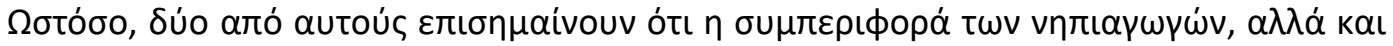

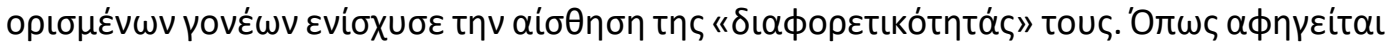

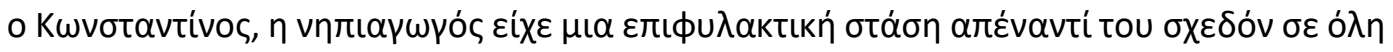

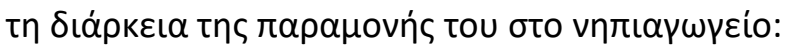

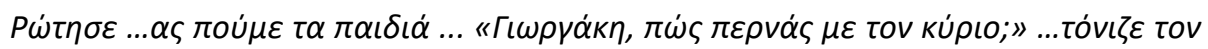

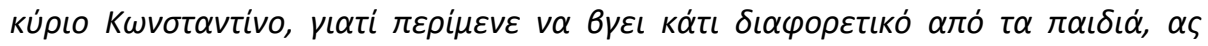

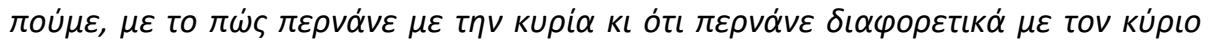

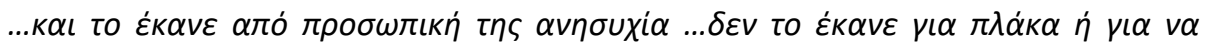

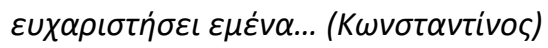

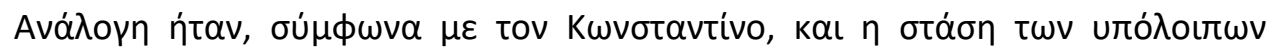

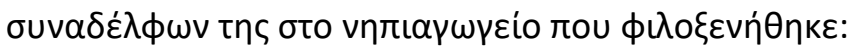

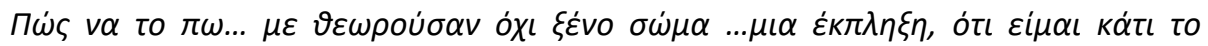

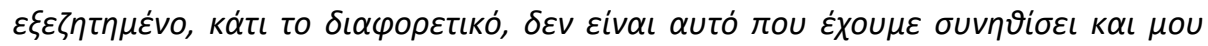

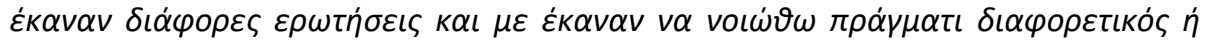

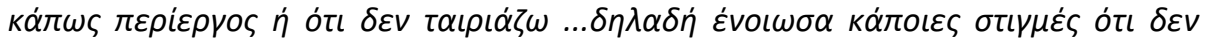

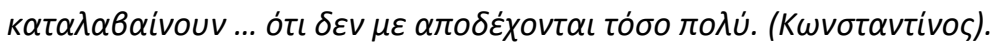

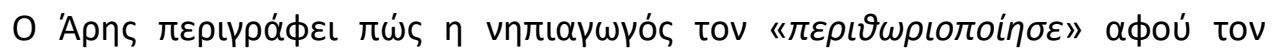

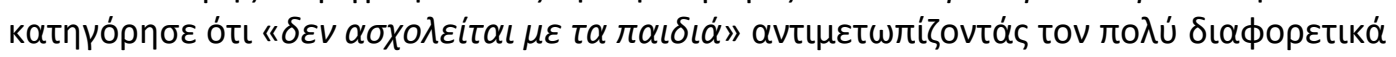

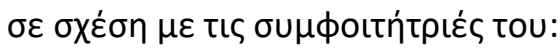

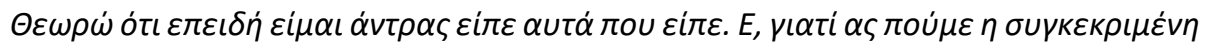

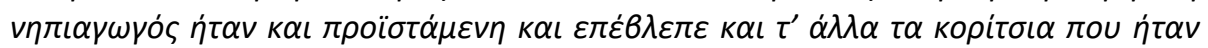

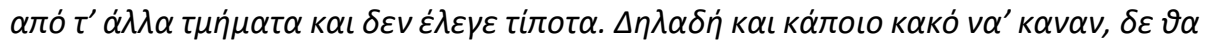

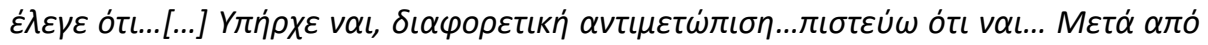

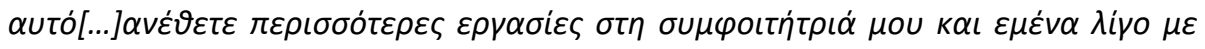

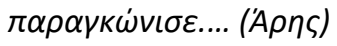




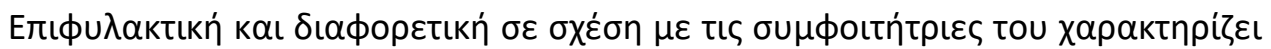

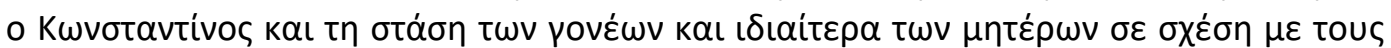

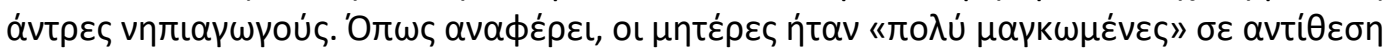

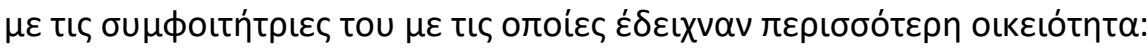

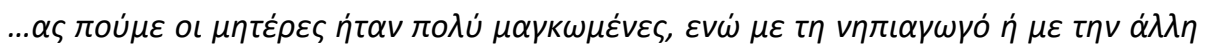

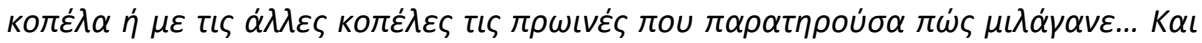

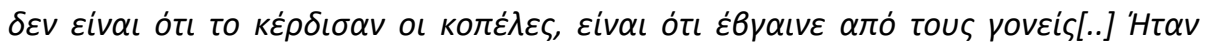

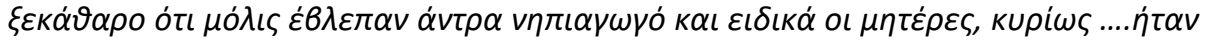

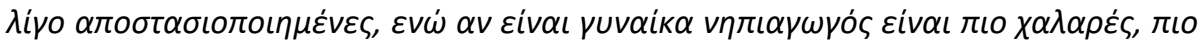

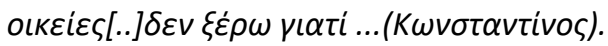

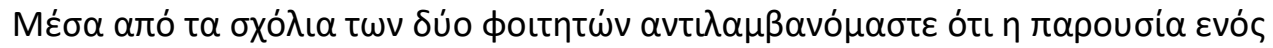

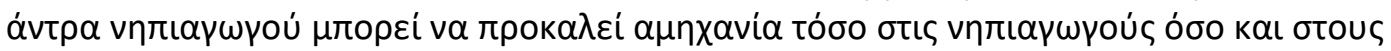

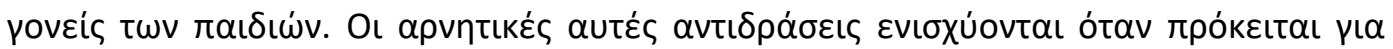

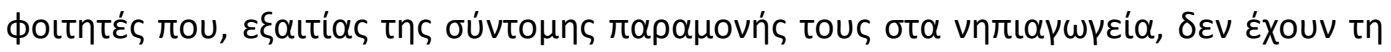

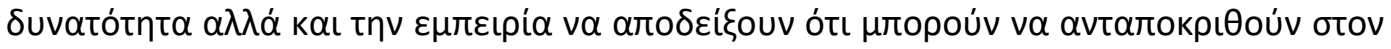

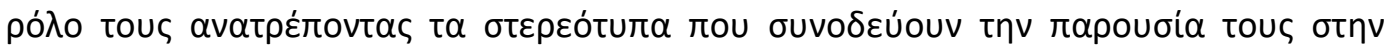

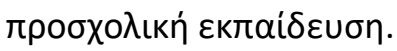

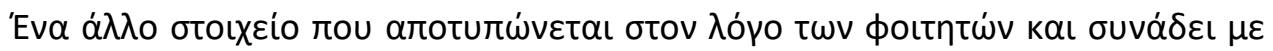

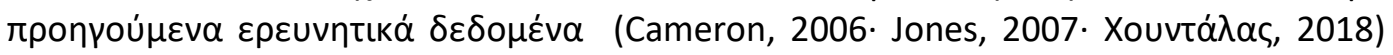

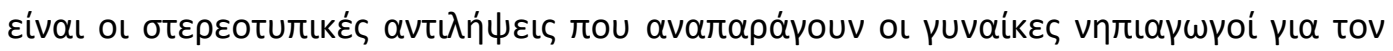

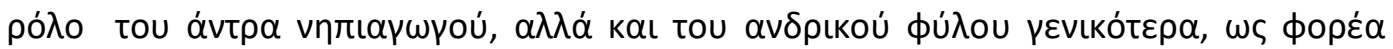

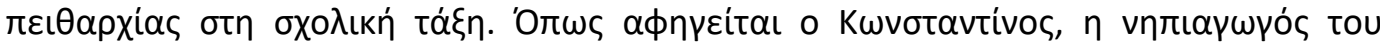

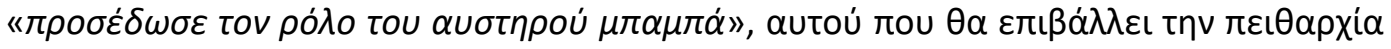

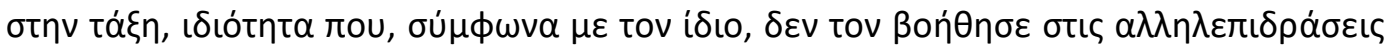

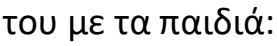

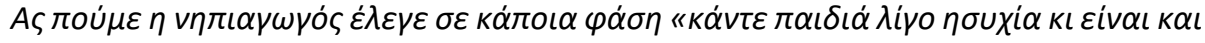

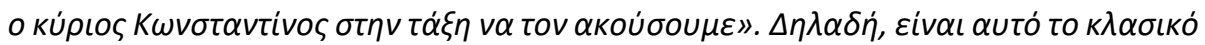

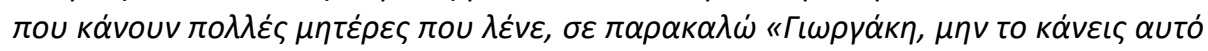

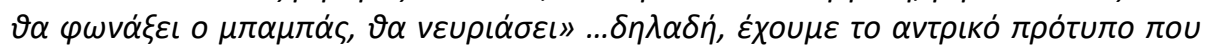

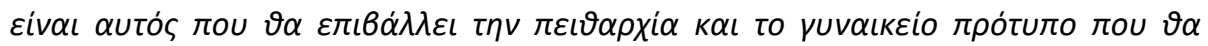

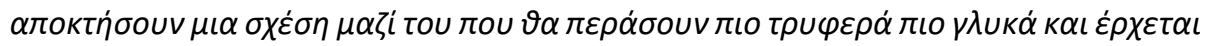

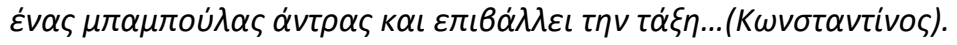

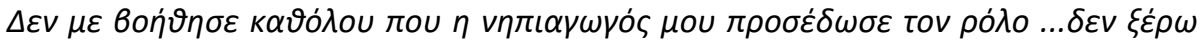

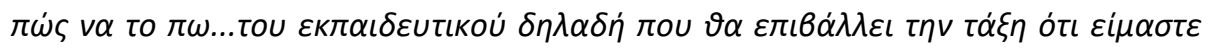

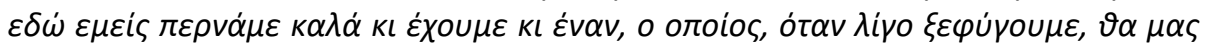

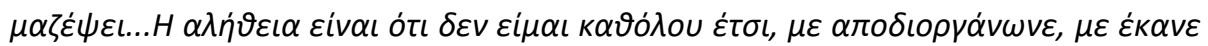

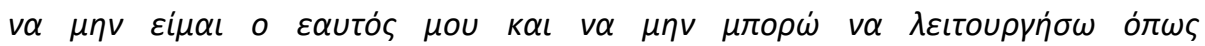

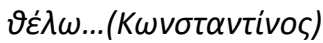

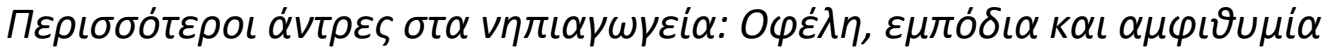

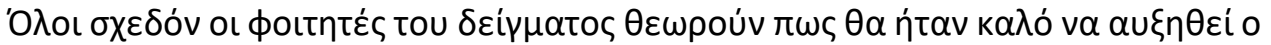

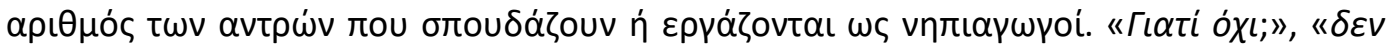

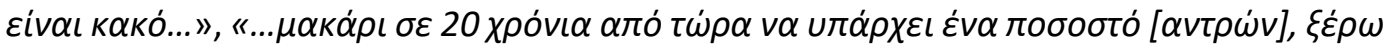

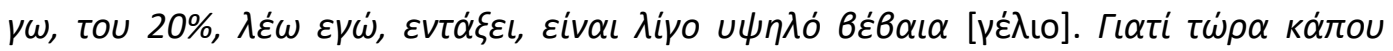

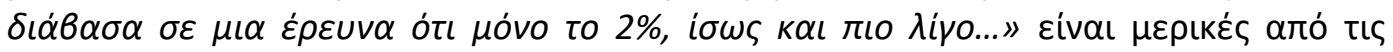

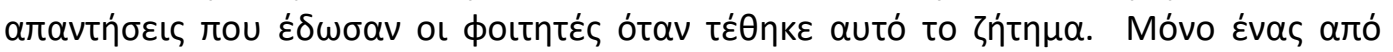




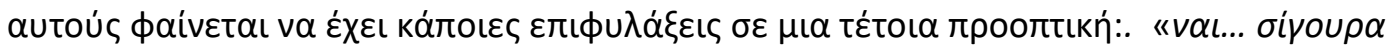

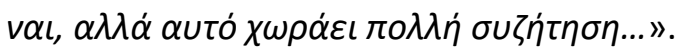

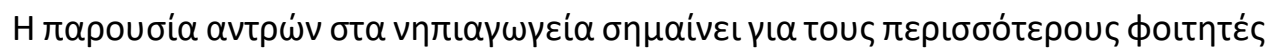

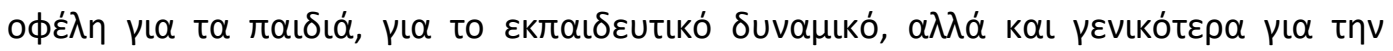

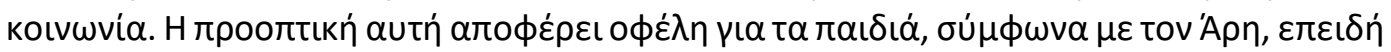

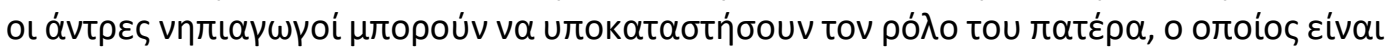

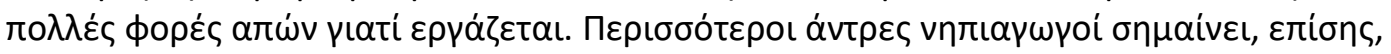

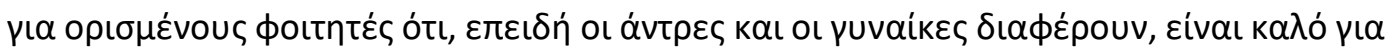

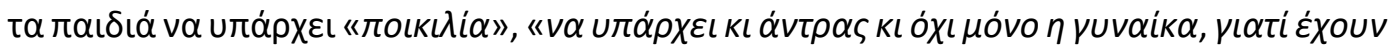

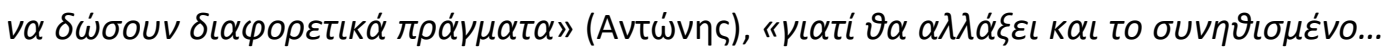

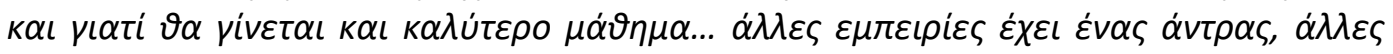

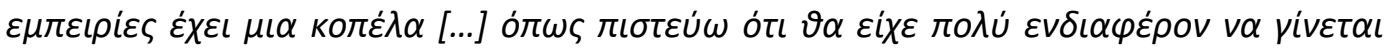

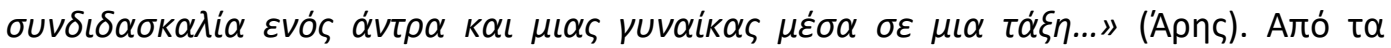

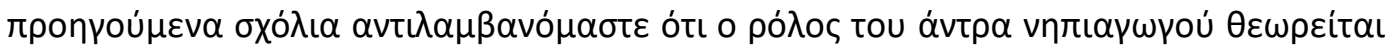

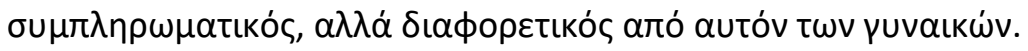

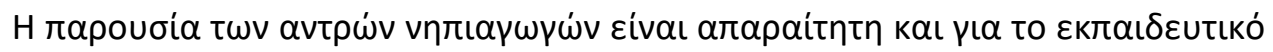

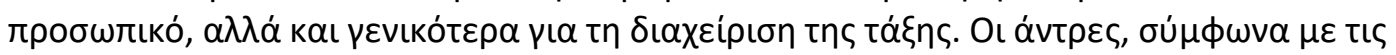

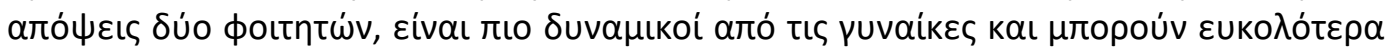

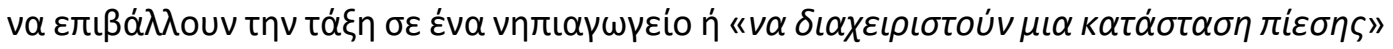

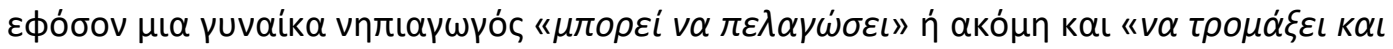

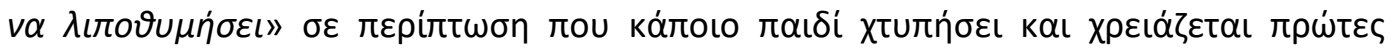

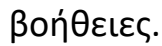

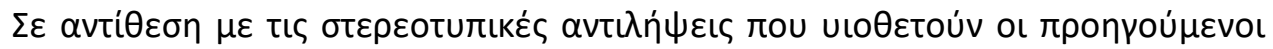

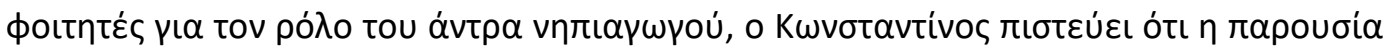

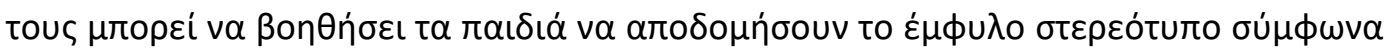

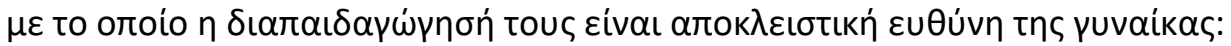

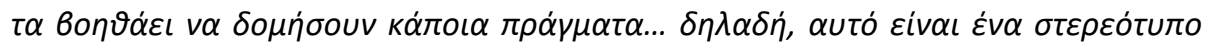

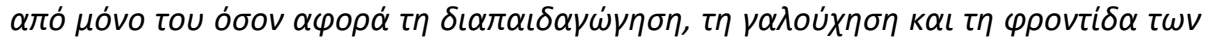

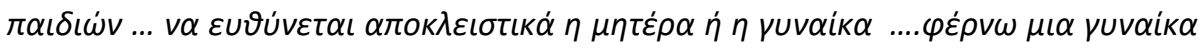

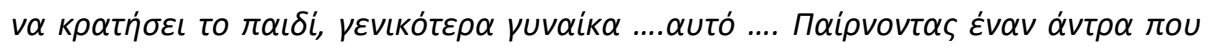

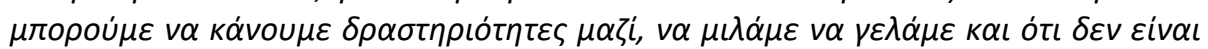

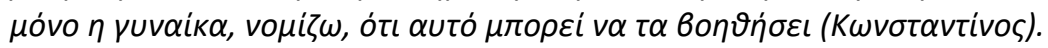

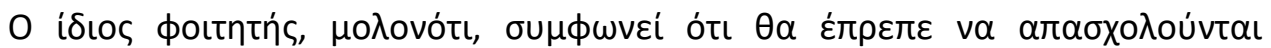

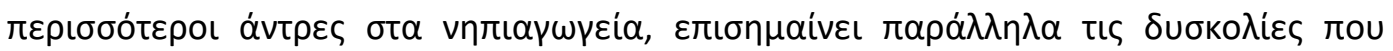

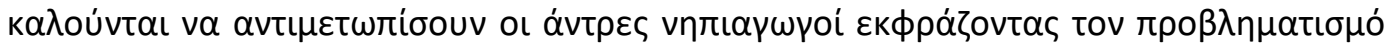

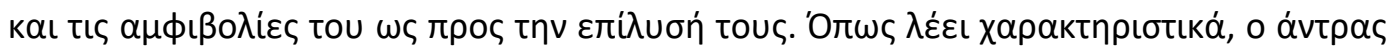

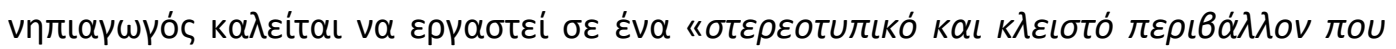

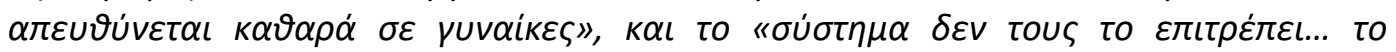

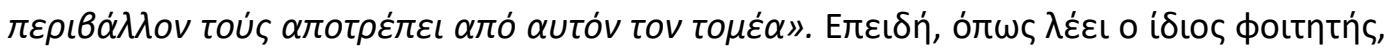

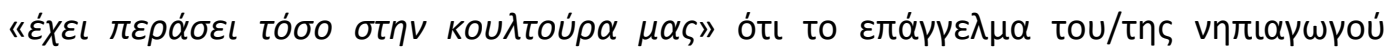

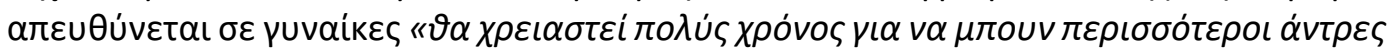

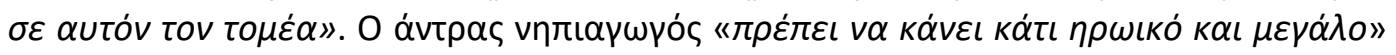

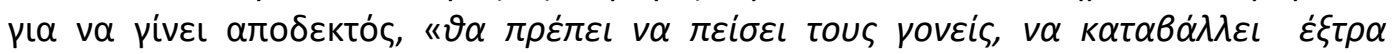

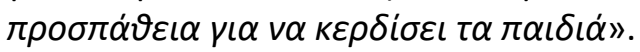




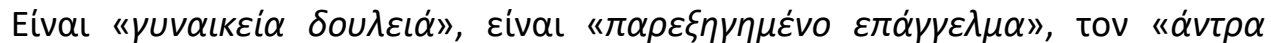

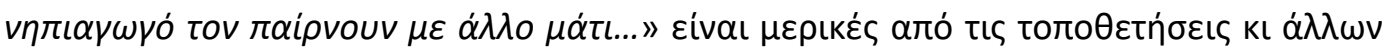

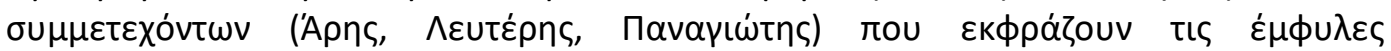

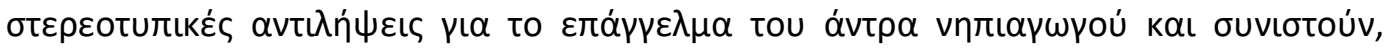

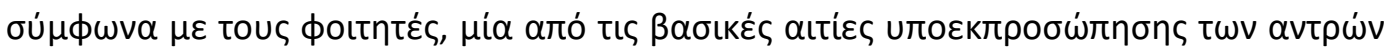

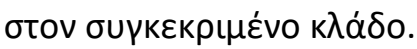

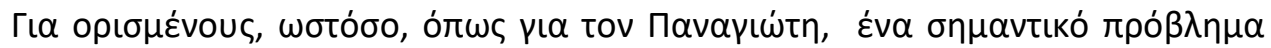

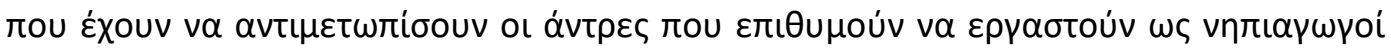

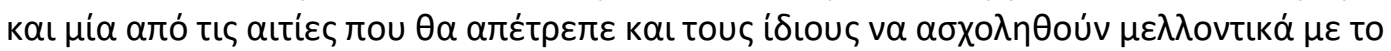

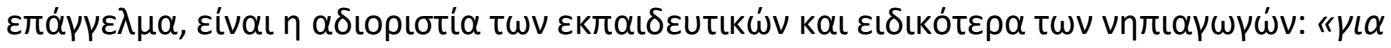

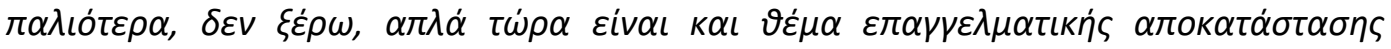

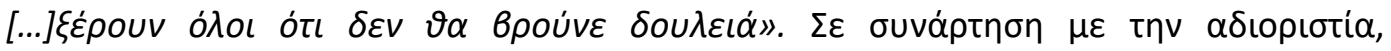

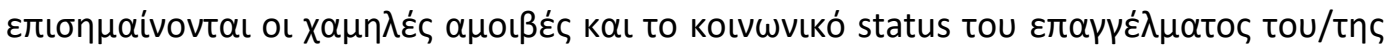

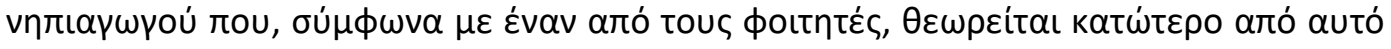

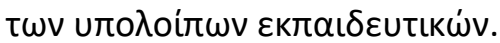

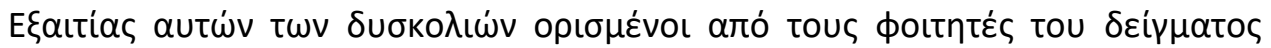

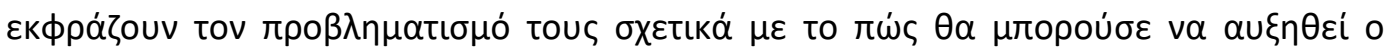

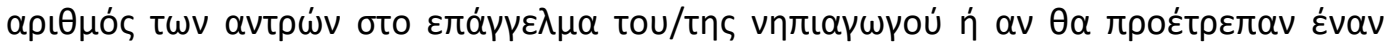

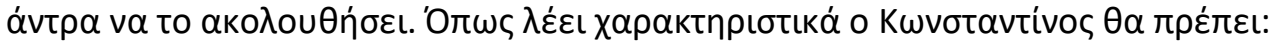

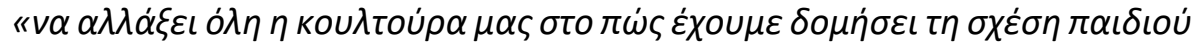

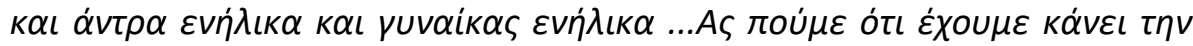

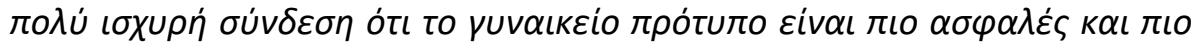

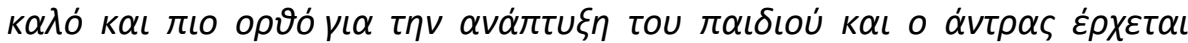

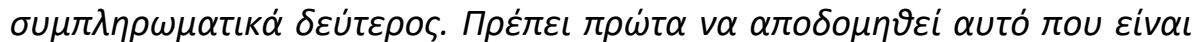

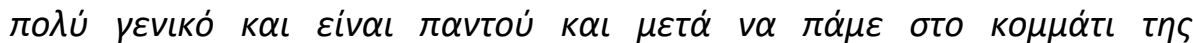

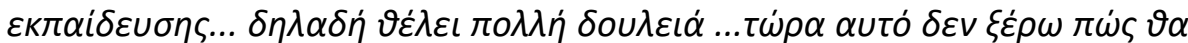

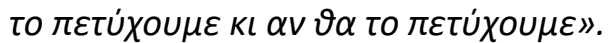

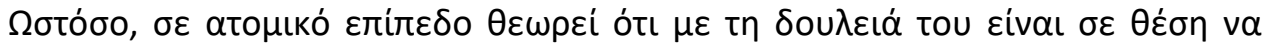

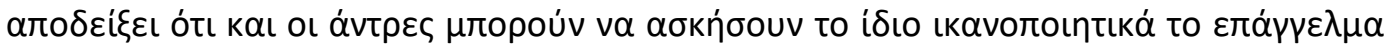

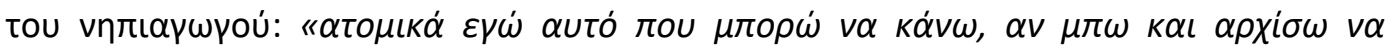

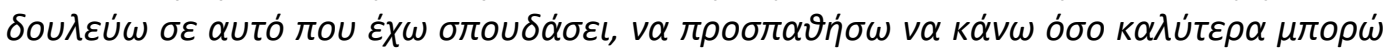

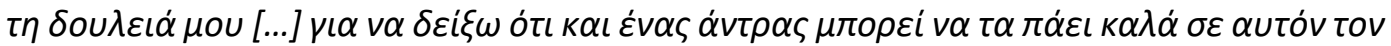

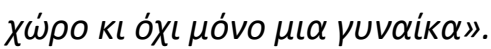

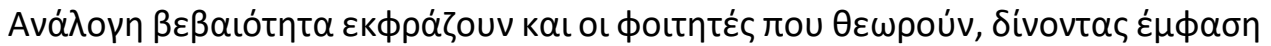

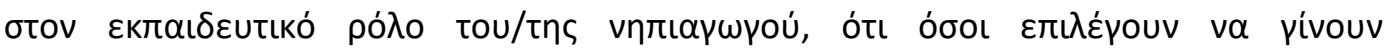

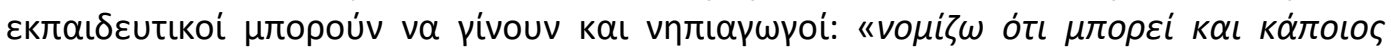

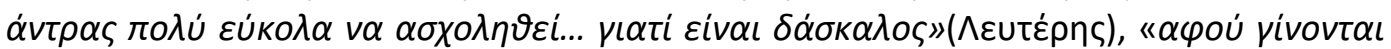

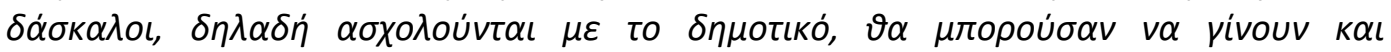

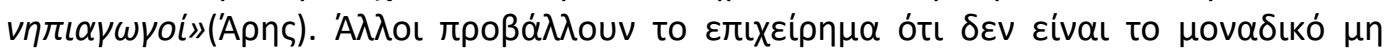

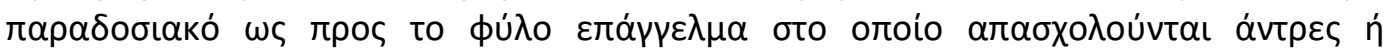

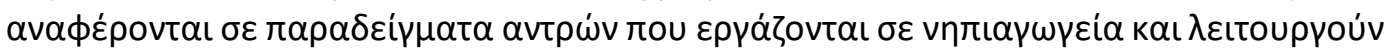

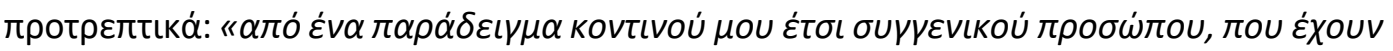

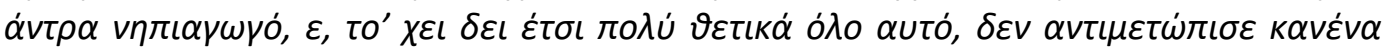

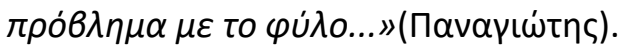




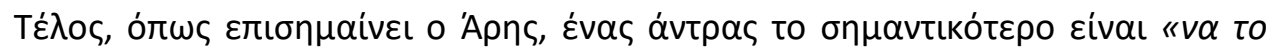

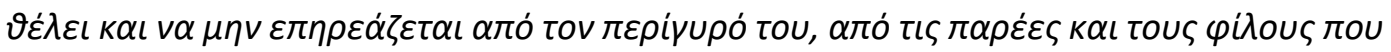

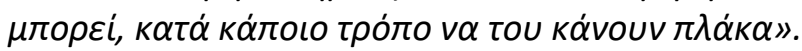

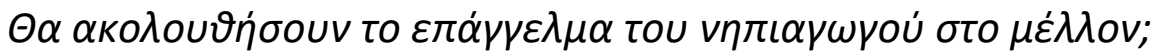

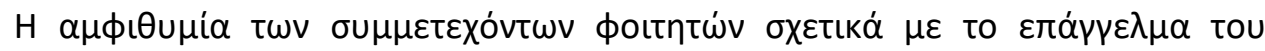

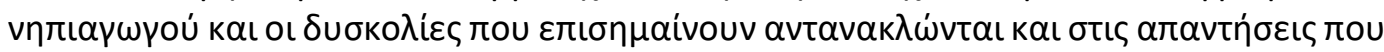

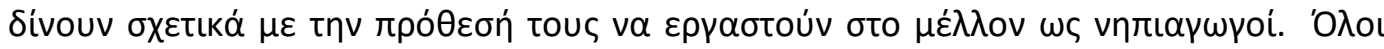

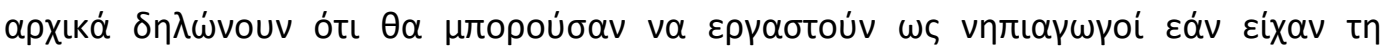

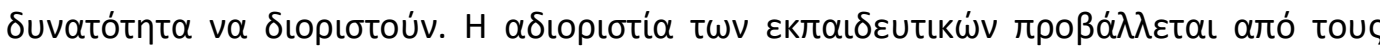

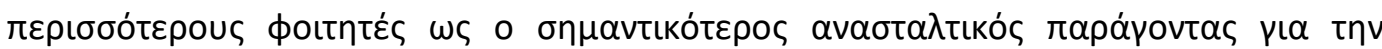

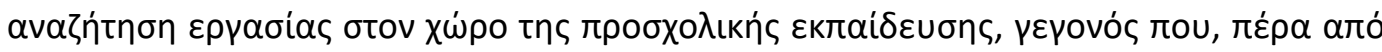

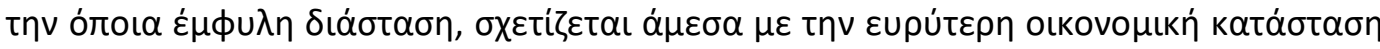

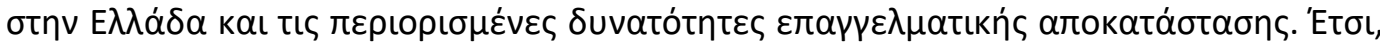

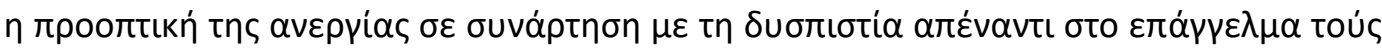

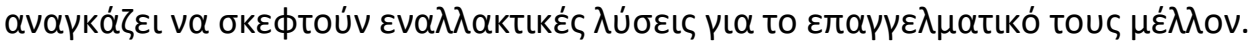

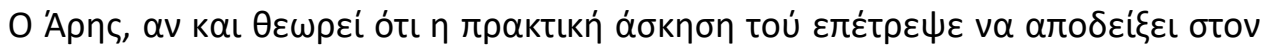

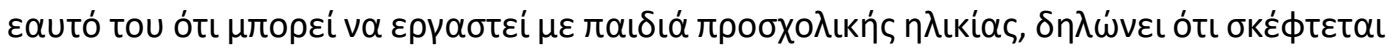

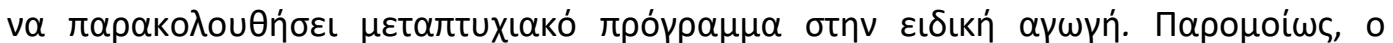

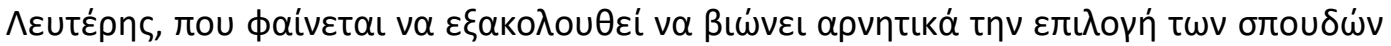

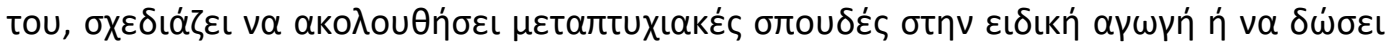

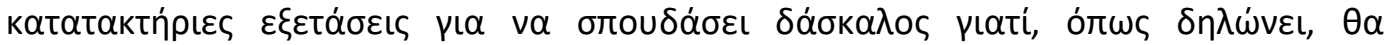

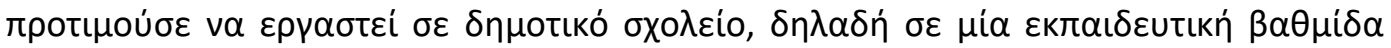

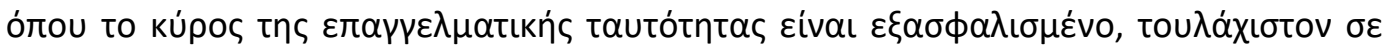

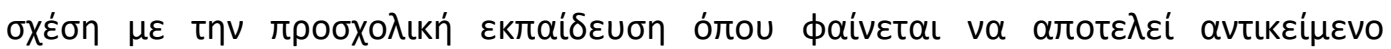

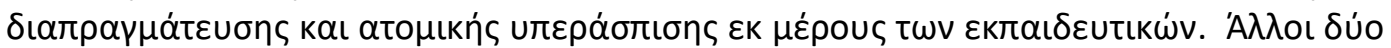

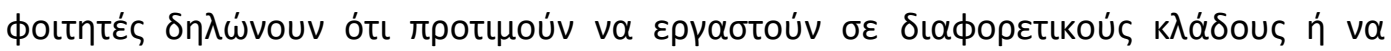

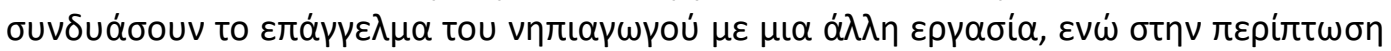

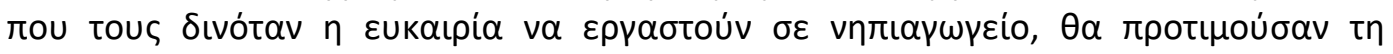

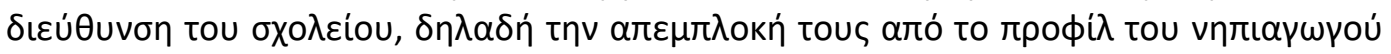

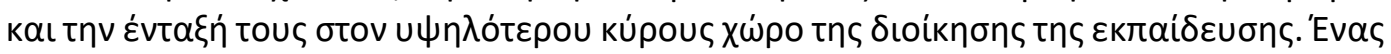

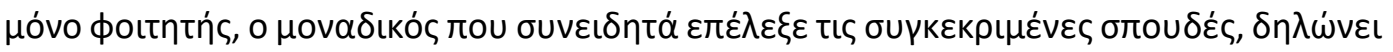

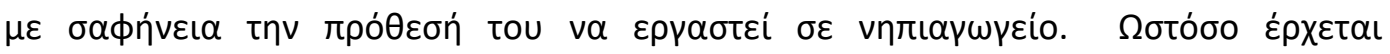

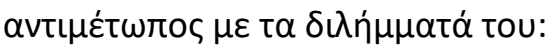

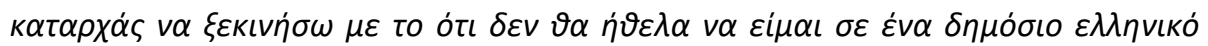

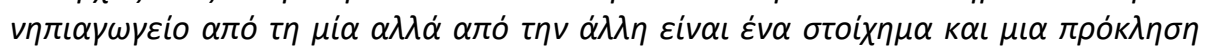

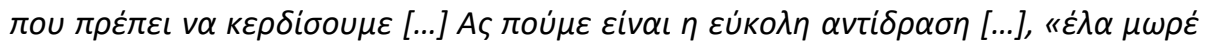

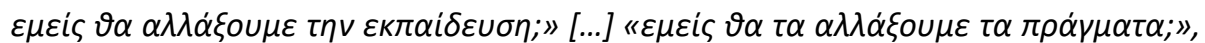

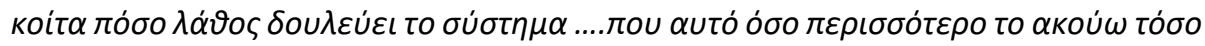

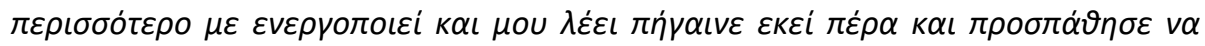

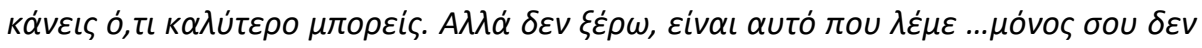

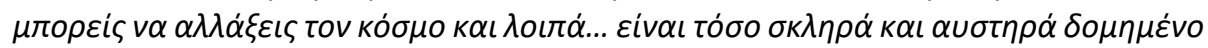

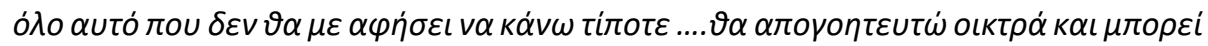

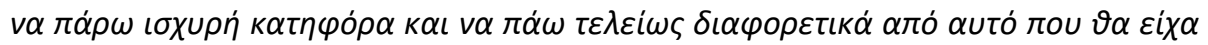

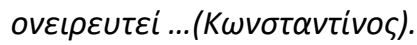

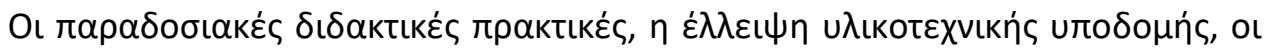

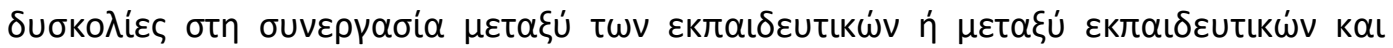




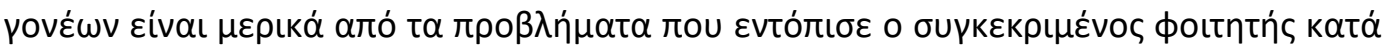

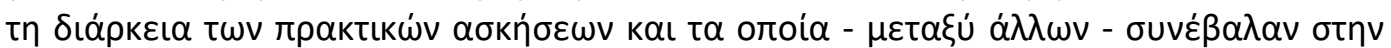

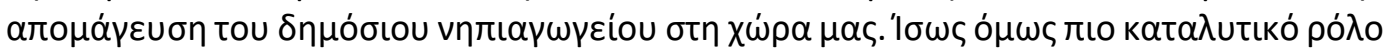

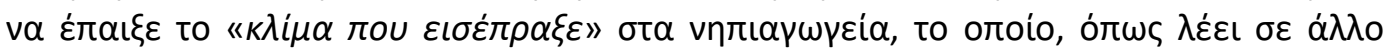

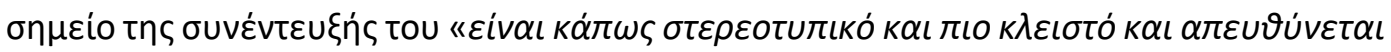

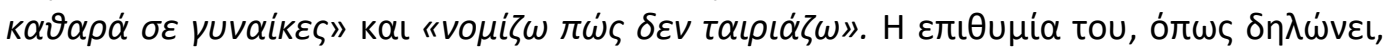

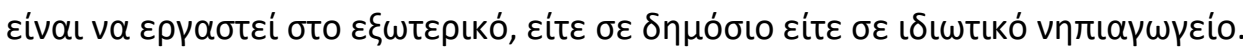

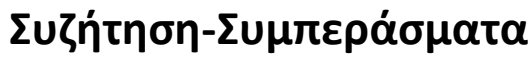

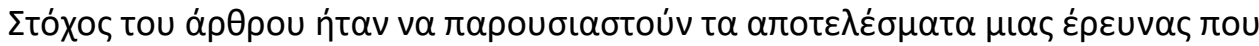

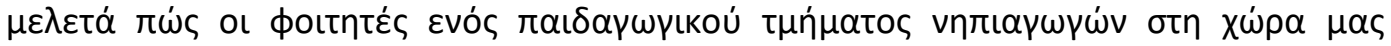

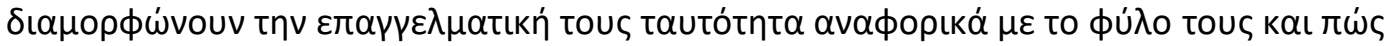

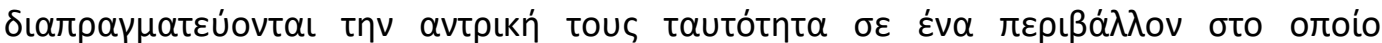

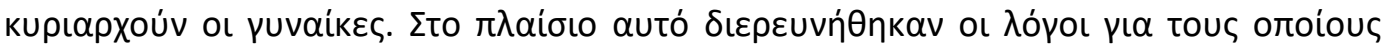

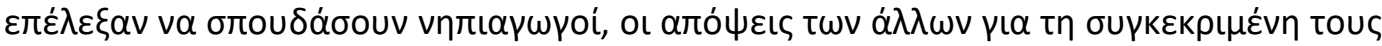

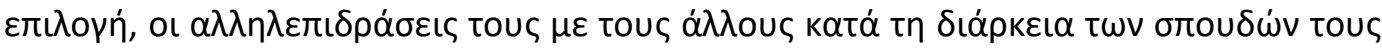

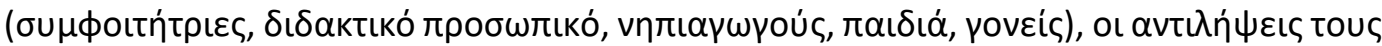

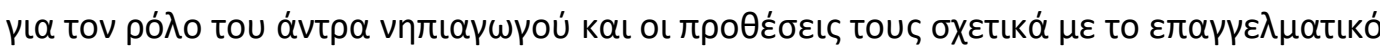

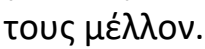

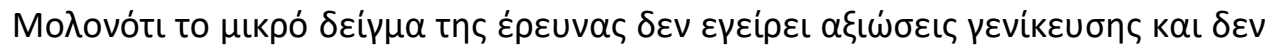

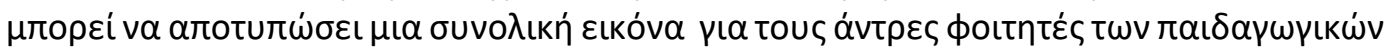

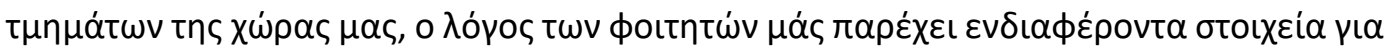

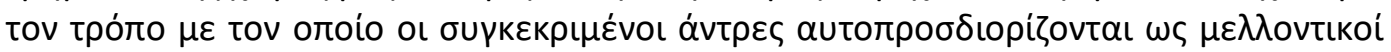

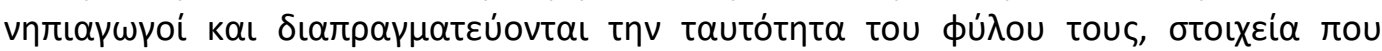

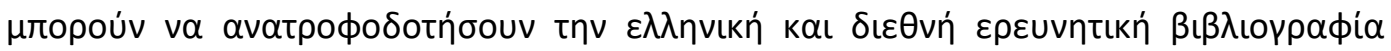

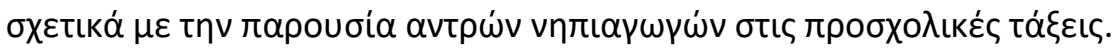

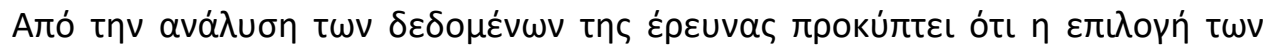

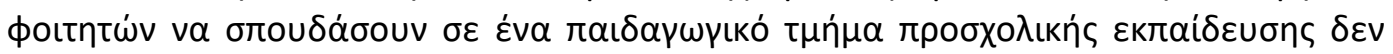

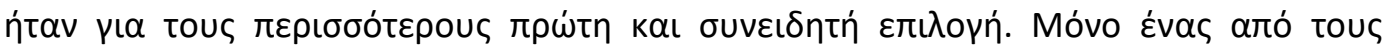

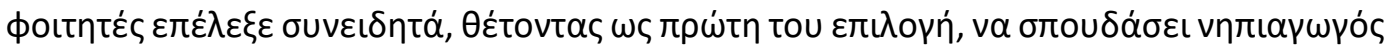

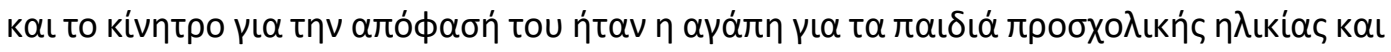

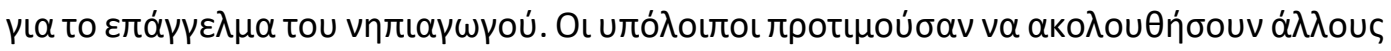

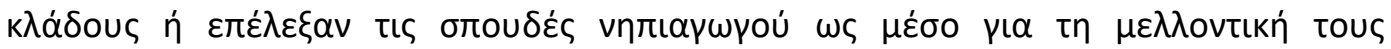

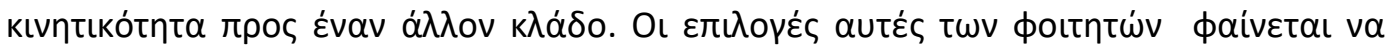

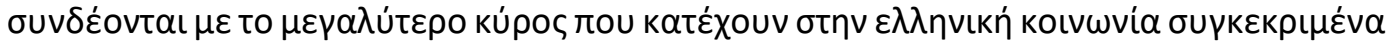

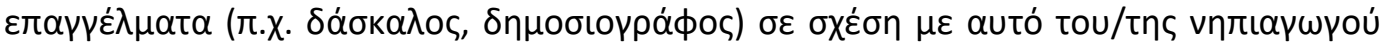

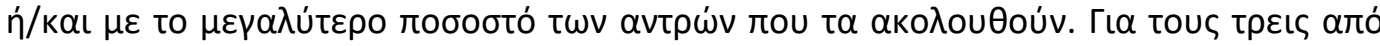

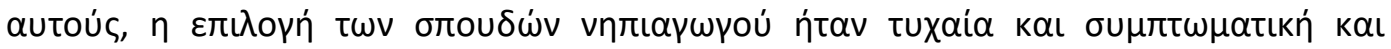

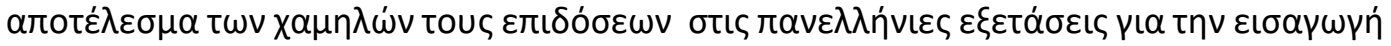
touৎ $\sigma \tau \alpha \mathrm{AEI}$.

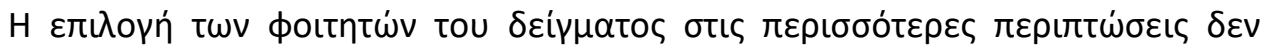

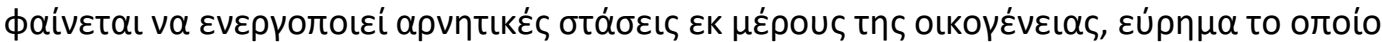

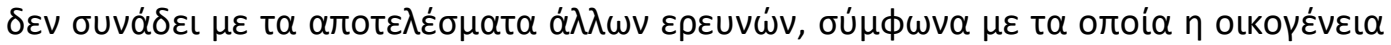

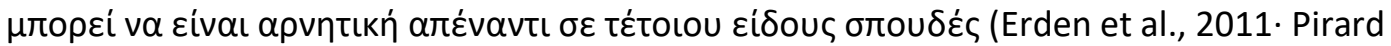

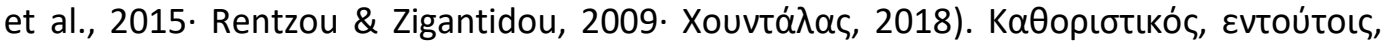




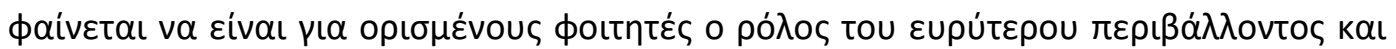

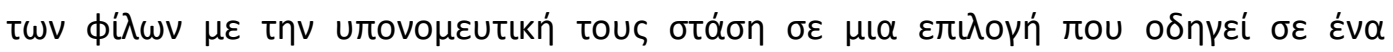

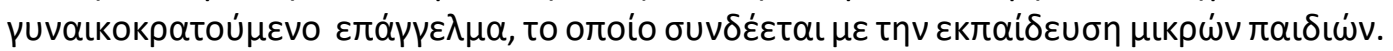

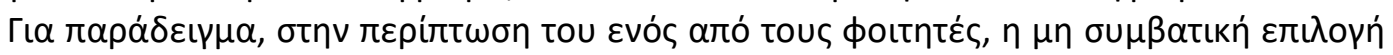

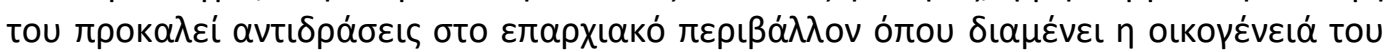

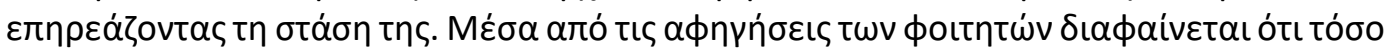

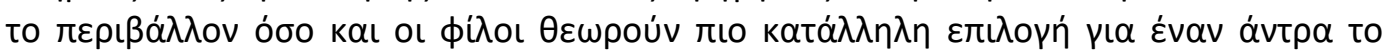

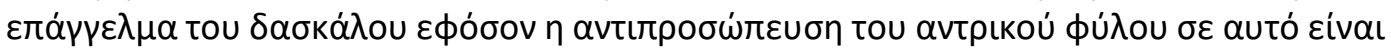

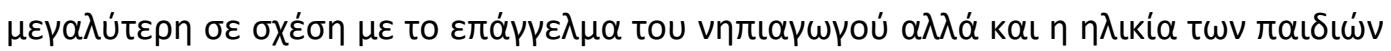

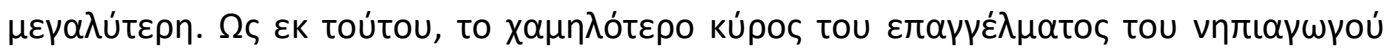

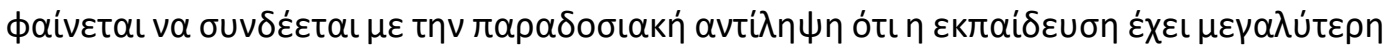

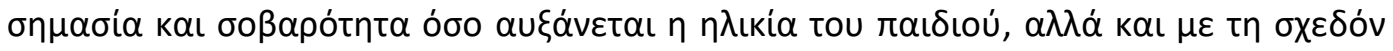

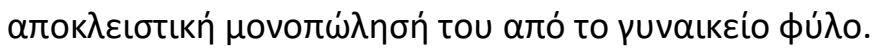

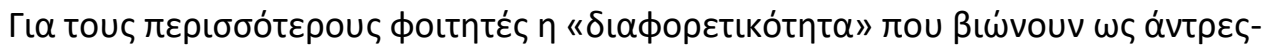

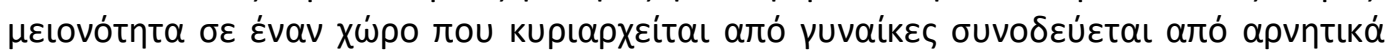

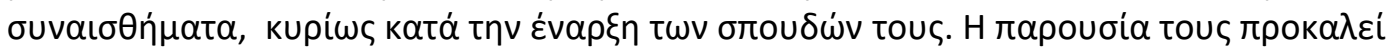

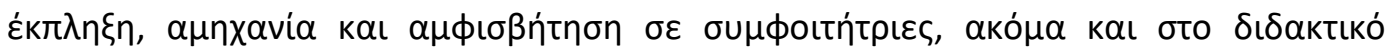

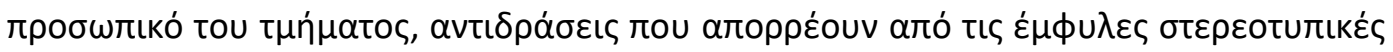

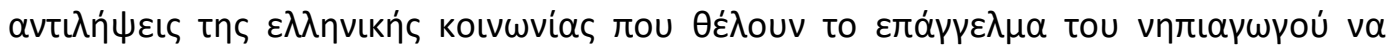

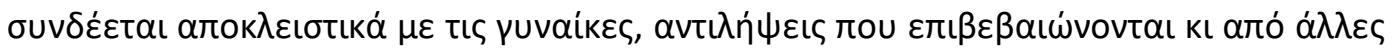

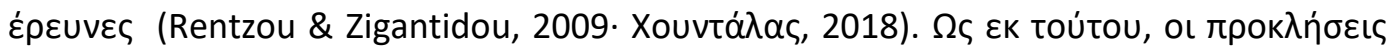

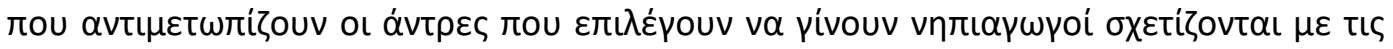

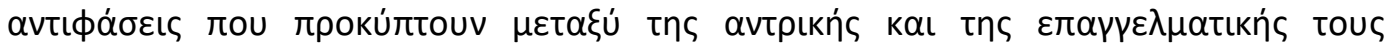

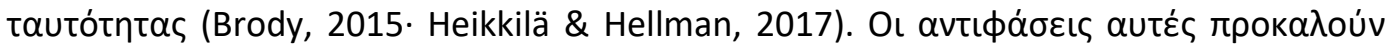

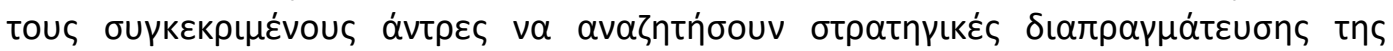

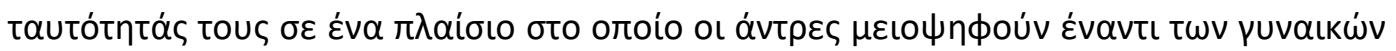

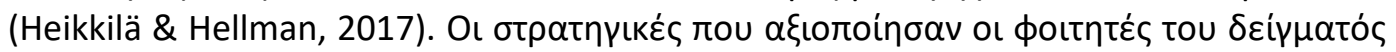

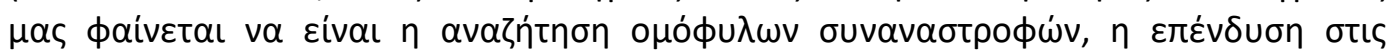

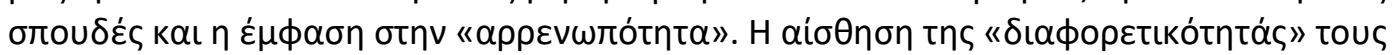

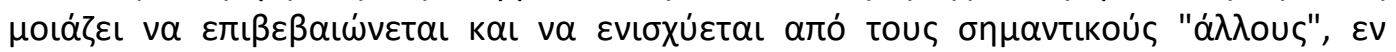

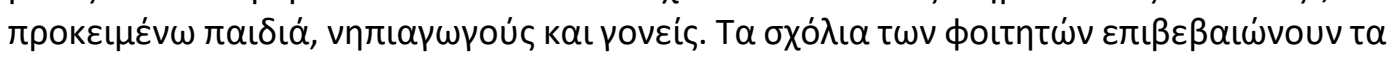

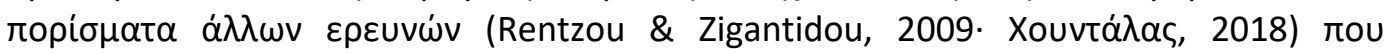

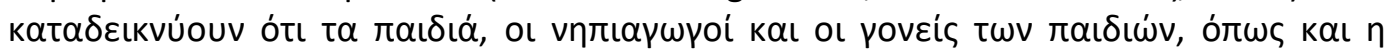

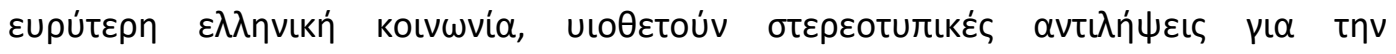

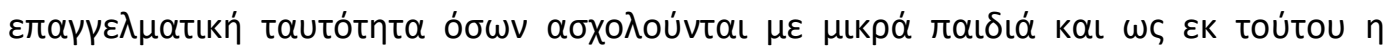

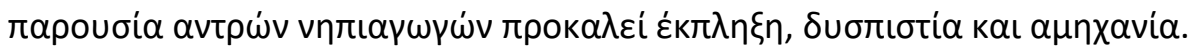

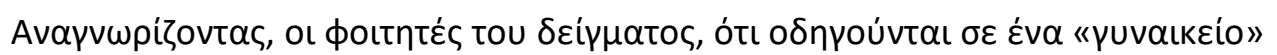

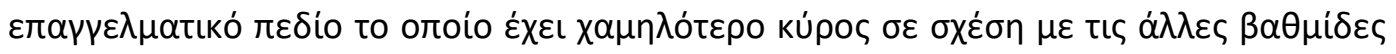

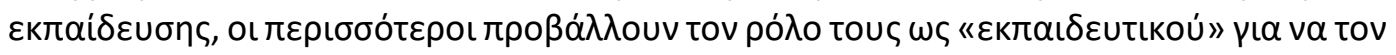

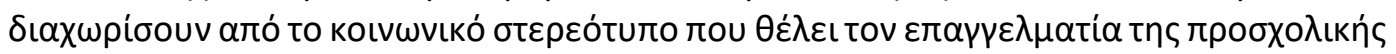

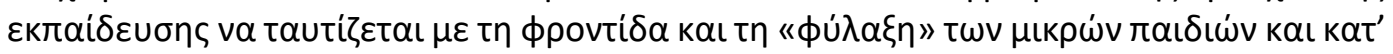

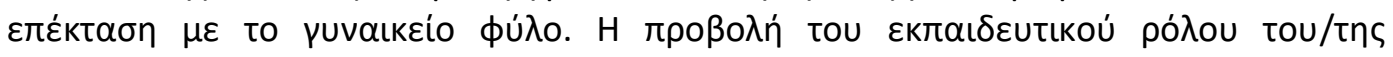

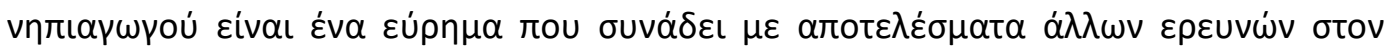

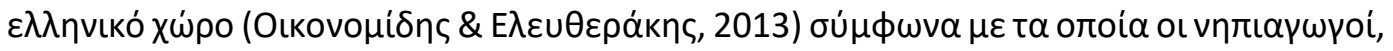

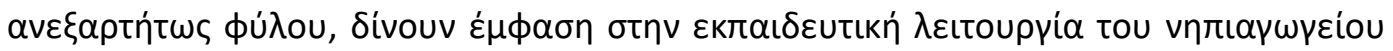

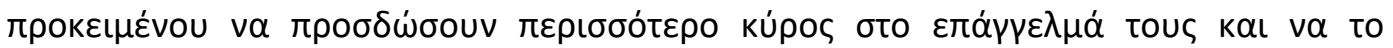

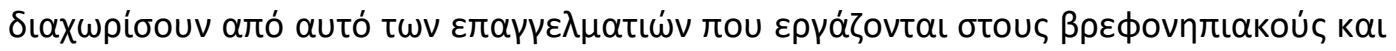




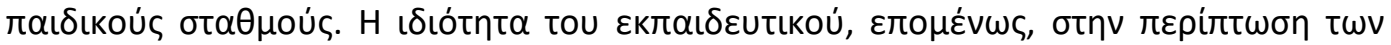

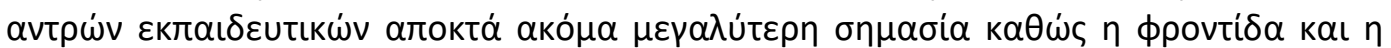

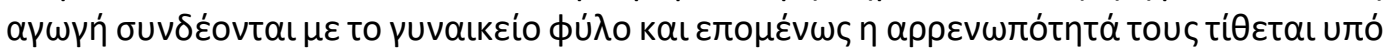

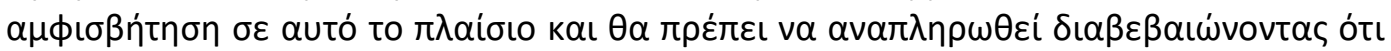

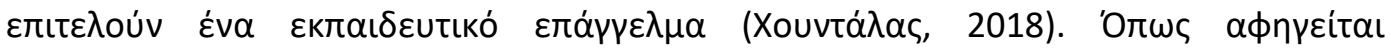

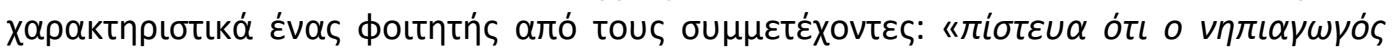

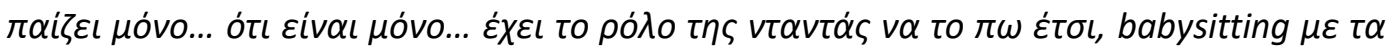

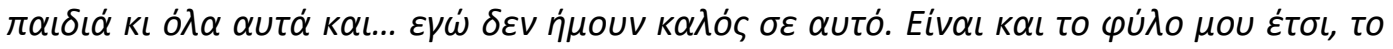

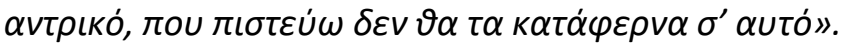

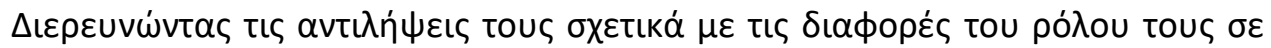

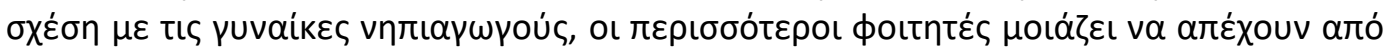

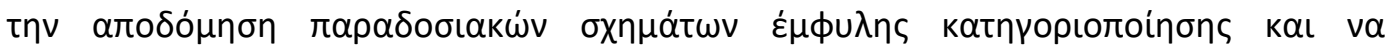

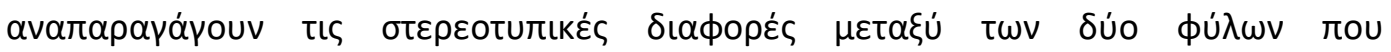

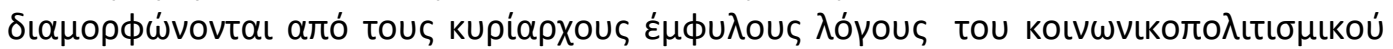

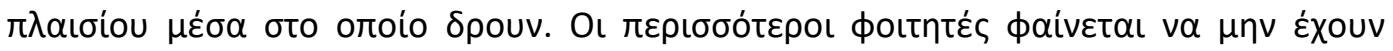

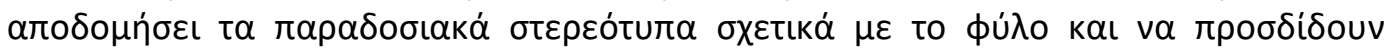

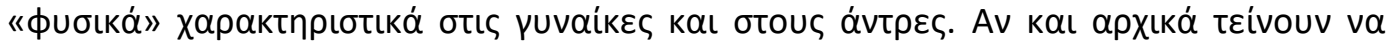

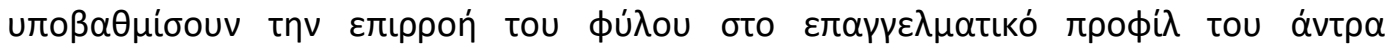

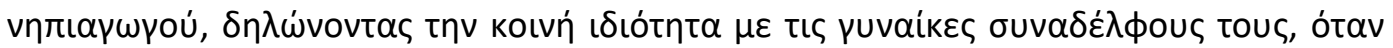

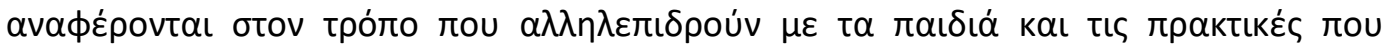

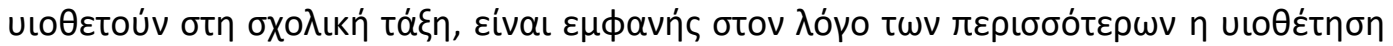

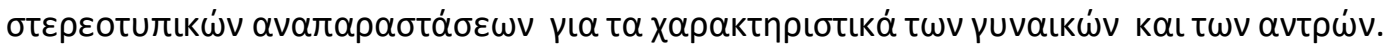

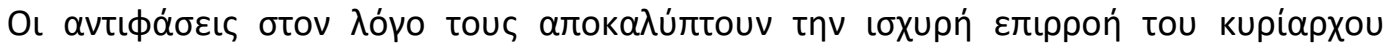

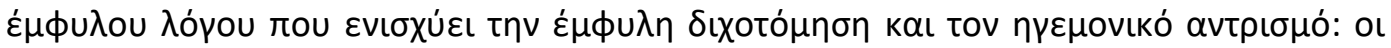

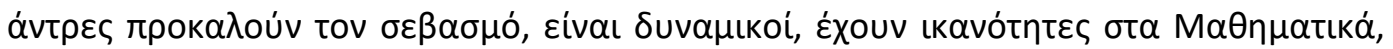

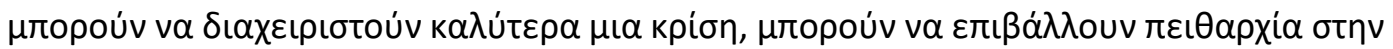

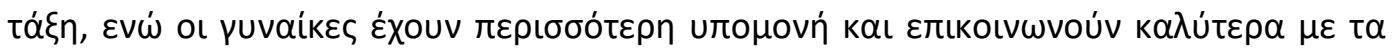

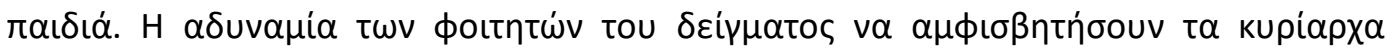

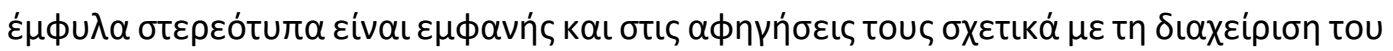

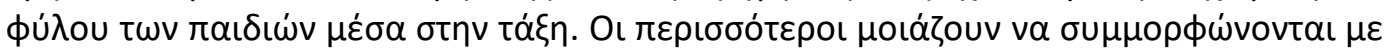

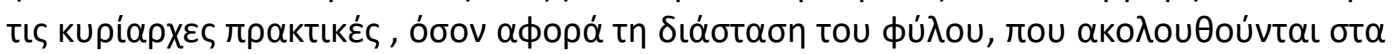

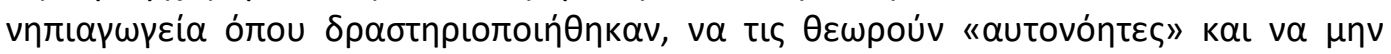

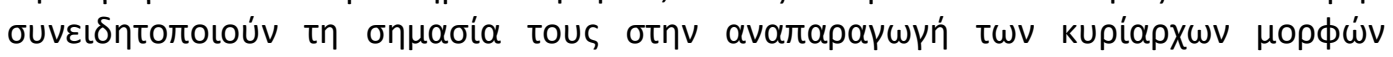

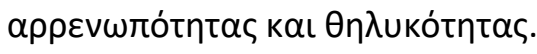

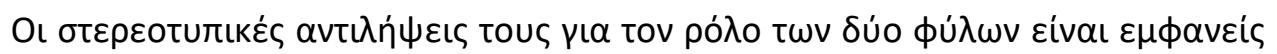

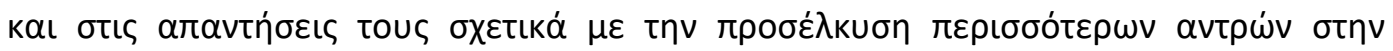

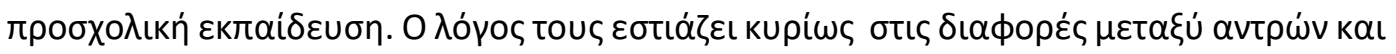

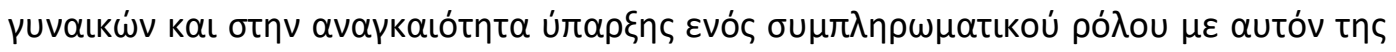

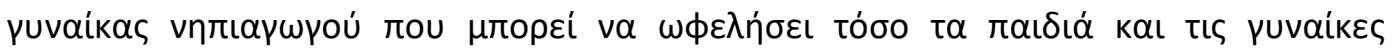

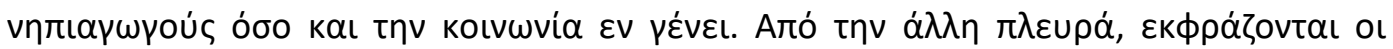

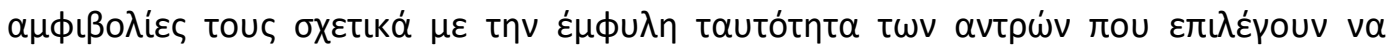

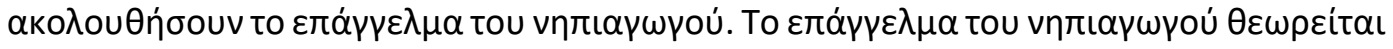

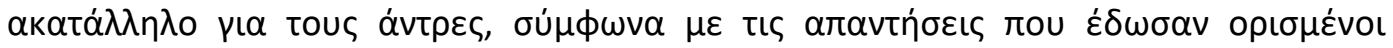

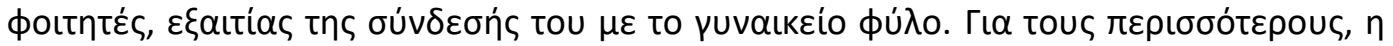

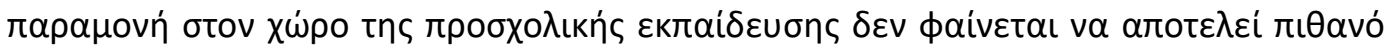

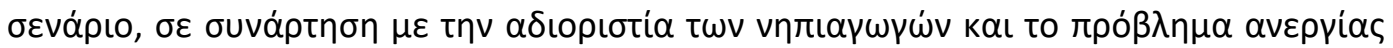

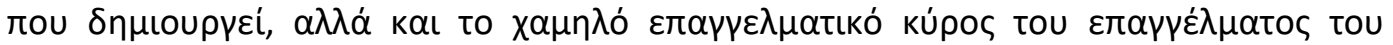




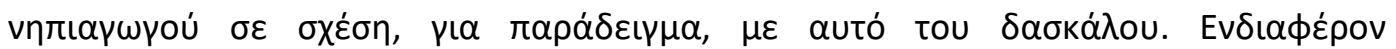

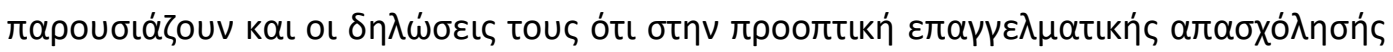

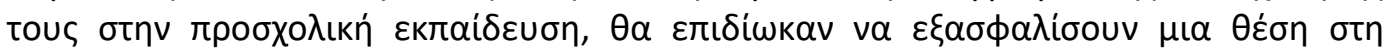

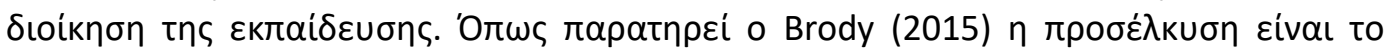

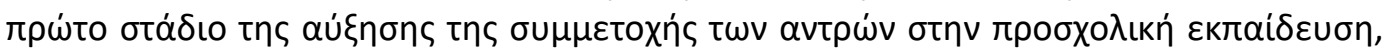

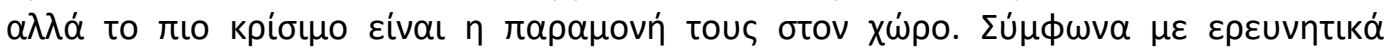

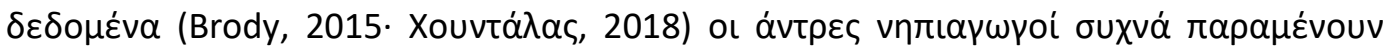

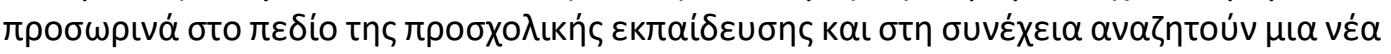

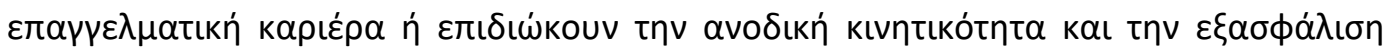
Ө

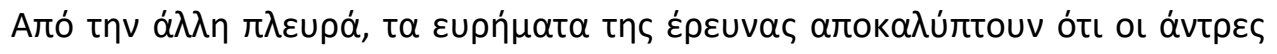

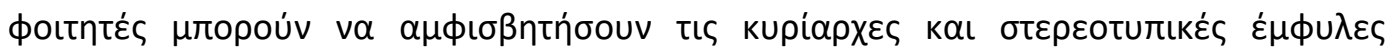

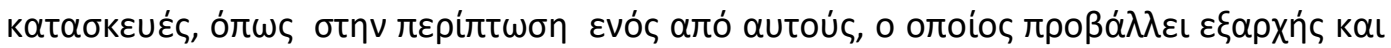

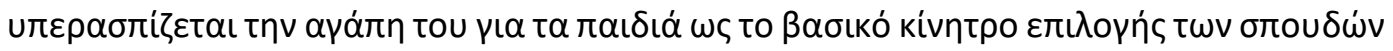

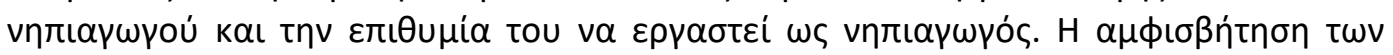

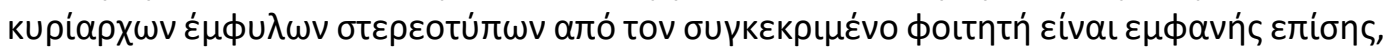

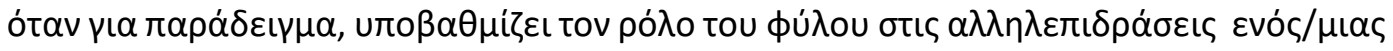

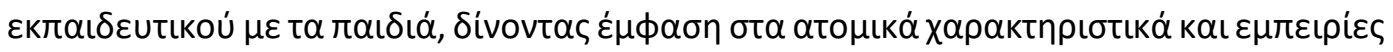

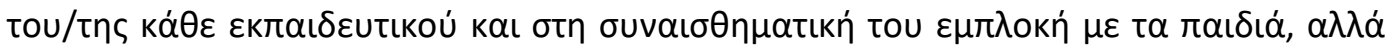

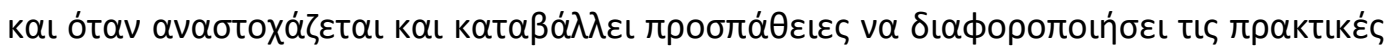

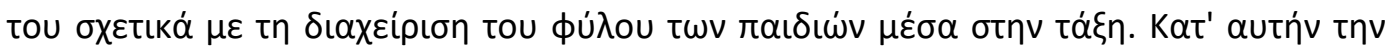

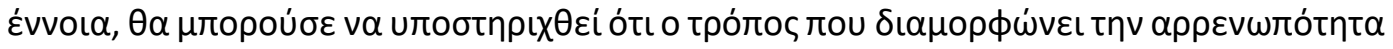

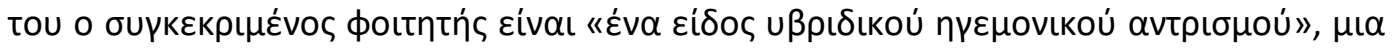

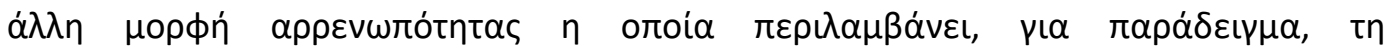

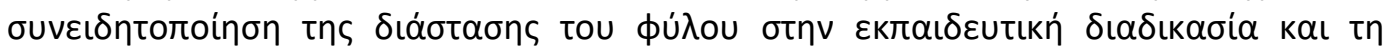

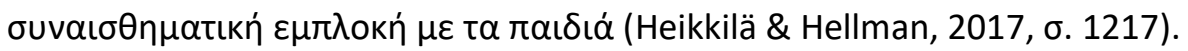

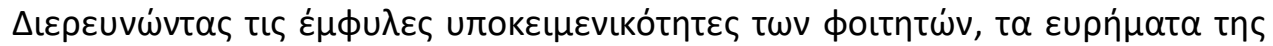

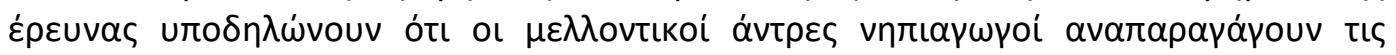

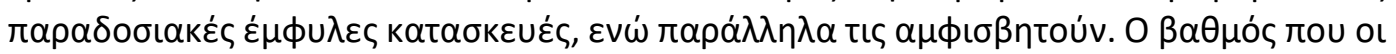

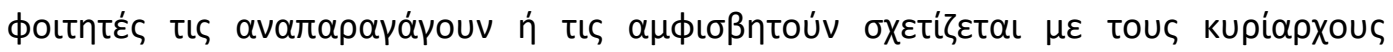

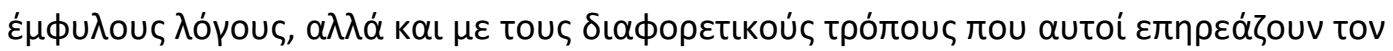

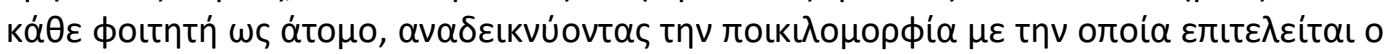

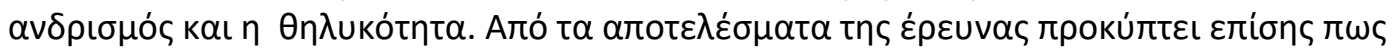

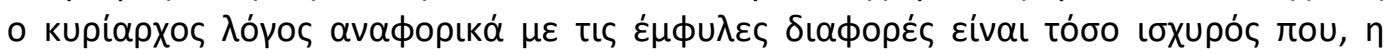

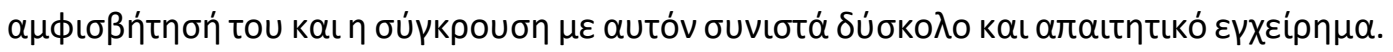

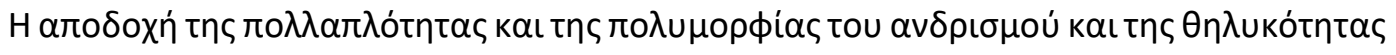

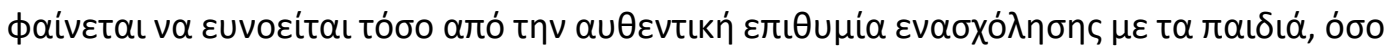

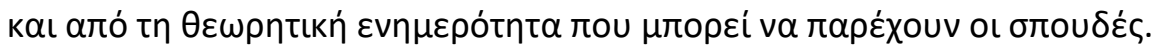

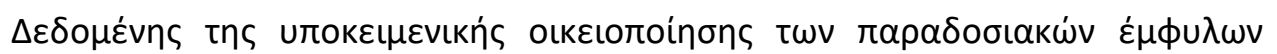

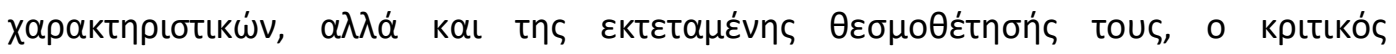

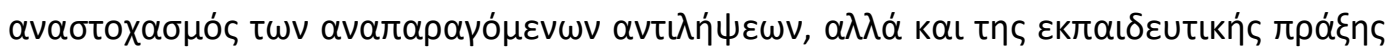

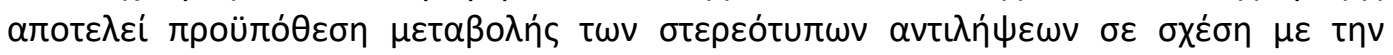

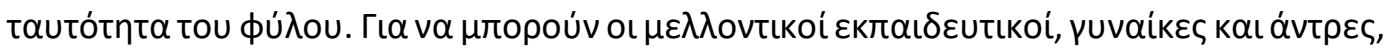

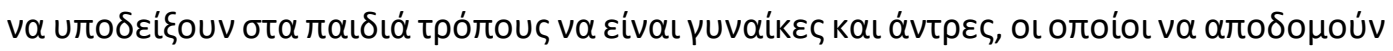

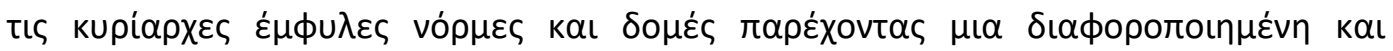

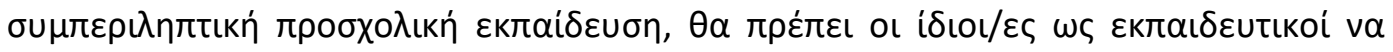




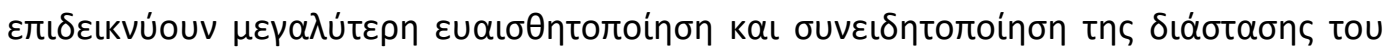

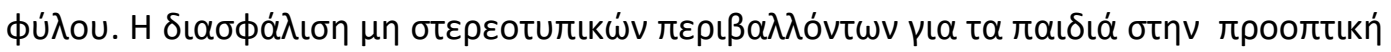

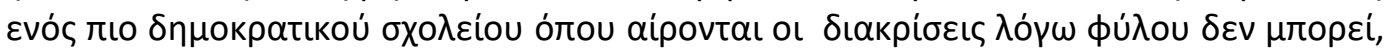

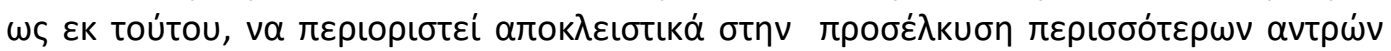

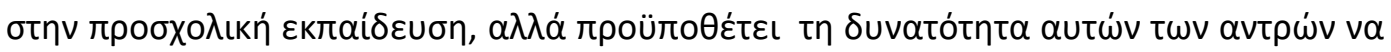

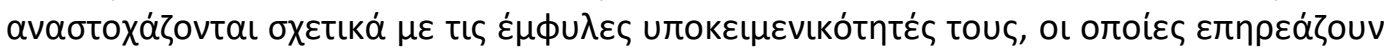

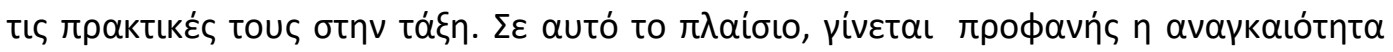

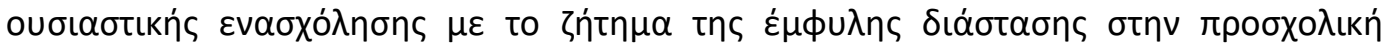

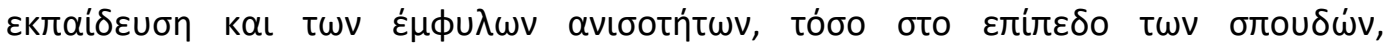

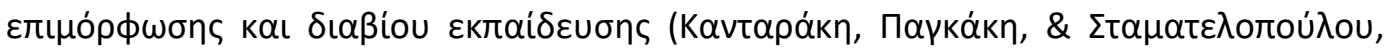

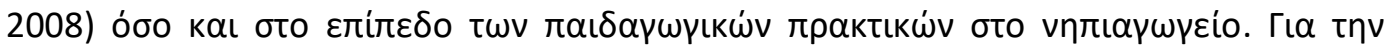

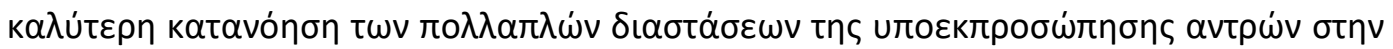

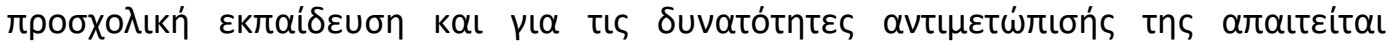

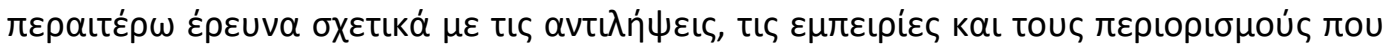

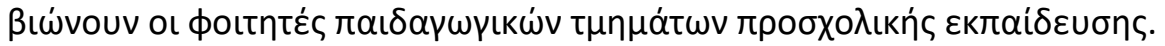

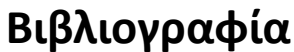

Brody, D. L. (2015). The construction of masculine identity among men who work with young children, an international perspective. European Early Childhood Education Research Journal, 23(3), 351-361.

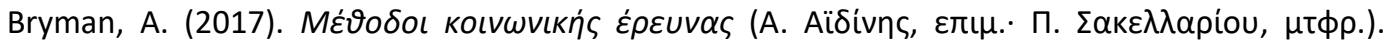
AӨńva: Gutenberg.

Brownhill, S., Warin, J., \& Wernersson, I. (Eds.) (2015). Men, masculinities and teaching in early childhood education: International perspectives on gender and care. London and New York, NY: Routledge.

Cameron, C., \& Moss, P. (1998) An introduction. In C. Owen, C. Cameron, \& P. Moss (Eds.), Men as workers in services for young children: issues of a mixed gender workforce (pp. 11-28). Bedford Way Papers. London: Institute of Education, University of London.

Cameron, C. (2006). Men in the nursery revisited: issues of male workers and professionalism. Contemporary Issues in Early Childhood, 7(1), 68-79.

Cameron, C., Owen, C., \& Moss, P. (2001). Entry, retention and loss: A study of childcare students and workers. London: Department for Education and Skills.

Carrington, B., Tymms, P., \& Merrell, C. (2008). Role models, school improvement and the 'gendergap' - do men bring out the best in boys and women bring out the best in girls? British Educational Research Journal, 34(3), 1-13.

Connell, R. W. (2005). Masculinities. Berkeley: University of California Press.

Cooney, M. H., \& Bittner, M. T. (2001). Men in early childhood education: Their emergent issues. Early Childhood Education Journal, 29(2), 77-82.

Cunningham, B., \& Watson, L. W. (2002). Recruiting male teachers. Young Children, 57(6), 10-15.

Cushman, P. (2010). Male primary school teachers: Helping or hindering a move to gender equity? Teaching and Teacher Education, 26, 1211-1218. 


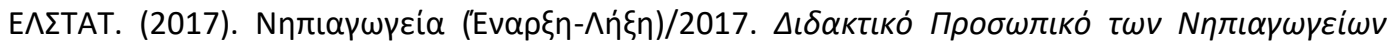

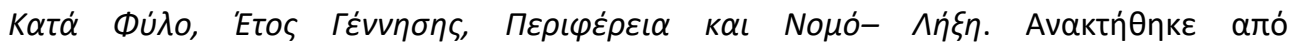
https://www.statistics.gr/el/statistics/-/publication/SED11/2017

Erden, S., Ozgun, O., \& Ciftci, M. A. (2011). "I am a man, but i am a pre-school education teacher": Self-and social-perception of male pre-school teachers. Procedia-Social and Behavioral Sciences, 15, 3199-3204.

Elliott, K. (2015). Caring masculinities: Theorizing an emerging concept. Men and Masculinities, 19(3), 240-259.

Farquhar, S. E. (1997). Of puppy dog tails, sugar and spice: Gender inequality and discrimination in early childhood education. Delta, 49(2), 405-416.

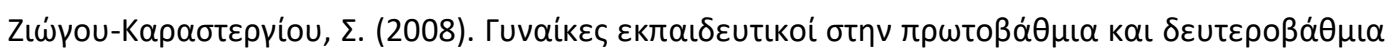

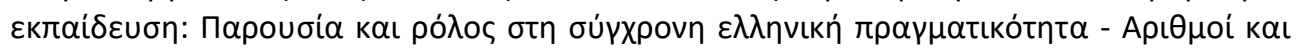

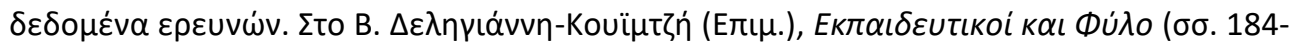

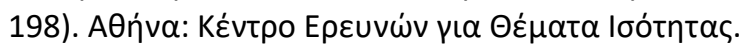

Goodman, J. (1987) Masculinity, feminism, and the male elementary school teacher: a case study of preservice teachers' perspectives, Journal of Curriculum Theorizing, 7, 30-59.

Hedlin, M., \& Åberg, M. (2013). The call for more male preschool teachers: Echoed and questioned by Swedish student teachers. Early Child Development and Care, 183(1), 149-162.

Heikkilä, M., \& Hellman, A. (2017). Male preschool teacher students negotiating masculinities: A qualitative study with men who are studying to become preschool teachers. Early Child Development and Care, 187(7), 1208-1220.

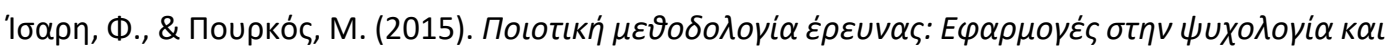

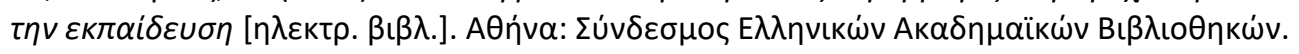

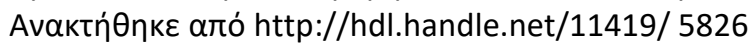

Jones, D. (2007). Millennium man: Constructing identities of male teachers in early years contexts. Educational Review, 59(2), 179-194.

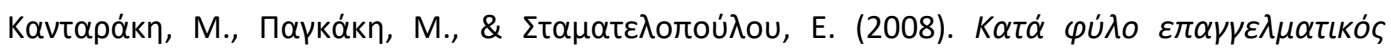

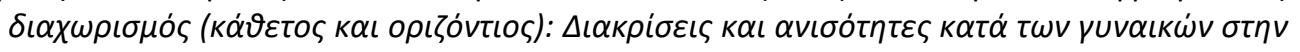

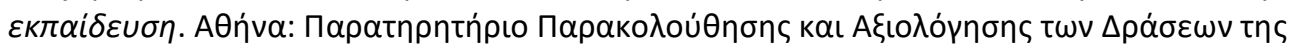

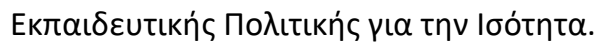

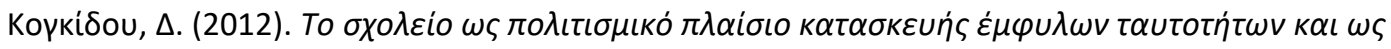

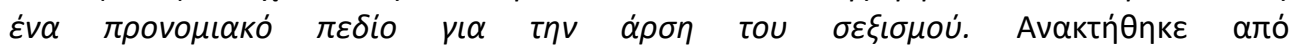
http://www.pi.ac.cy/pi/files/epimorfosi/synedria/gender

Kenway, J. (1995) Masculinities in schools: under siege, on the defensive and under reconstruction? Discourse: Studies in the Cultural Politics of Education, 16, 59-79.

Lupton, B. (2006). Explaining men's entry into female-concentrated occupations: Issues of masculinity and social class. Gender, Work and Organization, 13(2), 103-128.

MacNaughton, G., \& Newman, B. (2001). Masculinities and men in early childhood: Reconceptualising our theory and our practice. In The anti-bias approach in early childhood (pp. 145-157).

Moss, P. (2003). Who is the worker in services for young children? Children in Europe, 5, 2-5.

Murray, S. B. (1996). "WE ALL LOVE CHARLES" Men in child care and the social construction of gender. Gender \& Society, 10(4), 368-385. 


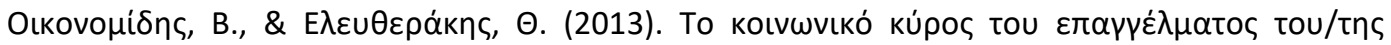

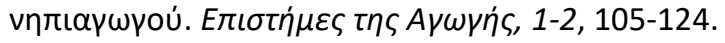

Owen, Ch. (2003). Men's work. Changing the gender mix of the childcare and early years workforce. Facing the Future: policy papers, 6. Retrieved from https://www.koordinationmaennerinkitas.de/uploads/media/Owen-Charlie-Men s-Work 01.pdf

Ottaviano, C., \& Persico, G. (2019). Educational care: Male teachers in early childhood education. Italian Journal of Sociology of Education, 11(1), 141-161. doi:10.14658/pupj-ijse-2019-1-7

Peeters, J. (2007). Including men in early childhood education: Insights from the European experience. New Zealand Research in Early Childhood Education, 10, 15.

Pirard, F., Schoenmaeckers, P., \& Camus, P. (2015). Men in childcare services: From enrolment in training programs to job retention. European Early Childhood Education Research Journal, 23(3), 362-369.

Rentzou, K. (2011). Greek parents' perceptions of male early childhood educators. Early Years, 31(2), 135-147. doi:10.1080/09575146.2010.530247

Rentzou, K. (2013). Male senior high school students' attitudes and perceptions towards early childhood education and care. International Journal of Adolescence and Youth, 18(1), 4562. doi:10/1080/02673843.2012.655442

Rentzou, K., \& Ziganitidou, K. (2009). Greek male early childhood educators: Self and societal perceptions towards their chosen profession. Early Years, 29(3), 271-279.

Ryan, G. W., \& Bernard, H. R. (2003). Techniques to identify themes. Field methods, 15(1), 85-109.

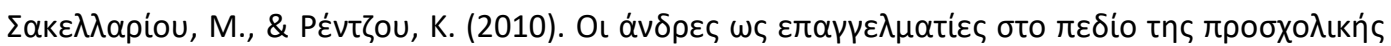

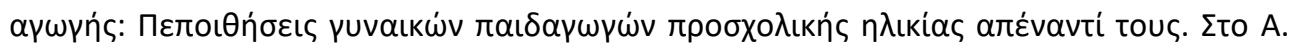

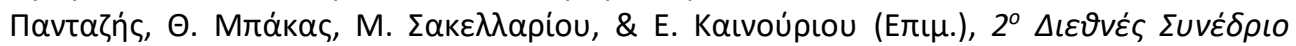

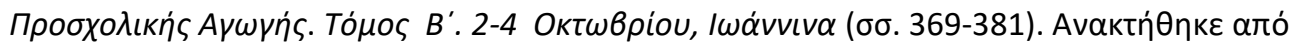
http://users.uowm.gr/kdinas/wp-content/uploads/2016

Sakellariou, M., \& Rentzou, K. (2007). Male early childhood educators: The element missing from preschool settings - A pilot study. International Journal of Learning, 14(1), 41-49.

Stroud, J. C., Smith, L. L., Ealy, L. T., \& Hurst, R. (2000). Choosing to teach: Perceptions of male preservice teachers in early childhood and elementary education. Early Child Development and Care, 163, 49-60.

Sumsion, J. (2000a). Rewards, risks and tensions: Perceptions of males enrolled in an early childhood teacher education programme. Asia-Pacific Journal of Teacher Education, 28(1), 87-100.

Sumsion, J. (2000b). Negotiating otherness: A male early childhood educator's gender positioning. International Journal of Early Years Education, 8(2), 129-140.

Sumsion, J. (2005). Male teachers in early childhood education: Issues and case study. Early Childhood Research Quarterly, 20, 109-123.

Tsigra, M. (2010). Male teachers and children's gender construction in preschool education. In Presentation on the XXVI OMEP world conference (Vol. 11, No. 13.8, p. 2010).

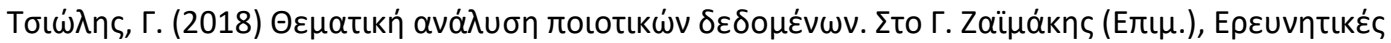

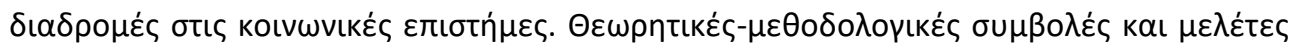

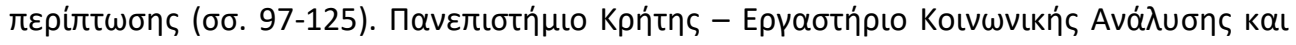

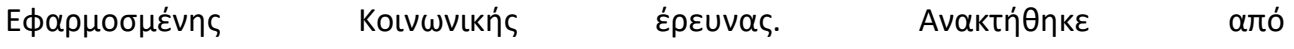
https://www.researchgate.net/publication/329363823 


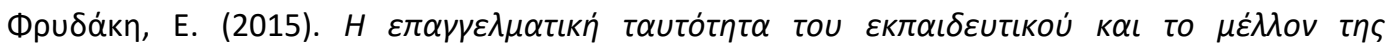

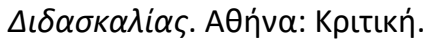

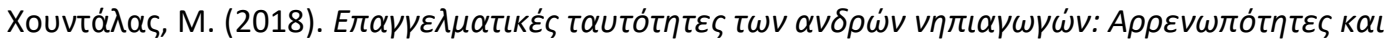

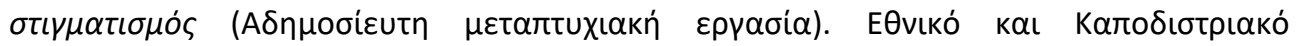

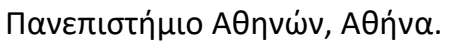

Warin, J. (2014). The status of care: linking gender and 'educare', Journal of Gender Studies, 23(1), 93-106. doi:10.1080/09589236.2012.754346 